NBER WORKING PAPER SERIES

\title{
CAN MONETARY POLICY CREATE FISCAL CAPACITY?
}

\author{
Vadim Elenev \\ Tim Landvoigt \\ Patrick J. Shultz \\ Stijn Van Nieuwerburgh \\ Working Paper 29129 \\ http://www.nber.org/papers/w29129 \\ NATIONAL BUREAU OF ECONOMIC RESEARCH \\ 1050 Massachusetts Avenue \\ Cambridge, MA 02138 \\ August 2021
}

The authors thank seminar participants at the Wharton macro lunch and the University of California at Santa Cruz. The views expressed herein are those of the authors and do not necessarily reflect the views of the National Bureau of Economic Research.

NBER working papers are circulated for discussion and comment purposes. They have not been peer-reviewed or been subject to the review by the NBER Board of Directors that accompanies official NBER publications.

(C) 2021 by Vadim Elenev, Tim Landvoigt, Patrick J. Shultz, and Stijn Van Nieuwerburgh. All rights reserved. Short sections of text, not to exceed two paragraphs, may be quoted without explicit permission provided that full credit, including $(\subset$ notice, is given to the source. 
Can Monetary Policy Create Fiscal Capacity?

Vadim Elenev, Tim Landvoigt, Patrick J. Shultz, and Stijn Van Nieuwerburgh

NBER Working Paper No. 29129

August 2021

JEL No. E1,E12,E13,E2,E31,E32,E37,E4,E42,E43,E44,E6,E62,E63,G12,G18,G21

\begin{abstract}
$\underline{\text { ABSTRACT }}$
Governments around the world have gone on a massive fiscal expansion in response to the Covid crisis, increasing government debt to levels not seen in 75 years. How will this debt be repaid? What role do conventional and unconventional monetary policy play? We investigate debt sustainability in a New Keynesian model with an intermediary sector, realistic fiscal and monetary policy, endogenous convenience yields, and substantial risk premia. When conventional monetary policy is constrained by the ZLB during an economic crisis, increased government spending and lower tax revenue lead to a large rise in government debt and raise the risk of future tax increases. We find that quantitative easing (QE), forward guidance, and an expansion in government discretionary spending all contribute to lowering debt/GDP ratio and reducing this fiscal risk. A transitory QE policy deployed during a crisis stimulates aggregate demand.
\end{abstract}

Vadim Elenev

Johns Hopkins University

100 International Drive

Suite 1329

Baltimore, MD 21202

velenev@jhu.edu

Tim Landvoigt

The Wharton School

University of Pennsylvania

3620 Locust Walk

Philadelphia, PA 19104

and NBER

timland@wharton.upenn.edu
Patrick J. Shultz

The Wharton School, University of Pennsylvania

Vance Hall

Philadelphia, PA 19104

pshultz@wharton.upenn.edu

Stijn Van Nieuwerburgh

Columbia University

Graduate school of Business

Uris Hall, office 809

3022 Broadway

New York, NY 10027

and NBER

svnieuwe@gsb.columbia.edu 


\section{Introduction}

The global covid-19 pandemic has resulted in unprecedented contraction in aggregate consumption, investment, and output in nearly every developed economy. For example, U.S. GDP fell 5\% in 2020.Q1 and 33\% in 2020.Q2 annualized. In response to the covid shock, both fiscal and monetary authorities mounted a massive response which mirrored the response after the Great Financial Crisis in magnitude but exceeded it in speed. Government spending increased dramatically in 2020. Government debt relative to GDP reached levels at the end of 2020 that have not been seen in the U.S. since 1947. On the monetary policy front, interest rates were slashed to zero. A large-scale quantitative easing (QE) program was launched, and through forward guidance, the Central Bank signaled that it would keep interest rates near zero and bond purchases high until the economy had fully recovered. The Fed also announced a new monetary policy regime in 2020 that would tolerate overshooting the $2 \%$ inflation target while the economy was still recovering. ${ }^{1}$

In this paper we ask whether these conventional and unconventional monetary and fiscal policy responses have helped the economy recover, and more controversially, whether they can help pay back the debt. We find that they have and that they can. Quantitative Easing (large-scale asset purchases), a relaxation of bank capital requirements, and a higher inflation target during the crisis and the early recovery, all contribute towards a smaller increase in the debt/GDP ratio during the crisis and a faster decline in its aftermath. Unconventional monetary policy also limits the risk of future tax increases substantially. Discretionary spending in a crisis is also a powerful stabilization tool because of a large fiscal multiplier when the economy is stuck at the zero lower bound (ZLB). Hence, fiscal and both conventional and unconventional monetary policy work together to create more fiscal space.

We study these questions by building a dynamic stochastic general equilibrium model in the New Keynesian (NK) tradition. Its main new feature is its ability to deliver non-trivial risk and risk premia. To that end, we let the economy undergo both transitory productivity shocks-standard in macro-and permanent productivity shocks-standard in finance- and insist on a high enough market price of risk associated with these shocks to deliver a quantitatively

\footnotetext{
${ }^{1}$ See https://www.federalreserve.gov/newsevents/pressreleases/monetary20200827a.htm.
} 
realistic output and equity risk premium. Standard NK models typically omit permanent risk, and stabilization policy reduces much of the consumption risk ultimately faced by households. As a result, the standard NK model generates trivial risk premia. In the presence of nontrivial risk, the NK model becomes more difficult to solve and calibrate since the stochastic steady state is far away from the deterministic steady state. We employ state-of-the-art global projection methods to overcome this challenge.

To study QE, we introduce two maturities for government debt and an intermediary sector. The intermediary sector uses its holdings of reserves and firm capital to back deposits, subject to leverage and liquidity constraints. Households invest in deposits, long-term government debt, and firm capital. A QE policy policy purchases long-term debt from households and issues (short-term) reserves to banks. By providing plentiful high-quality collateral to intermediaries, this policy crowds out intermediary demand for firm capital. The reduction in capital demand causes a shift from aggregate investment to consumption, which in the short-run affects the economy like a positive shock to aggregate demand. Due to a large consumption multiplier during the crisis when conventional monetary policy is constrained by the ZLB, QE is therefore an expansionary policy that causes higher output, labor demand, consumption and investment, ultimately resulting in a smaller increase in the debt/GDP ratio in the crisis. Furthermore, the policy lowers long-term interest rates, which combined with short-term policy rates that are lowered to the zero lower bound, substantially and persistently depresses the debt service on government debt.

We contrast a QE policy introduced in response to a crisis to QE policies introduced in normal times, either permanent or transitory in nature. We find that transitory QE policies introduced in normal times are largely ineffective. They provide a temporary consumption and output boost, but the latter is ten times smaller than the same-size QE policy in a crisis. As a thought experiment, we also consider a permanent QE program. This program is equivalent to a permanent reduction in the maturity structure of government debt held by the public. We find permanent QE to be welfare-increasing. While it boosts consumption temporarily, it lowers the return on household wealth and crowds out banks' investment in firm capital. These two forces lead to a permanently lower capital stock and slightly lower consumption in the longrun. At the same time, intermediaries enjoy a greater supply of liquid assets, increase leverage 
while becoming less risky, and supply more deposits to households. The benefits from greater liquidity provision to households outweigh the detrimental capital stock effect. However, we also find that permanent QE enacted in response to a crisis (as opposed to in normal times) is not effective in boosting aggregate demand and accelerating the recovery.

These differences between QE policies of varying persistence create a subtle policy dilemma. On the one hand, we find long-run benefits of permanent QE, which suggests that the current maturity structure of government debt puts too much weight on long maturities. On the other hand, it is important for QE policy to be (perceived as) temporary in order for the policy to be effective in boosting demand in crises.

In contrast to $\mathrm{QE}$, raising the inflation target for longer in response to a crisis has stronger real effects than an inflation target that is just increased for the duration of the crisis. This suggests that the new monetary policy framework laid out by the Fed is beneficial.

Related Literature Our paper contributes to the vast literature on macroeconomics in NewKeynesian (NK) models. Our contribution here is three-fold.

First, we consider a rich set of fiscal and monetary policy tools which have not been studied in this combination before. The "conventional" fiscal policies we study feature labor income and corporate profit taxation, transfer spending, and discretionary spending. Crucially, all four policies depend on the state of the economy, producing the counter-cyclicality of spending and pro-cyclicality of tax revenues observed in the data. The "unconventional" fiscal policy consists of an endogenous switching of regimes whereby the fiscal authority chooses tax rates to target debt reduction once the debt/GDP ratio exceeds a threshold. Unlike standard models in which fiscal policy responds to small changes in the debt-to-GDP ratio to keep debt bounded (reviewed comprehensively by Leeper and Leith (2016)), our method allows a more realistic fiscal regime that focuses on output stabilization most of the time, and only targets debt stabilization when debt/GDP reaches extreme values. This non-linear rule necessitates a global solution method. Conventional monetary policy consists of a standard Taylor rule. Unconventional monetary policy arises as a crisis response and includes quantitative easing (QE), a relaxation of intermediary leverage constraints, and a higher inflation target.

Second, we find a combination of preferences and shocks that generate a realistic amount of 
risk and risk premia. The standard NK model fails to produce any meaningful amount of risk or risk premia for realistically calibrated shocks. It is solved using log-linearization (or low-order perturbation methods) which mostly ignore aggregate risk premia (and their time-variation). Standard monetary and fiscal policies remove what little remaining risk households might otherwise face. ${ }^{2}$ The crucial ingredients in our paper that result in meaningful risk and risk premia are: (i) positively correlated transitory and permanent productivity shocks (calibrated to the data), (ii) Epstein-Zin preferences which separate risk aversion from intertemporal substitution motives, and (iii) a high enough coefficient of relative risk aversion, and (iv) a global solution method. Meaningful risk premia are not just nice to have, they are necessary to understand the effect of monetary and fiscal policies on debt sustainability. We suspect that they would make an important difference when evaluating many other policies in NK models.

Our third contribution is to introduce an intermediation sector which is better at providing credit to firms than households and produces deposits that are valued by households. ${ }^{3}$ It is subject to an occasionally-binding leverage constraint (Supplementary Leverage Ratio, SLR) and liquidity regulation (Liquidity Coverage Ratio, LCR), and faces equity issuance costs that make recapitalization during and after a crisis costly. This intermediary sector is important for understanding QE, since QE injects reserves into the banking sector. This affects SLR and LCR constraints and the allocation of assets between banks and households.

In contemporaneous work, Sims and Wu (2021) consider a NK model with credit shocks, financial intermediation, and short-term and long-term government debt to study conventional and unconventional monetary policy. Billi and Walsh (2021) find, as we do, that higher discretionary spending in an economic crisis can decrease the debt/GDP ratio due to a large fiscal multiplier. Andrade et al. (2021) study the effects of a higher inflation target in demand recessions at the ZLB.

\footnotetext{
${ }^{2}$ De Paoli, Scott, and Weeken (2010) document that nominal rigidities combined with monetary policy following a Taylor rule greatly reduce consumption risk in a standard business cycle model. Gourio and Ngo (2020) generate meaningful risk premia in a globally solved NK model with rare disasters and a ZLB on interest rates. Isoré and Szczerbowicz (2017) adapt Gourio (2012)'s approach to perturbation methods, yet require large disaster probabilities to create non-negligible risk premia. Campbell, Pflueger, and Viceira (2020) and Pflueger and Rinaldi (2021) introduce habit preferences in an NK model to produce realistically time-varying risk premia.

${ }^{3}$ Piazzesi, Rogers, and Schneider (2021) study the properties of the NK model in a world with financial intermediaries and ample reserves. Wang (2020) analyzes state-dependent pass-through of monetary policy in an NK model with a financial sector. Elenev (2020) and Faria-e-Castro (2020) develop quantitative NK models with intermediation sectors to evaluate policy responses during the GFC.
} 
In the wake of the financial crisis, large theoretical and empirical literatures arose on the efficacy of QE and the channels through which it operates (Woodford, 2012; Vissing-Jorgensen and Krishnamurthy, 2011, 2012, 2013; Vissing-Jorgensen et al., 2018; Bernanke, 2020). We study QE in our model, finding strong state-dependence; QE has much stronger effects when implemented in response to a crisis than in normal times. Like in the data, QE lowers long-term interest rates in the model and "spills over" to lower the equity risk premium.

A recent literature studies fiscal capacity in a world where the risk-free interest rate is below the growth rate in the economy (see Blanchard (2019), Jiang et al. (2019, 2020, 2021), Barro (2020), Brunnermeier et al. (2020), Reis (2021), Mankiw and Ball (2021), Cochrane (2019a,b), among others). The work of Jiang et al. (2019, 2020) emphasizes that, in the presence of realistic permanent output risk and risk premia, keeping government debt risk-free is challenging. It requires making the tax revenue claim safer than the government spending claim $\left(\beta^{T}<\beta^{G}\right)$. This in turn may mean raising taxes at inopportune (high marginal-utility) times. Our model generates this feature. Tax rates are pro-cyclical and government spending is counter-cyclical at business-cycle frequencies, helping households smooth aggregate risk. However, when the fiscal authority breaches a certain high level for the debt/gdp ratio, it switches to a debt management rule that brings debt/gdp levels back down. In this austerity regime, tax rates are set to implement the desired debt reduction, accounting for endogenous labor supply responses to those higher tax rates. The model quantitatively replicates the output risk premia in Jiang, Lustig, Van Nieuwerburgh, and Xiaolan (2019) as well as the tax and spending betas from Jiang, Lustig, Van Nieuwerburgh, and Xiaolan (2020). The calibration suggests that the U.S. economy entered the austerity region in 2021, and Congress should now be raising tax rates to control the debt. The model offers a cautionary tale. Postponing the tax (or spending) adjustment makes future austerity more severe, and can even lead to a situation where there no longer exists a tax rate that can tame the debt. The model also says that the U.S. would have been in a much deeper fiscal hole if it had not been for the extraordinary monetary policy response.

Our paper contributes to the large literature that studies the interaction of fiscal and monetary policy (e.g. Sargent and Wallace (1981); Leeper (1991); Sims (1991); Woodford (1994), Woodford (1995), Woodford (2001); Cochrane (1998), Cochrane (2001); Schmitt-Grohhe and 
Uribe (2000); Bassetto (2002); Reis (2016); Sims (2016)). Bianchi and Melosi (2019) introduce state-dependent policy targets for monetary and fiscal authorities. In an application, Bianchi, Faccini, and Melosi (2020) consider an emergency budget in the wake of the covid-19 pandemic which the monetary authority accommodates by temporarily tolerating higher inflation. Our fiscal rule is also state-dependent but not event driven. Rather, fiscal policy actively stabilizes aggregate fluctuations until the debt/gdp ratio breaches an upper (lower) bound. Beyond that point, fiscal policy becomes passive in that tax rates are adjusted to gradually lower (increase) the debt/gdp ratio. We study the role of conventional and unconventional monetary policy in this new setting of endogenously-switching fiscal policy regimes.

A literature at the intersection of macro-economics and asset pricing studies how fiscal risk manifests itself in asset prices (Croce, Nguyen, and Schmid, 2012b; Croce, Kung, Nguyen, and Schmid, 2012a; Pastor and Veronesi, 2012; Kelly, Pastor, and Veronesi, 2015; Croce, Nguyen, Raymond, and Schmid, 2019; Liu, Schmid, and Yaron, 2020; Corhay, Kind, Kung, and Morales, 2021). It typically works with models where uncertainty about future taxes affects firms incentives to invest in R\&D, leading to lower long-run productivity growth through an endogenous growth mechanism. Fiscal policies that stabilize the macro-economy in the short-run are welfare-reducing since they result in tax uncertainty and higher volatility of consumption growth in the long run, which hurts welfare when households have Epstein-Zin preferences. Our model does not feature an effect of tax uncertainty on long-run growth since it is not an endogenous growth model, and instead focuses on the effect of tax uncertainty on labor supply rather than investment. We find that additional government spending and unconventional monetary policy (UMP) lower risk premia in a macro-economic crisis, consistent with the stated objective of UMP.

The rest of the paper is organized as follows. Section 2 sets up the model. Section 3 describes the calibration. Section 4 discusses the properties of fiscal variables in normal times. Section 5 contains our main results describing crisis dynamics under various policy scenarios. Section 6 concludes. The appendix provides detailed model derivations (A), data sources used in the calibration (B), details on the computational method (C), and additional results on QE policies and forward guidance (D). 


\section{Model}

A representative household supplies labor, operates the investment technology, and owns shares in non-financial firms and banks. The household derives utility from holding deposits issued by financial intermediaries. The government issues nominal debt securities to fund its deficits. Government debt has two maturities: short-term debt that matures in the next model period, and long-term debt with duration $\delta^{B}$. Short-term debt includes both government debt securities with short maturity (T-bills), as well as high-powered money issued by the central bank (reserves).

Intermediaries hold short-term government debt and firm capital as assets and issue deposits and equity to households. Households also invest directly in firm capital and they hold longterm government debt. We assume that only intermediaries hold short-term debt and only households hold long-term debt, broadly in line with the aggregate data (as discussed in the calibration section).

\subsection{Production Technology}

Productivity. Productivity $Z_{t}$ has a permanent and a transitory component

$$
Z_{t}=Z_{t}^{p} Z_{t}^{r}
$$

where

$$
\begin{aligned}
& \log \left(Z_{t}^{r}\right)=z_{t}^{r}=\rho^{z} z_{t-1}^{r}+\varepsilon_{t}^{z}, \\
& \log \left(Z_{t}^{p}\right)=z_{t}^{p}=z_{t-1}^{p}+g_{t} .
\end{aligned}
$$

The growth rate of the permanent component evolves according to

$$
g_{t}=\left(1-\rho^{g}\right) \bar{g}+\rho^{g} g_{t-1}+\varepsilon_{t}^{g} .
$$


The innovations to transitory and permanent productivity are jointly normally distributed:

$$
\left(\varepsilon_{t}^{z}, \varepsilon_{t}^{g}\right) \sim \operatorname{Normal}\left(\mu_{t}, \Sigma_{t}\right) .
$$

Means $\mu_{t}$ are chosen such that $\mathrm{E}\left[Z_{t}^{r}\right]=1$ and $\mathrm{E}\left[g_{t}\right]=\bar{g}$. Productivity level and growth shocks are the only two sources of aggregate risk in the model. It will turn out to be very important to allow for a positive correlation between these two shocks.

Final Goods. Production follows the standard New Keynesian framework (Galí (2015)) with price rigidities. The final output good $Y_{t}$ is a composite of intermediate good varieties $Y_{t}(i), i \in$ $[0,1]$ that are combined by a final-goods producer.

Final output is

$$
Y_{t}=\left(\int_{0}^{1} Y_{t}(i)^{1-\frac{1}{\epsilon}} d i\right)^{\frac{\epsilon}{\epsilon-1}}
$$

where $\epsilon$ is the elasticity of substitution. Final goods producers maximize profit by solving

$$
\max _{\left\{Y_{t}(i)\right\}} P_{t} Y_{t}-\int_{0}^{1} P_{t}(i) Y_{t}(i) d i
$$

where $P_{t}$ is the aggregate price index and $P_{t}(i)$ is the price of input $i$. This implies the demand functions for all $i$ :

$$
Y_{t}(i)=\left(\frac{P_{t}(i)}{P_{t}}\right)^{-\epsilon} Y_{t}
$$

Intermediate Goods. Intermediate goods producers are monopolists for their varieties. They choose price $P_{t}(i)$ and inputs capital $k_{t}(i)$ and labor $n_{t}(i)$ to maximize profit

$$
D i v_{t}^{P}=P_{t}(i) Y_{t}(i)-P_{t}\left(w_{t} n_{t}(i)+r_{t}^{K} k_{t}(i)\right)-Z_{t}^{p} P_{t} \Xi^{P}\left(P_{t}(i) / P_{t-1}(i)\right),
$$

where $w_{t}$ is the real wage and $\Xi^{P}\left(P_{t}(i) / P_{t-1}(i)\right)$ is a convex menu cost for adjusting prices. Profit is paid out in the form of dividends to households. Intermediate output is produced using a standard Cobb-Douglas technology with aggregate productivity $Z_{t}$

$$
Y_{t}(i)=\left(k_{t}(i)\right)^{1-\alpha}\left(Z_{t} n_{t}(i)\right)^{\alpha} .
$$




\section{$2.2 \quad$ Financial Intermediaries}

Financial intermediaries are firms that maximize the present value of dividends paid to their shareholders. On the asset side, intermediaries invest in $X_{t}^{I, K}$ units of capital at real price $Q_{t}$ and buy $X_{t}^{I, S}$ short-term government bonds at nominal price $p_{t}^{S}$. On the liability side, they issue deposits $D_{t}^{I}$, modeled as one-period discount bonds, at nominal price $p_{t}^{D}$, and equity to the households. Intermediaries have beginning of period equity capital $W_{t}^{I}$ and are expected to pay a fraction $\tau$ of equity to their shareholders each period. When they raise new outside equity $A_{t}$, they incur a quadratic equity adjustment cost with parameter $\chi$. The total payout to households each period is

$$
D i v_{t}^{I}=\tau W_{t}^{I}-A_{t}
$$

Intermediaries are subject to two regulatory restrictions. First, equity capital regulation requires the following constraint on deposits (bank debt):

$$
D_{t}^{I} \leq \nu\left(X_{t}^{I, S}+\nu_{K} P_{t} Q_{t} X_{t}^{I, K}\right)
$$

where $\nu$ restricts the total leverage of the intermediary, and $\nu_{K}$ reflects the higher risk weight on capital relative to deposits. The overall maximum leverage ratio $\nu$ reflects the Supplementary Leverage Ratio (SLR) constraint in real world bank capital regulation.

The second regulatory restriction banks face captures the Liquidity Coverage Ratio (LCR) in the real world. Banks incur a liquidity cost per unit of deposits issued:

$$
\varrho_{t}=\varrho_{0} \zeta_{\varrho}\left(\frac{X_{t}^{I, S}}{\zeta_{\varrho} D_{t}^{I}}\right)^{1-\varrho_{1}}
$$

where $\zeta_{\varrho}$ is the fraction of deposits a particular bank's depositors can be expected to withdraw per period, and $\varrho_{0}$ scales the liquidity cost. We assume that exponent $\varrho_{1}>1$, such that the cost is decreasing in short-term bonds.

In summary, financial intermediaries solve:

$$
\max _{X_{t}^{I, K}, X_{t}^{I, S}, D_{t}^{I}, A_{t}} \sum_{k=0}^{\infty} \mathcal{M}_{t, t+k} P_{t+k} D_{i v_{t+k}^{I}}^{I}
$$


subject to the budget constraint:

$$
(1-\tau) W_{t}^{I}+P_{t} A_{t}+\left(p_{t}^{D}-P_{t} \varrho_{t}\right) D_{t}^{I}+\operatorname{Rebates}_{t}^{I} \geq p_{t}^{S} X_{t}^{I, S}+P_{t} Q_{t} X_{t}^{I, K}+\frac{P_{t}}{Z_{t}^{p}} \frac{\chi}{2} A_{t}^{2},
$$

no-shorting constraints $X^{I, j} \geq 0$, for $j \in\{K, S\}$, and the regulatory constraint (6). Intermediaries discount dividend payouts with the household discount factor $\mathcal{M}_{t, t+k}$. Further, they receive liquidity costs as lump-sum rebates, i.e. $\operatorname{Rebates}_{t}^{I}=P_{t} \varrho_{t} D_{t}^{I}$.

The transition law for bank equity $W_{t}^{I}$ is given by

$$
W_{t}^{I}=P_{t}\left(r_{t}^{K}+(1-\delta) Q_{t}\right) X_{t-1}^{I, K}+X_{t-1}^{I, S}-D_{t-1}^{I}
$$

\subsection{Households}

The representative household consumes $C_{t}$ of the final output good and supplies labor $N_{t}$ to intermediate goods producers.

Households invest $D_{t}^{H}$ in intermediary deposits, which they value for their liquidity services in addition to their pecuniary payoff, giving rise to the intra-period utility function:

$$
u\left(C_{t}, D_{t}^{H}, N_{t}\right)=\frac{\left(C_{t}^{1-\psi}\left(D_{t}^{H}\right)^{\psi}\right)^{1-\varphi}}{1-\varphi}-\left(Z_{t}^{p}\right)^{1-\varphi} \omega_{0} \frac{N_{t}^{1+\omega_{1}}}{1+\omega_{1}}-\left(Z_{t}^{p}\right)^{1-\gamma} \bar{u}
$$

where $\bar{u}>0$ is a constant ensuring that $u\left(C_{t}, D_{t}^{H}, N_{t}\right)<0$.

Households have recursive preferences with subjective time discount factor $\beta$, inter-temporal elasticity of substitution $1 / \varphi$, and risk aversion parameter $\gamma$, such that their value function is:

$$
V_{t}=(1-\beta) u\left(C_{t}, D_{t}^{H}, N_{t}\right)-\beta \mathrm{E}_{t}\left[\left(-V_{t+1}\right)^{\frac{1-\gamma}{1-\varphi}}\right]^{\frac{1-\varphi}{1-\gamma}}
$$

In addition to deposits, households purchase $X_{t}^{H, K}$ units capital at real price $Q_{t}$ and $X_{t}^{H, L}$ long-term government bonds at nominal price $p_{t}^{L}$.

Capital and bond purchases are subject to portfolio costs. The long-term bond portfolio cost 
takes the form

$$
\Xi^{L}\left(X_{t}^{H, L}, Y_{t}\right)=\frac{\xi_{0}^{L}}{\xi_{1}^{L}}\left(\frac{X_{t}^{H, L}}{Y_{t}}\right)^{\xi_{1}^{L}} Y_{t},
$$

where $Y_{t}$ is aggregate output. Intuitively, this cost creates a downward-sloping demand curve for long-term debt relative to GDP. The presence of this cost helps the model generate an upward sloping term structure of interest rates, as well as capture the price impact of long-term bond purchases by the central bank (Quantitative Easing). Capital costs take a similar form

$$
\Xi^{K}\left(X_{t}^{H, K}, K_{t}\right)=\frac{\xi_{0}^{K}}{\xi_{1}^{K}}\left(\frac{X_{t}^{H, K}}{K_{t}}\right)^{\xi_{1}^{K}} K_{t}
$$

where $K_{t}$ is the aggregate capital stock. Costs associated with capital holdings capture households' comparative disadvantage of lending directly to firms. ${ }^{4}$

Households further operate the economy's investment technology, which creates $I_{t}$ units of capital from $I_{t}+\Phi\left(I_{t}, K_{t}\right)$ units of the consumption good.

In summary, each period households choose consumption, investment, deposits, capital, and long-term bond holdings to maximize (8) subject to the budget constraint:

$$
\begin{aligned}
P_{t} C_{t} & +P_{t}\left(I_{t}+\Phi\left(I_{t}, K_{t}\right)\right)+p_{t}^{D} D_{t}^{H}+p_{t}^{L} X_{t}^{H, L}+P_{t} Q_{t} X_{t}^{H, K}+\Xi^{L}\left(X_{t}^{H, L}, Y_{t}\right)+\Xi^{K}\left(X_{t}^{H, K}, K_{t}\right) \\
& \leq W_{t}^{H}+P_{t}\left(1-\tau_{t}^{w}\right) w_{t} N_{t}+P_{t} Q_{t} I_{t}+\left(1-\tau_{t}^{d i v}\right)\left(\text { Div }_{t}^{I}+\text { Div }_{t}^{P}\right)+\Theta_{t}+\text { Rebates }_{t},
\end{aligned}
$$

where $W_{t}^{H}$ is household financial wealth at the beginning of $t$. Additional resources for households are labor income $w_{t} N_{t}$, which gets taxed at rate $\tau_{t}^{w}$ (equation (22)), profits of intermediategoods producers and financial intermediaries, which gets taxed at rate $\tau_{t}^{d i v}$ (equations (4) and (5)), transfer payments from the government $\Theta_{t}$ (equation (16)), and lump-sum rebates of menu costs from producers, equity issuance costs from banks, and bond portfolio costs: ${ }^{5}$

$$
\text { Rebates }_{t}=Z_{t}^{p} P_{t} \Psi\left(P_{t}(i) / P_{t-1}(i)\right)+\frac{P_{t}}{Z_{t}^{p}} \frac{\chi}{2} A_{t}^{2}+\Xi^{L}\left(X_{t}^{H, L}, Y_{t}\right)
$$

\footnotetext{
${ }^{4}$ We follow the literature on intermediation (He and Krishnamurthy, 2013) and interpret capital holdings of households as direct, capital-market based finance through equities or bonds. Capital held by intermediaries reflects indirect finance through loans. The cost captures intermediaries' advantage for indirect finance.

${ }^{5}$ Capital portfolio costs $\Xi^{K}\left(X_{t}^{H, K}, K_{t}\right)$ are not rebated and thus represent resource losses. We view these costs as inefficiencies stemming from suboptimal lending by households.
} 
The transition law for household wealth is:

$$
W_{t}^{H}=P_{t}\left(r_{t}^{K}+(1-\delta) Q_{t}\right) X_{t-1}^{H, K}+D_{t-1}^{H}+\left(c+1-\delta^{B}+\delta^{B} p_{t}^{L}\right) X_{t-1}^{H, L} .
$$

The payoff to each long-term bond in (13) consists of the coupon $c$, amortization of old debt $1-\delta^{B}$, and the market value of remaining debt $\delta^{B} p_{t}^{L}$.

\subsection{Government}

\subsubsection{Fiscal Policy}

The fiscal authority follows decision rules for transfers and discretionary spending that depend on the level of output relative to the economy's productivity trend, $\hat{Y}_{t}=Y_{t} / Z_{t}^{p}$ :

$$
\begin{aligned}
& \theta_{t}=\theta\left(\hat{Y}_{t}\right), \\
& \gamma_{t}=\gamma\left(\hat{Y}_{t}\right),
\end{aligned}
$$

such that total spending is

$$
F_{t}=\underbrace{\gamma_{t} P_{t} Y_{t}}_{\equiv G_{t}}+\underbrace{\theta_{t} P_{t} Y_{t}}_{\equiv \Theta_{t}}
$$

Given these spending rules, the government follows either active or passive fiscal policy. When the government follows active fiscal policy, then tax rates on wage income and profits depend only on cyclical output $\hat{Y}_{t}$

$$
\tilde{\tau}_{t}^{n}=\tilde{\tau}^{n}\left(\hat{Y}_{t}\right)
$$

for $n \in\{w, d i v\}$. We refer to this fiscal policy as active, since the government is only concerned with actively stabilizing the economy by responding to deviations from the stochastic growth trend. With intermediary profits as in equation (5) and intermediate goods producer profits as in equation (4), tax revenue is

$$
\tilde{T}_{t}=P_{t} \tilde{\tau}_{t}^{w} w_{t} N_{t}+\tilde{\tau}_{t}^{d i v}\left(\operatorname{Div}_{t}^{P}+\operatorname{Div}_{t}^{I}\right)
$$

The combination of tax and spending rules determine the primary surplus $\tilde{S}_{t}=\tilde{T}_{t}-F_{t}$. Denoting 
the market value of government debt outstanding at the beginning of $t$ by $W_{t}^{G}$, this implies that the government needs to issue new debt $\tilde{W}_{t}^{G}$ at the end of the period, where

$$
\tilde{W}_{t}^{G}=W_{t}^{G}-\tilde{S}_{t}
$$

When the government follows passive fiscal policy instead, tax rates are indirectly determined as result of a debt issuance target. We refer to this fiscal policy regime as passive, since its goal is to stabilize the level of government debt once it reaches very high levels (very low levels), rather than insulate taxpayers from aggregate shocks.

In particular, passive fiscal policy specifies a target level $\vec{W}_{t}^{G}$ for end-of-period debt as a function of the active issuance $\tilde{W}_{t}^{G}$ given in (19). Passive policy occurs when this debt level is either below the profligacy threshold $\underline{W}^{G}$ or above the austerity threshold $\bar{W}^{G}$.

We can summarize the combination of active and passive policy by the target level of debt:

$$
\vec{W}_{t}^{G}= \begin{cases}(1-v) \underline{W}^{G}+v \tilde{W}_{t}^{G} & \text { if } \tilde{W}_{t}^{G} \leq \underline{W}^{G} \\ \tilde{W}_{t}^{G} & \text { if } \bar{W}^{G}>\tilde{W}_{t}^{G}>\underline{W}^{G} \\ (1-v) \bar{W}^{G}+v \tilde{W}_{t}^{G} & \text { if } \tilde{W}_{t}^{G} \geq \bar{W}^{G},\end{cases}
$$

where $v \in(0,1)$ parameterizes the degree of fiscal adjustment in the austerity and profligacy regions. The government will then choose tax rates to target a surplus that satisfies:

$$
S_{t}=S\left(\vec{W}_{t}^{G}\right)=W_{t}^{G}-\vec{W}_{t}^{G}
$$

To implement this surplus, the government adjusts tax rates by factor $f\left(\vec{W}_{t}^{G}\right)$, such that tax revenue is:

$$
T_{t}=T\left(\vec{W}_{t}^{G}\right)=P_{t} \underbrace{f\left(\vec{W}_{t}^{G}\right) \tilde{\tau}_{t}^{w}}_{\equiv \tau_{t}^{w}} w_{t} N_{t}+\underbrace{f\left(\vec{W}_{t}^{G}\right) \tilde{\tau}_{t}^{d i v}}_{\equiv \tau_{t}^{d i v}}\left(D_{i v}^{P}+\operatorname{Div}_{t}^{I}\right)=f\left(\vec{W}_{t}^{G}\right) \tilde{T}_{t} .
$$

The debt target rule (20) combined with the tax rule (22) implies that the tax adjustment factor $f\left(\vec{W}_{t}^{G}\right)=1$ when active debt issuance $\tilde{W}_{t}^{G}$ is in the interior region between profligacy and austerity thresholds. In that region, unconstrained active issuance $\tilde{W}_{t}^{G}$ is by definition 
equal to the debt target $\vec{W}_{t}^{G}$. However, when active issuance surpasses the austerity threshold, the government will need to raise tax rates by setting $f\left(\vec{W}_{t}^{G}\right)>1$ to achieve its target issuance, which by definition is below active (unconstrained) issuance $\tilde{W}_{t}^{G}$. Analogously, when active issuance drops below the profligacy threshold, the government can lower tax rates by setting $f\left(\vec{W}_{t}^{G}\right)<1$.

To fund the debt $\vec{W}_{t}^{G}$, the fiscal authority keeps the maturity composition of newly issued government debt constant in book value terms, with a fraction $\bar{\mu}$ of debt being long-term. As a useful normalization, we assume that coupon $c$ on long-term bonds is always chosen such that the average long-term bond price $p_{t}^{L}$ is one (par bond). Then constant issuance in book values requires:

$$
\frac{B_{t}^{G, S}}{B_{t}^{G, L}}=\frac{1-\bar{\mu}}{\bar{\mu}} .
$$

Combined with the requirement that the total issuance target must be met in market value terms, $\vec{W}_{t}^{G}=p_{t}^{S} B_{t}^{G, S}+p_{t}^{L} B_{t}^{G, L}$, we obtain:

$$
\begin{aligned}
B_{t}^{G, S} & =\frac{(1-\bar{\mu}) \vec{W}_{t}^{G}}{(1-\bar{\mu}) p_{t}^{S}+\bar{\mu} p_{t}^{L}}, \\
B_{t}^{G, L} & =\frac{\bar{\mu} \vec{W}_{t}^{G}}{(1-\bar{\mu}) p_{t}^{S}+\bar{\mu} p_{t}^{L}} .
\end{aligned}
$$

\subsubsection{Monetary Policy}

The central bank chooses the interest rate on short-term government debt $i_{t}^{S}=1 / p_{t}^{S}$. This is consistent with the central bank directly setting the interest rate on reserves, as in the current policy regime. It is also compatible with a central bank that has a small balance sheet and uses open-market operations to target the rate in the interbank market. In both cases, absence of arbitrage ensures the policy rate set by the central banks coincides with yield on short-term debt and reserves.

We consider a standard monetary policy rule subject to a zero lower bound

$$
\frac{1}{p_{t}^{S}}=\max \left\{\frac{1}{p_{t}^{*}}, 1\right\}
$$


where

$$
\frac{1}{p_{t}^{*}}=\frac{1}{\bar{p}^{S}}\left(\frac{\Pi_{t}}{\bar{\Pi}}\right)^{\phi^{\pi}}\left(\frac{\hat{Y}_{t}}{\bar{Y}}\right)^{\phi^{y}},
$$

where we denote gross inflation as $\Pi_{t}=P_{t} / P_{t-1}$. The central bank's inflation target is $\bar{\Pi}$ and its target level for cyclical output is $\bar{Y}$. The rule specifies deviations from the average gross interest rate $1 / \bar{p}^{S}$.

We consider the balance sheet of the central bank as an additional policy tool. The central bank can shorten the maturity structure of debt held by the public by buying long-term bonds with reserves, or extend the maturity structure by selling long-term bonds for reserves. Note that these operations do not affect the total face amount of outstanding government liabilities, which are determined by the government budget constraint in (21). Rather, they just change the composition of these liabilities.

In particular, we assume the central bank chooses short- and long-term bond purchases, $B_{t}^{C B, S}$ and $B_{t}^{C B, L}$, subject to a revenue neutrality constraint

$$
\begin{aligned}
-p_{t}^{l} B_{t}^{C B, L} & =p_{t}^{s} B_{t}^{C B, S}, \\
B_{t}^{C B, L} & \leq B_{t}^{G, L}, \\
B_{t}^{C B, S} & \leq B_{t}^{G, S} .
\end{aligned}
$$

Constraint (27) imposes that the central bank swaps government liabilities at market value. For example, a purchase of long-term bonds $\left(B_{t}^{C B, l}>0\right)$ needs to be paid for by a sale of shortterm bonds $\left(B_{t}^{C B, s}<0\right)$. Sales of short-term bonds are equivalent to new reserve creation. For simplicity, we assume that the central bank can also short-sell long-term bonds to invest in short-term bonds. ${ }^{6}$ Constraints (28) and (29) ensure that the central bank cannot purchase more than the total supply of either bond.

The payoff of the central bank's portfolio in $t+1$ is

$$
D i v_{t+1}^{C B}=B_{t}^{C B, S}+\left(c+1-\delta^{B}+\delta^{B} p_{t+1}^{l}\right) B_{t}^{C B, L} .
$$

\footnotetext{
${ }^{6}$ In reality, the central bank's ability to extend the maturity structure is limited by its holdings of long-term bonds. We do not explore maturity-extending balance sheet policies in this paper.
} 
Since new purchases are revenue-neutral by (27), this is also the profit of the central bank in $t+1$. The central bank remits this profit to the fiscal authority.

\subsubsection{Consolidated Government Budget Constraint}

Given both fiscal and monetary policy choices, the market value of next period government debt is

$$
\begin{aligned}
W_{t+1}^{G} & =B_{t}^{G, S}+\left(c+1-\delta^{B}+\delta^{B} p_{t+1}^{L}\right) B_{t}^{G, L}-D_{i v_{t+1}^{C B}}^{C} \\
& =B_{t}^{G, S}-B_{t}^{C B, S}+\left(B_{t}^{G, L}-B_{t}^{C B, L}\right)\left(c+1-\delta^{B}+\delta^{B} p_{t+1}^{L}\right) .
\end{aligned}
$$

We view central bank balance sheet operations as overriding the fixed maturity structure $\bar{\mu}$ chosen by the fiscal authority. For example, quantitative easing involves purchasing long-term bonds by issuing short-term bonds, and thereby lowering the fraction of long-term bonds held by the public under a QE policy $\mu^{Q E}<\bar{\mu}$.

The evolution equation for the value of government liabilities (31) clarifies that for the accounting of debt claims between the government (central bank and fiscal authority), and the public (banks and households), it suffices to keep track of the consolidated balance sheet of fiscal and monetary authorities. By purchasing $B_{t}^{C B, S}$ and $B_{t}^{C B, L}$, respectively, the central bank simply changes the net supply available to the public of both bonds to $B_{t}^{G, S}-B_{t}^{C B, S}$ and $B_{t}^{G, L}-B_{t}^{C B, L}$. 


\subsection{Market Clearing}

Short-term and long-term government debt, deposit, labor, firm capital, and goods market must clear in equilibrium:

$$
\begin{aligned}
B_{t}^{G, S} & =B_{t}^{I, S}+B_{t}^{C B, S}, \\
B_{t}^{G, L} & =B_{t}^{H, L}+B_{t}^{C B, L}, \\
D_{t}^{I} & =D_{t}^{H} \\
N_{t} & =\int_{0}^{1} n_{t}(i) d i \\
K_{t-1} & =\int_{0}^{1} k_{t}(i) d i \\
X_{t}^{I, K}+X_{t}^{H, K} & =(1-\delta) K_{t-1}+I_{t}=K_{t}, \\
Y_{t} & =C_{t}+I_{t}+G_{t}+\Phi\left(I_{t} / K_{t-1}\right) K_{t-1}+\Xi^{K}\left(X_{t}^{H, K}, K_{t}\right) .
\end{aligned}
$$

where we have invoked the transition law for the aggregate capital stock.

\section{Calibration}

The model is solved and calibrated at a quarterly frequency. A subset of model parameters have direct counterparts in the data. The remaining parameters are calibrated to match target moments from the data within the model. To compute model-implied moments, we simulate the model for 120,000 periods (quarters) in total, consisting of 24 simulation runs of 5,000 periods each (with a 3,000 period burn-in). Appendix $\mathrm{C}$ provides details on the solution method and simulation approach. While these parameters are chosen simultaneously to match all targeted moments, Tables 1 and 2 list for each parameter the specific moment that is most affected by this parameter. 
Table 1: Parameters: Shocks, Firms, Households, and Intermediaries

\begin{tabular}{|c|c|c|c|c|c|}
\hline Par & Description & Value & Source & Data & Model \\
\hline \multicolumn{6}{|c|}{ Exogenous Shocks } \\
\hline$\rho_{g}$ & persistence perm. TFP & 0.6 & AC(1) real GDP growth (1870-2017, Jorda et al. (2016)) & 0.25 & 0.27 \\
\hline$\sigma_{g}$ & innovation vol. perm. TFP & 1.2 & Vol. real consumption growth $(1870-2017$, Jorda et al. (2016)) & $1.7 \%$ & $1.64 \%$ \\
\hline$\rho_{z}$ & persistence trans. TFP & 0.87 & AC(1) Ham. filtered TFP (Fernald (2012)) & - & - \\
\hline$\sigma_{z}$ & innovation trans. TFP & 1.5 & Vol. Ham. filtered TFP (Fernald (2012)) & - & - \\
\hline \multicolumn{6}{|c|}{ Production } \\
\hline$\phi$ & marginal adjustment cost & 10 & Vol. investment-to-GDP ratio $(53-20)$ & $1.50 \%$ & $0.77 \%$ \\
\hline$\delta$ & capital depreciation rate & 0.02 & investment-to-GDP ratio $(53-20)$ & $17.94 \%$ & $16.26 \%$ \\
\hline$\xi$ & Rotemberg adjustment cost & 140 & Vol. inflation (53-20) & $0.65 \%$ & $0.39 \%$ \\
\hline$\epsilon$ & Intermediate goods elast. & 7 & Markup (van Vlokhoven (2020)) & - & - \\
\hline \multicolumn{6}{|c|}{ Preferences and Household Sector } \\
\hline$\beta$ & discount rate & 0.992 & real risk free rate (1870-2017, Jorda et al. (2016)) & $0.42 \%$ & $0.42 \%$ \\
\hline$\gamma$ & risk aversion & 20 & Unlevered RP on GDP claim & $1.00 \%$ & $0.99 \%$ \\
\hline$\varphi$ & $1 / \mathrm{IES}$ & 0.7 & Vol. consumption-to-GDP ratio $(53-20)$ & $0.76 \%$ & $0.92 \%$ \\
\hline$\omega_{0}$ & disutility of labor & 3.12 & normalize $\mathrm{E}[Y]=1$ & - & - \\
\hline$\omega_{1}$ & labor supply power & 2 & standard value & - & - \\
\hline$\xi_{0}^{L}$ & portfolio cost bonds & 0.0017 & Term spread $(53-20)$ & $0.30 \%$ & $0.29 \%$ \\
\hline$\xi_{1}^{L}$ & portfolio cost bonds, elast. & 1.8 & Term spread vol. $(53-20)$ & $0.26 \%$ & $0.25 \%$ \\
\hline$\xi_{0}^{K}$ & portfolio cost capital & 0.003 & Household capital share (He and Krishnamurthy (2019)) & - & \\
\hline$\xi_{1}^{K}$ & portfolio cost capital, elast. & 2 & Quadratic & - & - \\
\hline \multicolumn{6}{|c|}{ Intermediaries } \\
\hline$\varrho_{0}$ & liquidity cost level & 0.12 & FFR-time deposit spread (94-14) & $0.32 \%$ & $0.46 \%$ \\
\hline$\varrho_{1}$ & liquidity cost power & $1 /\left(1-\zeta_{\varrho}\right)$ & normalization & - & \\
\hline$\tau$ & dividend target & 0.08 & bank leverage & $92 \%$ & $91.18 \%$ \\
\hline$\chi$ & equity issuance cost & 25 & bank net payout rate & $5.7 \%$ & $7.84 \%$ \\
\hline
\end{tabular}


Aggregate Productivity The aggregate productivity process has permanent and transitory components. The permanent productivity process, $Z_{t}^{p}$, is subject to a growth rate shock, $g_{t}$ which follows an $\mathrm{AR}(1)$ process with persistence $\rho_{g}=0.6$ and volatility $\sigma_{g}=1.2 \%$. The volatility of this process is chosen to match the volatility of real consumption growth for the U.S. for the period 1870-2017, based on the macrofinancial database by Jorda, Schularick, and Taylor (2016). We choose the persistence to match the persistence of real output growth for the same period. ${ }^{7}$ The transitory productivity process, $Z_{t}^{r}$, also follows an AR(1) in logs with persistent parameter $\rho_{z}=0.87$ and volatility parameter $\sigma_{z}=1.5 \%$. These parameters are directly taken from Fernald (2012). Since both shocks are persistent, they become state variables. We discretize $g_{t}$ and $Z_{t}^{r}$ into 3-state Markov chains using the Rouwenhorst (1995) method. We further assume that transitory TFP innovations and growth rate shocks are perfectly positively correlated. While our model admits any correlation structure between the two shocks, a strong positive correlation between the shocks is required to match the term structure of risk premia for government debt. Intuitively, the government pursues fiscal stabilization policy through cyclical tax and spending rules to buffer deviations of output from trend. To get the right correlation structure of spending and taxation with consumption growth, permanent and transitory shocks must coincide; Section 4.2 provides an in-depth discussion of the model's ability to match empirical properties of risk premia on government spending and tax claims.

Production Investment adjustment costs are quadratic. We set the marginal cost parameter to $\phi=10$ to match the observed volatility of (detrended) investment to GDP of 1.5\%. Depreciation, $\delta$, is set to 0.02 to match the investment to output ratio of $17.94 \%$ observed in the data. We set the parameter $\alpha$ in the Cobb-Douglas production function equal to 0.78 to target the observed labor share of income of $64.16 \%$. The elasticity of substitution for the wholesaler, $\epsilon$, is set to 7 to target a markup of 0.15 from van Vlokhoven (2020). The Rotemberg adjustment cost $\xi$ is set to 140 and targets the observed quarterly volatility of inflation of $0.65 \%$.

Intermediaries Intermediaries are subject to a supplementary leverage ratio (SLR) and equity capital requirements. The SLR constraint is parameterized by $\nu=0.97$ to reflect real-world

\footnotetext{
${ }^{7}$ Since our model features persistent shocks to the growth rate of productivity, we use the longest available sample to determine the size of these shocks.
} 
regulation on total leverage. The additional risk weight on capital $\nu_{K}=0.959=\frac{1-\tilde{\nu}_{K}}{\nu}$, where $\tilde{\nu}_{K}=0.07$. Together these parameters determine the maximum leverage ratio and equity requirement for capital.

We choose the equity payout target of banks, $\tau=0.08$ we to target leverage of the intermediary sector, calculated by Elenev, Landvoigt, and Van Nieuwerburgh (2021) to be $92 \%{ }^{8}$ A higher value of $\tau$, in combination with the equity issuance cost, makes equity finance more costly for banks and creates incentives for higher leverage. We further follow Elenev et al. (2021) in calibrating the equity issuance cost to target the net payout ratio of the financial sector, defined as dividends plus share repurchases minus equity issuance divided by book equity. A higher equity issuance cost makes external equity more expensive and raises the net payout ratio. Elenev et al. (2021) construct a time series of dividends, share repurchases, equity issuances, and book equity, aggregating across all publicly traded banks from $1974-2018$. They report an annual net payout ratio of $5.7 \%$, which the model approximately matches with $\chi=25$.

The liquidity cost per unit of deposits of banks, reflecting real-world liquidity coverage ratio (LCR) regulation, is determined by the parameters $\zeta_{\varrho}, \varrho_{0}$, and $\varrho_{1}$. $\zeta_{\varrho}$ represents the fraction of deposits a particular bank's depositors can be expected to withdraw per period and is set to 0.05 following BIS (2013). $\varrho_{0}$ is set to 0.12 to target the spread between short-term debt and deposits of $0.31 \%$ and $\varrho_{1}$ is set to $1 /\left(1-\zeta_{\varrho}\right)$ for parsimony. The liquidity cost captures the observed disconnect between deposit rates and short-term debt (Lenel et al., 2019).

Households and Preferences The coefficient of risk aversion, $\gamma$, is set to 20 and targets the unlevered risk premium on the GDP claim of $1 \%$ per quarter. The corresponding ArrowPratt measure of relative risk aversion is around $5 .^{9}$ We set the elasticity of inter-temporal substitution to $1 / 0.7$ to target the volatility of the consumption to GDP ratio. The subjective discount factor of households $\beta=0.992$ targets the average quarterly real rate of $0.42 \%$, based on the 1870-2017 sample from Jorda et al. (2016). The coefficient on the disutility of labor, $\omega_{0}$,

\footnotetext{
${ }^{8}$ This approach takes a broad view of intermediaries to include depository institutions, government-sponsored enterprises, hedge funds, and some types of insurers.

${ }^{9}$ The Arrow-Pratt measure of relative risk aversion is not equal to $\gamma$ in a model with Epstein-Zin preferences and leisure in the utility function (Swanson, 2018). We also have the additional complication of the scalar $\bar{u}$ in the period utility function. We compute the coefficient of relative risk aversion to average to 5.4 in a long simulation of the model. Appendix C.2 provides the details of this calculation.
} 
is set to 3.12 to normalize the unconditional mean of output to $1 .^{10}$

The portfolio cost for long-term bonds targets the mean and volatility of the term spread, computed as the difference between the 10-year treasury yield and a weighted average of the yield on 3-month Tbills and the Federal Funds rate. We calculate the weights for the shortterm rate based on outstanding market values of Tbills and reserves. This calculation yields and average quarterly term spread of $0.36 \%$ with a quarterly volatility of $0.29 \%$. The model matches these targets with marginal cost $\xi_{0}^{L}=0.0017$ and elasticity $\xi_{1}^{L}=1.8$. Without the portfolio cost, the model would generate a slightly negative term spread, a well known feature of models with long-run risk.

The portfolio cost for capital targets the fraction of firm capital held by households. There are several forces in the model that determine the split of firm capital holdings between banks and households. First, absent equity issuance and liquidity costs for intermediaries, firm capital is more valuable to intermediaries than households, since it serves as collateral for issuing deposits that earn a liquidity premium. Therefore, banks would hold all capital in the economy without these costs. Second, firm capital has a relatively high bank equity requirement and, unlike short-term debt and reserves, it does not relax banks' LCR requirement (i.e., at a given balance sheet size, a marginal unit of capital that backs deposits increases banks' marginal liquidity cost). Both regulatory costs reduce bank holdings of capital. Third, households have an inferior technology for screening and monitoring firms, captured by households' capital portfolio cost. Ceteris paribus, this cost increases the bank capital share.

We follow the macro-finance literature on intermediation (e.g. He and Krishnamurthy (2019)) and target an intermediary capital share of $60 \%$, reflecting the broad need of firms and households for intermediation. The model matches this share with $\xi_{0}^{K}=0.003$. For parsimony, we work with a quadratic cost function, $\xi_{K}=2$.

Government Parameters Our fiscal policy rules are calibrated to match the unconditional average and cyclical properties of transfer spending, discretionary spending, and tax revenue.

\footnotetext{
${ }^{10}$ Monetary policy and fiscal rules in the model are parameterized with the implicit assumption that average output is 1 . Since the unconditional mean of output in a long-simulation of the nonlinearly solved model is far away from the model's deterministic "steady-state", this normalization leads to a fixed-point: $\omega_{0}$ needs to be set such that jointly with all other parameters, $\mathrm{E}\left[Y_{t}\right]=1$ in the stationarized model.
} 
Table 2: Parameters: Government

\begin{tabular}{|c|c|c|c|c|c|}
\hline Par & Description & Value & Source & Data & Model \\
\hline \multicolumn{6}{|c|}{ Government: Fiscal Policy Rules } \\
\hline$\tau_{0}^{\pi}$ & base corp. tax rate & 21 & BEA corp. tax to GDP (53-20) & $2.8 \%$ & $3.33 \%$ \\
\hline$\tau_{0}^{w}$ & base lab. tax rate & 25.5 & BEA personal tax to GDP $(53-20)$ & $16.39 \%$ & $15.43 \%$ \\
\hline$\gamma_{0}$ & average spending/GDP & 25.5 & BEA govt. spending to GDP (53-20) & $16.40 \%$ & $17.57 \%$ \\
\hline$\theta_{0}$ & average transfers/GDP & 3.4 & BEA govt. transfers to GDP $(53-20)$ & $3.45 \%$ & $3.35 \%$ \\
\hline$b_{\tau}$ & tax cyclicality & 2 & regr. slope tax revenue/GDP on GDP growth (53-20) & 0.32 & 0.26 \\
\hline$b_{\gamma}$ & spending cyclicality & -2 & regr. slope spending/GDP on GDP growth (53-20) & -0.86 & -0.54 \\
\hline$b_{\theta}$ & transfer cyclicality & -10 & regr. slope transfers/GDP on GDP growth (53-20) & -5.03 & -2.75 \\
\hline $\bar{\mu}$ & share of long-term debt & 0.67 & Share of LT treasuries $(00-20)$ & $66.82 \%$ & $68.45 \%$ \\
\hline$\underline{W}^{G}$ & Profligacy threshold & 2.4 & See Section 4.1 & - & - \\
\hline $\bar{W}^{G}$ & Austerity threshold & 4.5 & See Section 4.1 & - & - \\
\hline \multicolumn{6}{|c|}{ Government: Monetary Policy Rule } \\
\hline $\bar{\Pi}$ & inflation target & 1 & Fed inflation target ( $2 \%$ p.a.) & - & - \\
\hline$\phi^{\Pi}$ & Weight on inflation & 3 & standard value & - & - \\
\hline$\phi^{Y}$ & weight on output & 0.5 & standard value & - & - \\
\hline $\bar{p}^{S}$ & natural interest rate & 0.99 & normalization & - & - \\
\hline \multicolumn{6}{|c|}{ Government: Financial Regulation } \\
\hline$\nu$ & max. intermediary leverage & 0.97 & Basel regulation & - & - \\
\hline$\nu_{K}$ & add. risk weight on capital & 0.959 & Basel regulation & - & - \\
\hline
\end{tabular}


The exact functional forms of the fiscal policy rules in equations (41) and (42) for transfers and spending, and algorithm (1) for tax rates, are given in Appendix A.6. These rules are parameterized by a base rate with subscript ${ }_{0}$ that determines average transfers (discretionary spending, taxes) as fraction of output, and a cyclicality coefficient $b_{j}, j=\theta, \gamma, \tau$, that governs the correlation with the cyclical component of output. In addition, discretionary spending follows a so-called "fading" rule, meaning that the responsiveness of spending to output fluctuations does not grow proportionally with the deviation of output from its balanced growth path. The solid line in the left panel of Figure 1 plots the resulting cyclical rule for discretionary government spending. ${ }^{11}$

Figure 1: Government Spending Rule
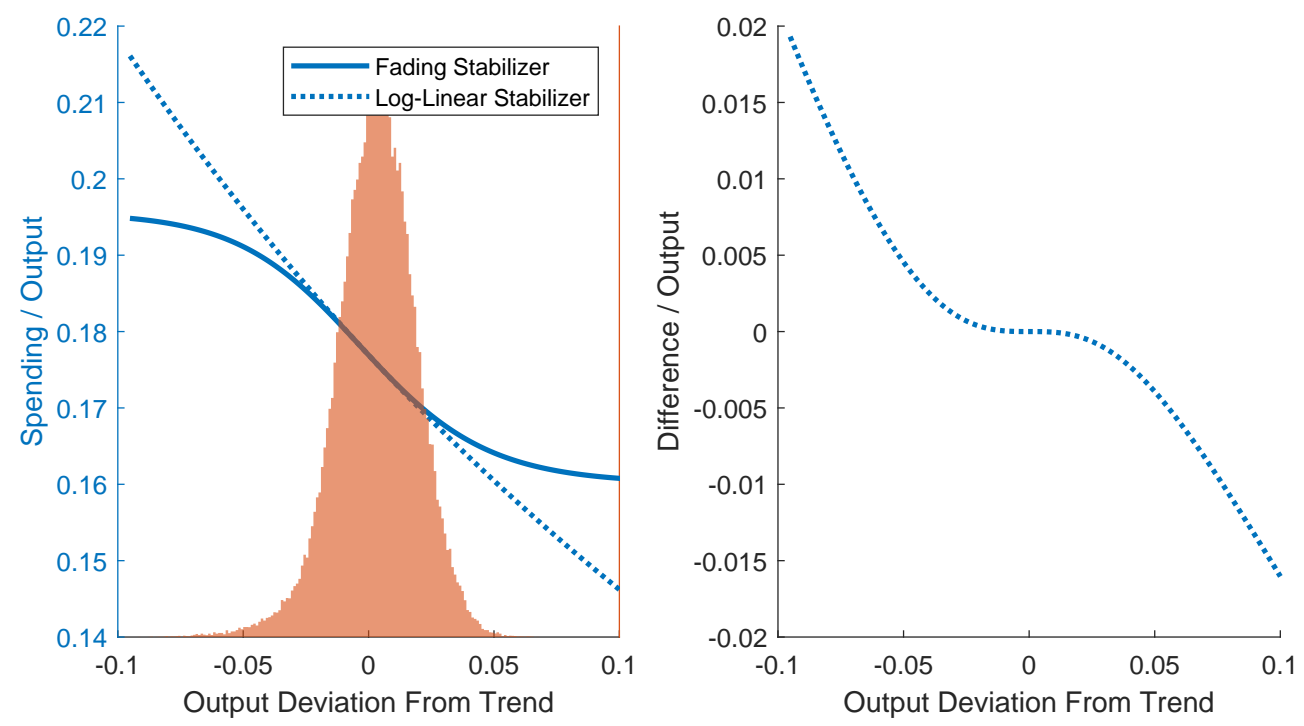

The parameters $\tau_{0}^{\pi}, \tau_{0}^{w}$ and $b_{\tau}$ control the base corporate tax rate, base tax rate on wages, and their cyclicalities, respectively. $\tau_{0}^{\pi}$ is set to $21 \%$ to target the observed corporate tax revenue of $2.8 \%$ of GDP and $\tau_{0}^{w}$ is set to $25.5 \%$ to match the observed tax revenue from wages to GDP of $16.37 \%$. We set $b_{\tau}=2$ to match the observed quarterly correlation between log tax revenue and the log of GDP growth of 0.08 .

The unconditional averages of spending and transfers are controlled by the parameters $\gamma_{0}$ and $\theta_{0}$, respectively. We set $\gamma_{0}$ to $17.7 \%$ to target the observed average spending to GDP of $16.40 \%$

\footnotetext{
${ }^{11}$ The gap between the linear and fading spending rules, plotted in the right panel of Figure 1, is calibrated such that the fading aspect has no effects given the cyclical fluctuations caused by productivity shocks. However, the rule disciplines our thinking about the magnitude of extra discretionary spending for our policy experiments in Section 5.1.
} 
and $\theta_{0}$ to $3.4 \%$ to match the observed average transfers to GDP of $3.46 \%$. The cyclicalities of spending and transfers are controlled by $b_{\gamma}=-2$ and $b_{\theta}=-10$, respectively. We choose the cyclicality coefficients such that model regressions of the transfer spending, discretionary spending, and tax revenue to GDP ratios, respectively, on GDP growth match the data. ${ }^{12}$

We allow for the government to issue both short-term and long-term debt. The parameter $\bar{\mu}=0.67$ determines the constant fraction of debt being long-term. This parameter is chosen to reflect the reported maturity distribution of outstanding debt. The average share of long-term debt (greater than one year in maturity) of this series from 2000-2020 is $67.88 \%$. The duration of long-term government debt is 7.76 years, which we match in our model by setting $\delta^{B}$ to 0.92 .

The central bank follows a Taylor rule for the interest rate on short-term government debt. The coefficient on inflation, $\phi^{\pi}$, is set to 3 , and the coefficient on output, $\phi^{y}$, is set to 0.5. The values are chosen to match slope coefficients in a regression of short-term interest rates on inflation and output. The inflation target $\bar{\Pi}=1$ is set to target average inflation of $2 \%$ per year.

Short-term and Long-term Debt Holdings We assume that households hold all of the long-term debt and the intermediary holds all of the short-term debt in our model. For shortterm bonds, this assumption follows Lenel et al. (2019). To assess the assumption on long-term bonds, we look at Treasury holdings from the Financial Accounts of the United States. The broadly defined financial sector (insurance companies, money market funds, mutual funds, and depository institutions) only holds $5.8 \%$ of long-term debt on average over the period $1953-2020$.

\section{Properties of Fiscal Policy}

Before we evaluate whether monetary policy can help alleviate the government's debt burden after economic crises, this section studies fiscal policies during "normal times", i.e., when only productivity shocks to $Z_{t}^{p}$ and $Z_{t}^{r}$ drive economic dynamics, and only conventional monetary policy is operative. We compare model outcomes from a long simulation to the data.

\footnotetext{
${ }^{12}$ The model regressions allow for a different slope in profligacy and austerity.
} 
Figure 2: Distribution of Government Debt and Tax Adjustment

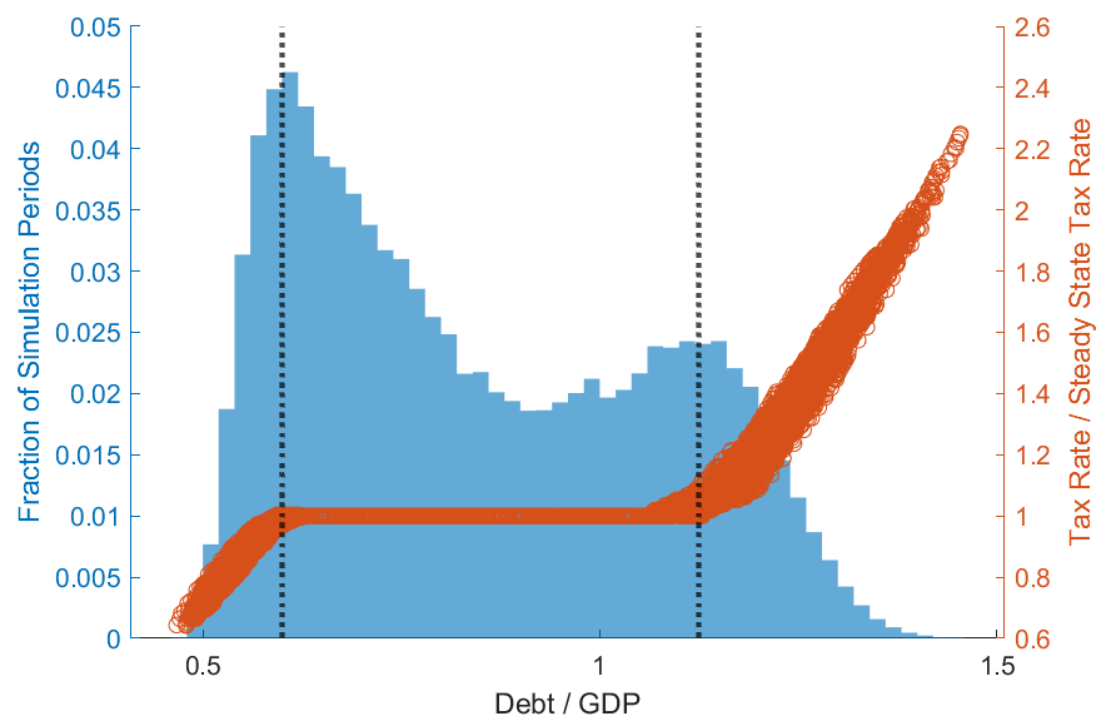

\subsection{Endogenous Regime-Switching Model of Fiscal Policy}

Figure 2 shows a histogram of the government debt/GDP ratio for the full 120,000 simulation periods, overlaid with a scatter plot of the tax adjustment factor $f\left(\vec{W}_{t}^{G}\right)$. Vertical lines indicate the profligacy and austerity bounds, respectively. The economy spends the majority of time (approximately $70 \%$ of all simulation periods) in the interior region between these thresholds. Sequences of shocks may push debt/GDP into either one of the adjustment regions. In that case, as described in Section 2.4, fiscal policy endogenously switches from active to passive, meaning that the fiscal authority now chooses tax rates with the goal of stabilizing debt/GDP.

These tax adjustments are successful in reigning in debt/GDP. However, the figure reveals a clear asymmetry with respect to profligacy (low debt/GDP) and austerity (high debt/GDP). This is caused by the distortionary effect of labor income taxation, resulting in a concave "Laffer" curve of tax revenue generated from tax increases. Thus, consecutive marginal increases in tax rates yield smaller marginal increases in tax revenue in the austerity region. In contrast, consecutive tax rate decreases will yield greater marginal reductions in revenue in the profligacy region.

A direct implication of this Laffer curve effect is that the threshold for entering austerity cannot be arbitrarily large. In particular, the model features an upper bound for the austerity threshold: if the austerity regime only starts for levels of debt/GDP above this bound, then 
there does not exist a sequence of tax rate increases that can prevent government debt/GDP from exploding for any possible path of exogenous shocks. Put simply, if austerity kicks in "too late" in terms of debt/GDP, then government debt is not guaranteed to remain stationary and is therefore no longer truly risk-free. While we have not systematically characterized this bound, we have verified that for the calibrated model, the simulated time series meets the conditions for stationary. Given all model parameters, the calibrated fiscal rules guarantee that government debt remains well in the interior of the state space for which we have solved the model. ${ }^{13}$ Among other factors, the maximum level of the austerity threshold depends on equilibrium bond yields, which determine the government's interest expenses, the labor supply elasticity, which controls the sensitivity of labor supply to higher tax rates, and the monetary policy rule, which dictates how strongly the central bank responds to higher inflation caused by tax increases (tax increases are negative aggregate supply shocks in the model).

Since debt/GDP is in the interior region most of the time, the model generates long time paths with changes in debt/GDP, but no adjustments in tax rates or spending in response. This is a realistic feature of the model: Table 3 demonstrates that in the post-war sample, we do not observe tax increases prompted by higher debt/GDP ratios. Rather, column (1) shows that increases in debt/GDP coincide with lower tax revenue to GDP ratio periods. Similarly, debt/GDP growth from $t-1$ to $t$ is associated with lower primary surplus in $t$ in the data. These correlations in the data are likely driven by (1) long-run trends of rising debt/GDP and declining tax revenue since the early 1980s, and (2) the strong cyclicality of government spending and tax revenues: during recessions, spending rises and revenues decline, causing higher debt/GDP going forward. The model matches the data coefficients qualitatively and is broadly comparable in magnitude (columns (3) and (4)). As in the data, the cyclical responses of spending and tax revenue drive the correlations in the model (see also Section 4.2 below). Since we have a much longer sample for the model-generated data, we observe rare visits to profligacy (the indicator variable "Prof" is one if the economy is in the profligacy region, and zero otherwise) and austerity regions (the indicator "Aust."). Columns (5) and (6) verify that profligacy leads to lower revenue and surpluses, while austerity has the opposite effects. Furthermore, an increase of debt/GDP in the austerity (profligacy) region causes a steeper

\footnotetext{
${ }^{13}$ We have also verified that significantly increasing the austerity threshold will cause the simulated paths to violate the state space boundaries.
} 
Table 3: Debt/GDP and Surplus Dynamics: Model versus Data

\begin{tabular}{|c|c|c|c|c|c|c|}
\hline & $\begin{array}{c}\text { Tax Rev. } \\
\text { Data } \\
(1)\end{array}$ & $\begin{array}{c}\text { Pr. Sur. } \\
\text { Data } \\
(2)\end{array}$ & $\begin{array}{c}\text { Tax Rev. } \\
\text { Model } \\
(3)\end{array}$ & $\begin{array}{c}\text { Pr. Sur } \\
\text { Model } \\
(4)\end{array}$ & $\begin{array}{c}\text { Tax. Rev. } \\
\text { Model } \\
(5)\end{array}$ & $\begin{array}{c}\text { Pr. Surp. } \\
\text { Model } \\
(6)\end{array}$ \\
\hline$\Delta$ Debt/GDP & $\begin{array}{c}-0.300^{* * *} \\
(0.034)\end{array}$ & $\begin{array}{c}-0.693^{* * *} \\
(0.064)\end{array}$ & $\begin{array}{c}-0.119^{* * *} \\
(0.003)\end{array}$ & $\begin{array}{c}-0.309^{* * *} \\
(0.005)\end{array}$ & $\begin{array}{c}-0.137^{* * *} \\
(0.001)\end{array}$ & $\begin{array}{c}-0.323^{* * *} \\
(0.003)\end{array}$ \\
\hline Prof. & & & & & $\begin{array}{c}-0.017^{* * *} \\
(0.0002)\end{array}$ & $\begin{array}{c}-0.015^{* * *} \\
(0.0004)\end{array}$ \\
\hline Aus. & & & & & $\begin{array}{l}0.039^{* * *} \\
(0.0005)\end{array}$ & $\begin{array}{c}0.028^{* * *} \\
(0.001)\end{array}$ \\
\hline$\Delta$ Debt/GDP $\times$ Prof & & & & & $\begin{array}{c}-0.014^{* * *} \\
(0.002)\end{array}$ & $\begin{array}{c}-0.069^{* * *} \\
(0.003)\end{array}$ \\
\hline$\Delta$ Debt/GDP $\times$ Aus & & & & & $\begin{array}{c}0.031^{* * *} \\
(0.002)\end{array}$ & $\begin{array}{c}0.042^{* * *} \\
(0.003)\end{array}$ \\
\hline Observations & 272 & 272 & 119,976 & 119,976 & 119,976 & 119,976 \\
\hline $\mathrm{R}^{2}$ & 0.220 & 0.305 & 0.197 & 0.565 & 0.654 & 0.756 \\
\hline
\end{tabular}

Note:

${ }^{*} \mathrm{p}<0.1 ;{ }^{* *} \mathrm{p}<0.05 ;{ }^{* * *} \mathrm{p}<0.01$

This table presents the results of regressing tax revenue to GDP and primary surplus to GDP on log changes in the debt to GDP ratio. Columns (1) and (2) present the results from observed quarterly data for 1953-2021 for tax revenues and primary surpluses, respectively. Columns (3) and (4) present analogous results using the simulated data. Columns (5) and (6) use the simulated data and include dummy variables to compute the slopes in the austerity and profligacy regions. Columns (2)-(6) are computed using 24 different simulated sample paths of 5,000 quarters each. We include a fixed effect for, and cluster standard errors by, simulation run. 
increase (decrease) in tax revenue and surpluses, as expected from the alternative fiscal regime in these regions of the state space. Finally, both in model and data, debt/GDP is highly persistent: the (quarterly) auto-correlation coefficient of the data debt/GDP ratio is 0.9946, while in the model it is 0.9950 . Therefore, our model demonstrates that lack of responsiveness in fiscal policy to changes in debt/GDP is still consistent with stationary debt dynamics in the long-run. This is because such fiscal adjustments can be triggered by debt/GDP reaching extreme levels, which we have not observed in the modern history of U.S. fiscal policy.

At the same time, our model clarifies that fiscal adjustments cannot be arbitrarily delayed. In particular, if government debt is to remain stationary and riskfree, adjustments to the primary surplus are necessary before debt/GDP becomes unsustainably large. Figure 2 shows that this must begin with debt/GDP ratios of around 112.5\%. The U.S. economy is expected to breach this level in 2021. The model predicts that delaying tax increases until debt/gdp is higher results in more severe austerity, at a minimum, and in the potential impossibility of debt stabilization (due to ever stronger Laffer curve effects at high debt levels) and eventual default.

\subsection{Cyclical Properties of Fiscal Policy}

In the short run, fiscal policy provides insurance to taxpayers. When output is below trend, tax rates decline and government discretionary spending rises, as governed by the policy rule coefficients $b_{\tau}$ and $b_{\gamma}$. But to make government debt risk-free, fiscal policy cannot provide this insurance in the long run (Jiang, Lustig, Van Nieuwerburgh, and Xiaolan (2020)). To illustrate the this horizon dependence in the simulated model, we regress cumulative fiscal policy growth rates on cumulative GDP growth over increasing horizons. For each fiscal claim $X_{t} \in\left\{T_{t}, F_{t}\right\}$, we estimate

$$
\log X_{t+h}-\log X_{t}=\alpha_{h}^{X}+\beta_{h}^{X}\left(\log Y_{t+h}-\log Y_{t}\right)+\epsilon_{t, h}^{X}
$$

and plot the coefficients $\beta_{h}^{X}$ in the left panels of Figure 3. The bottom-left panel plots coefficients for 400 quarters, while the top-left panel "zooms in" on the first 60 quarters. Contemporaneously, the tax claim has a positive cash flow beta - tax revenues rise more when GDP goes up - and the spending claim has a negative beta. But as the horizon increases, the spending 
beta rises above tax beta i.e. cumulative spending growth increases in cumulative GDP growth more than tax growth. This reversal is necessary to keep government debt risk-free. At long horizons, fiscal policy must be co-integrated with output through spending and taxation rules in (16) and (18), so both betas converge to 1.

As pointed out by Jiang, Lustig, Van Nieuwerburgh, and Xiaolan (2019), the intertemporal government budget constraints implies that investors in government securities hold claims that entitle them to future primary surpluses. This in turn means that we can view bondholders as holding a long position in an asset that pays out tax revenues, and a short position in an asset that pays out government spending. The value of government debt can be expressed as the expected present discounted value of this long-short portfolio, evaluated at the household's $\mathrm{SDF} \mathcal{M}_{t, t+h}^{H}$, plus a residual term $\mathcal{E}_{t}$ that arises from incomplete markets between households and intermediaries, as well as frictions associated with holding government debt e.g. liquidity benefits for intermediaries from holding short-term debt and portfolio costs for households from holding long-term debt.

$$
\tilde{W}_{t}^{G}=\sum_{h=1}^{\infty} \mathcal{M}_{t, t+h}^{H} T_{t+h}-\sum_{h=1}^{\infty} \mathcal{M}_{t, t+h}^{H} F_{t+h}+\mathcal{E}_{t}
$$

The cyclicality of fiscal policies provides insurance to taxpayers at business-cycle frequencies and, by the same token, creates risk that must be borne by bondholders. To see how this risk varies by horizon, we compute the risk premium on claims to $h$-period ahead taxes and spending, or $h$-strips. We compute prices of these strips recursively. The 0 -ahead claim is equal to the cash flow received that period, and the $h$-period ahead claim is equal to the price of the $h-1$-period ahead claim next period, discounted using the one-period SDF:

$$
p_{t, h}^{X}=\mathrm{E}_{t}\left[\mathcal{M}_{t, t+1}^{H} p_{t+1, h-1}^{X}\right], \quad p_{t, 0}^{X}=X_{t}
$$

Risk premia can be computed as expected returns in excess of the risk-free rate $\mathrm{E}_{t}\left[\mathcal{M}_{t, t+1}^{H}\right]^{-1}$ i.e.

$$
r p_{t, h}^{X}=\mathrm{E}_{t}\left[\frac{p_{t+1, h-1}^{X}}{p_{t, h}^{X}}\right]-\mathrm{E}_{t}\left[\mathcal{M}_{t, t+1}^{H}\right]^{-1}
$$


Figure 3: Fiscal Risk and Cyclicality of Fiscal Policies
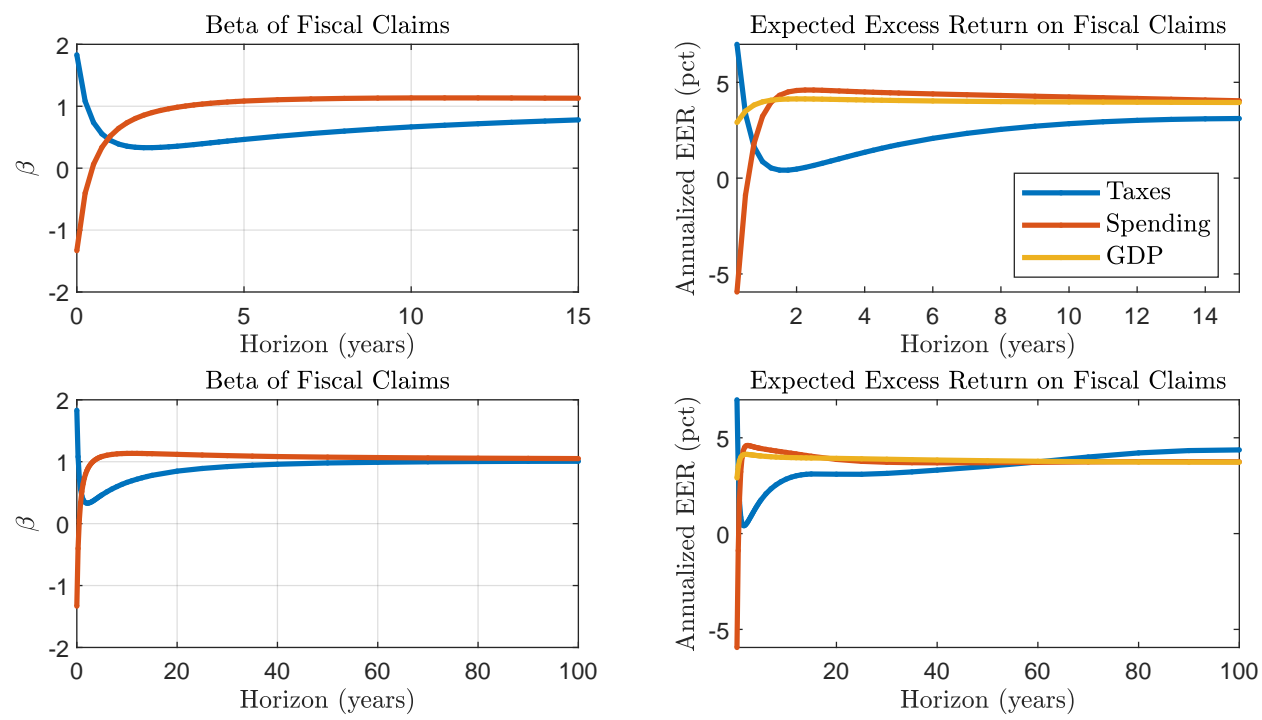

In the right panel of Figure 3, we plot the risk premia for $h$-quarter ahead tax and spending strips, and plot them along side the risk premium on claims to $h$-quarter ahead GDP. Since a claim to GDP is like an unlevered claim to firm dividends, GDP strip risk premia are like the risk premia on (unlevered) dividend strips. As the yellow line in the right panel shows, the model generates a high (unlevered) equity risk premium of about $4 \%$ per year.

Over short horizons, the bondholder is exposed to a great amount of risk. The risk premium on the tax claim, which the bondholder is long, is high, while the risk premium on the spending claim, which the bondholder is short, is very negative. Put differently, at business cycle frequency, bondholders are providing insurance to taxpayers, who are short the tax claim.

To keep government debt risk-free, these premia must reverse at longer horizons. That is, the return to the long taxes, short spending portfolio must become a hedge at longer horizons. Put differently, taxpayers, who are short the tax revenue claim, face substantial risk at intermediate horizons as shown by the low tax betas in the left panels: $\beta^{T}<\beta^{G}$ for intermediate and long horizons. As emphasized by Jiang, Lustig, Van Nieuwerburgh, and Xiaolan (2020), keeping the debt safe requires shifting aggregate risk onto the taxpayers. 


\section{Main Results: Crisis Response}

\subsection{Fiscal and Monetary Policy in Crises}

Our main experiment is an unanticipated demand shock that coincides with a negative permanent (and transitory) productivity shock (since they are perfectly correlated). The demand shock is modeled as a $0.9 \%$ increase in the subjective time discount factor $\beta$. Once the shock to the discount factor and productivity hits, agents in the model expect it to mean-revert with probability 0.5 . We study a specific path where the shock lasts for four quarters before stochastically mean-reverting. The central bank's ability to lower the policy rate in response to this shock is limited by a zero lower bound.

\subsubsection{Macro Variables}

Baseline: Only Automatic Stabilizers and Conventional Monetary Policy We first study the recovery paths of the economy for the baseline policy, which includes a Taylor rule governing the conventional monetary response and automatic fiscal stabilizers given by countercyclical spending rules (14) - (15) and procylical tax rule (17). Government purchases (discretionary spending) follow the fading rule plotted in Figure 1. We label this baseline scenario as "Autom. Stab."

The effects of the negative shock and these different policy responses on macroeconomic aggregates are displayed in Figure 4. The two left-most panels in the top row show the exogenous shocks and their persistence (these are the same for all policies). The bottom row shows that the combination of the productivity and discount factor shocks cause a deep economic crises absent additional policy interventions (Autom, Stab., blue line). Output and consumption decline by $8 \%$, investment by $20 \%$ and labor by $11 \%$. The recession is highly deflationary (top right), with the inflation rate dropping below $-10 \%$. The central bank tries to counter the demand shock as much as possible through lowering the policy rate to zero. The policy rate remains trapped at the ZLB for the duration of the shock (4 quarters). 
Figure 4: Main Policy Experiments: Macro Variables
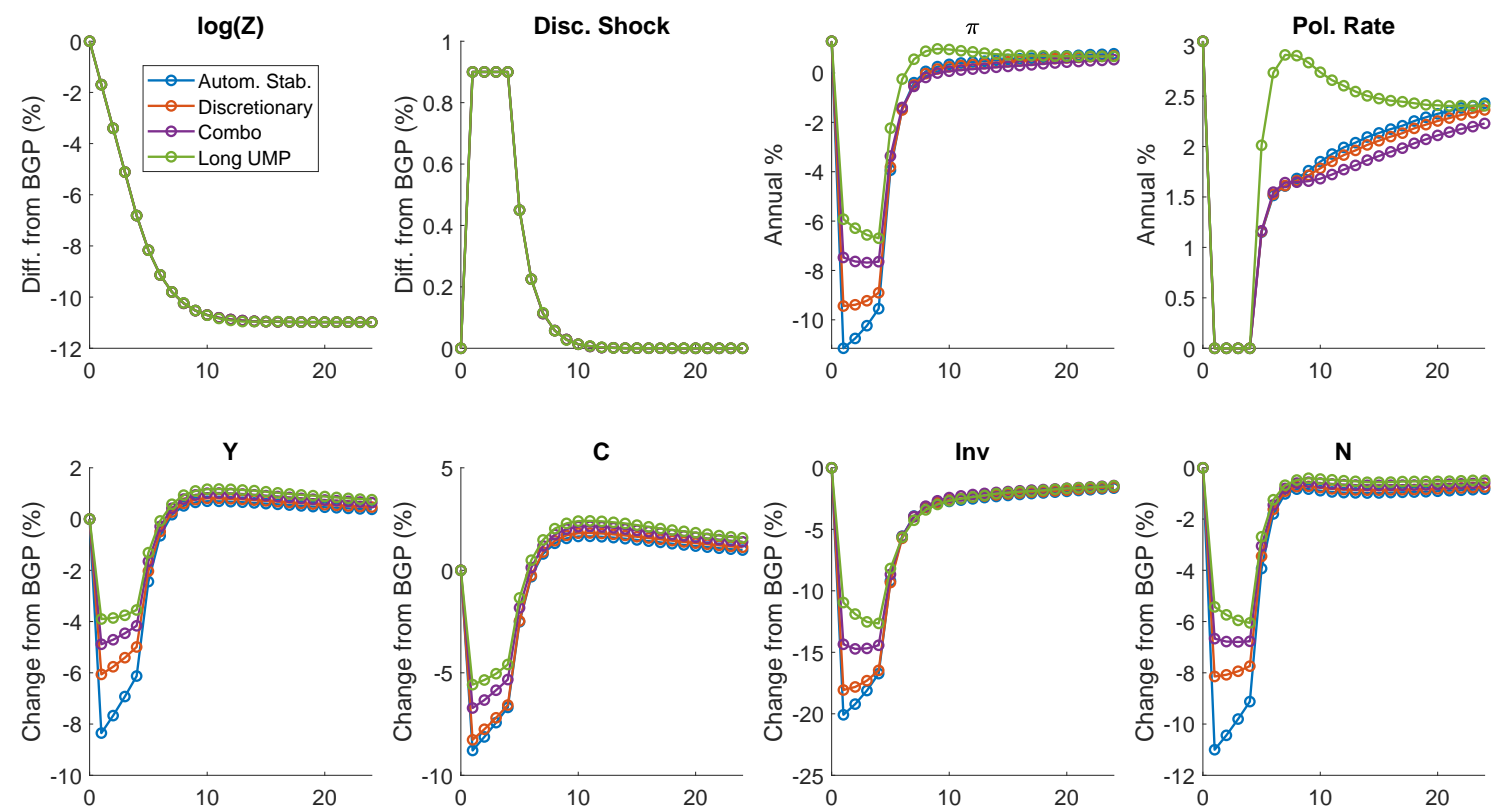

Policy 1: Additional Discretionary Fiscal Stimulus We then study how different policies with additional fiscal and monetary stimulus affect the economy's recovery path. In the first policy experiment, the government pursues discretionary spending beyond what is implied by the automatic stabilizers. For this policy, we assume that the government closes the gap between the fading rule and spending that increases linearly in the output gap; this gap is plotted in the right panel of Figure 1. We label this policy "Discretionary."

Turning to the first policy experiment, additional government purchases (Discretionary, red line) have a moderately stimulative effect. We can read the difference off the right panel of Figure 1 as extra spending of around $1.8 \%$ of output given the realized output drop of $8 \%$. Since output increases by more than $2 \%$ in response to this policy (difference between blue and red lines), we can conclude that government purchases have a fiscal multiplier above unity, consistent with other studies of fiscal policy at the zero lower bound (see, e.g., Christiano et al. (2011); Eggertsson (2011); Woodford (2011) on the theory and Klein and Winkler (2019) on the empirics).

Policy 2: Adding Unconventional Monetary Policy In the second policy experiment, the government augments the first policy with unconventional monetary policy (UMP). UMP 
consists of three legs. The first leg is QE, the second leg is an exemption of reserves from banks' Supplemental Leverage Ratio (SLR), and the third leg is a higher inflation target. QE in our model is equivalent to a change in the maturity structure of debt held by the public. We assume that the central bank builds up a portfolio of long-term with total value equal to $32 \%$ of GDP, or equivalently $40 \%$ of the stock of long-term debt before the policy. ${ }^{14}$

Exempting central bank reserves and certain treasury securities from the SLR was a realworld feature of policy, which we capture in our model. ${ }^{15}$ The inflation target is raised from $2 \%$ to $3 \%$ annually. This third leg captures forward guidance. With a Taylor rule, raising the inflation target is akin to keeping the policy rate lower for longer. We refer to the combination of discretionary and unconventional monetary policy as the "Combo" experiment.

The Combo policy (purple line) adds unconventional monetary policy (UMP) on top of the discretionary fiscal spending. The combination of QE, SLR relaxation, and a higher inflation target has a clear positive impact on macro aggregates: output, consumption, and labor all see declines that are about $1 \%$ point of GDP smaller relative to the previous experiment. Investment and inflation improve by around $4 \%$ points.

We provide a detailed discussion of each aspect of the three-legged UMP mechanism in Section 5.2 below. For now, we point to QE generating a response that is akin to a positive demand shock through a crowding-out effect and a liquidity creation effect. The crowding-out channel says that QE leads banks to reduce their demand for firm capital, now that they are flush with reserves. Reserves enjoy lower bank equity requirements than firm capital, and no capital charges at all during the SLR relaxation, making them better collateral for deposits. QE also directly lowers banks' cost of creating deposits (equation (7)). Since deposits are valued for their liquidity benefits by households, QE lowers the production cost of a good from which households derive utility. We refer to this benefit of QE as the liquidity creation channel.

Committing to a higher inflation target for the duration of UMP is equivalent to setting a lower policy rate at any given level of inflation. This is expansionary at the ZLB, since the central bank effectively promises to compensate for its inability to lower rates during the crisis

\footnotetext{
${ }^{14}$ As of July 2021, the Fed holds $\$ 8.1$ trillion worth of assets, roughly $36 \%$ of 2021.Q2 GDP.

${ }^{15}$ The exact policy is that we increase $\nu$ in (6) to 1 from 0.97 , while keeping the product $\nu \nu_{K}$ constant. This implies that the equity requirement for capital is unaffected. The SLR exemption for bank reserves was in effect from April 2020 until March 2021; see Federal Reserve System (2020). Regulators are currently considering permanent changes to SLR requirements for safe assets.
} 
with lower rates during the recovery, once rates lift off from the ZLB (Werning, 2011; Basu and Bundick, 2017).

Policy 3: Longer-term Unconventional Monetary Policy In the third policy experiment, we allow UMP to persist well into recovery. For the automatic stabilizer baseline as well as policies (1) and (2) above, the shock and any policy responses last for 4 quarters and mean revert with probability 0.5 thereafter. For this third experiment, the demand and productivity shocks still follow these laws of motion. However, the unconventional monetary policy response is now assumed to only mean revert with probability 0.1 each quarter, such that the policy persists for an expected additional 10 quarters after the crisis ends in expectation. Policy parameters are exactly the same as in the second experiment. Thus, the only difference between (2) and (3) for the duration of the negative shock is an announcement effect: in case of policy (3), agents know that the government's policy response will persist with probability 0.9 per quarter after the demand and productivity shocks have mean-reverted. We refer to this policy as "Long UMP." One aspect of Long UMP is that the inflation target is kept high for longer. One interpretation of this is the new monetary policy framework the Fed adopted in 2019, in which it would tolerate higher inflation for longer if the economy had not returned to full employment. Another aspect of Long UMP is that QE is phased out more slowly, consistent with the experience post-GFC and the expectation post-covid.

Adding persistence to UMP greatly increases its benefits (green line in Figure 4). This is mostly due to announcement effects upon impact. During the crisis (periods 1 through 4), all policy variables are identical for the purple and green lines. Yet, announcing higher persistence of UMP has immediate positive effects on output, consumption, and investment.

Interestingly, long-running UMP causes the short-term policy rate set by the central bank to overshoot (top right panel of Figure 4). This is because announcing this policy causes extra inflation in the short-run, to which the central bank responds with rate increases based on its monetary policy rule. ${ }^{16}$

\footnotetext{
${ }^{16}$ One could consider additional policy variations that feature a lower coefficient on inflation in the Taylor rule for the duration of the policy.
} 
Figure 5: Main Policy Experiments: Fiscal Variables
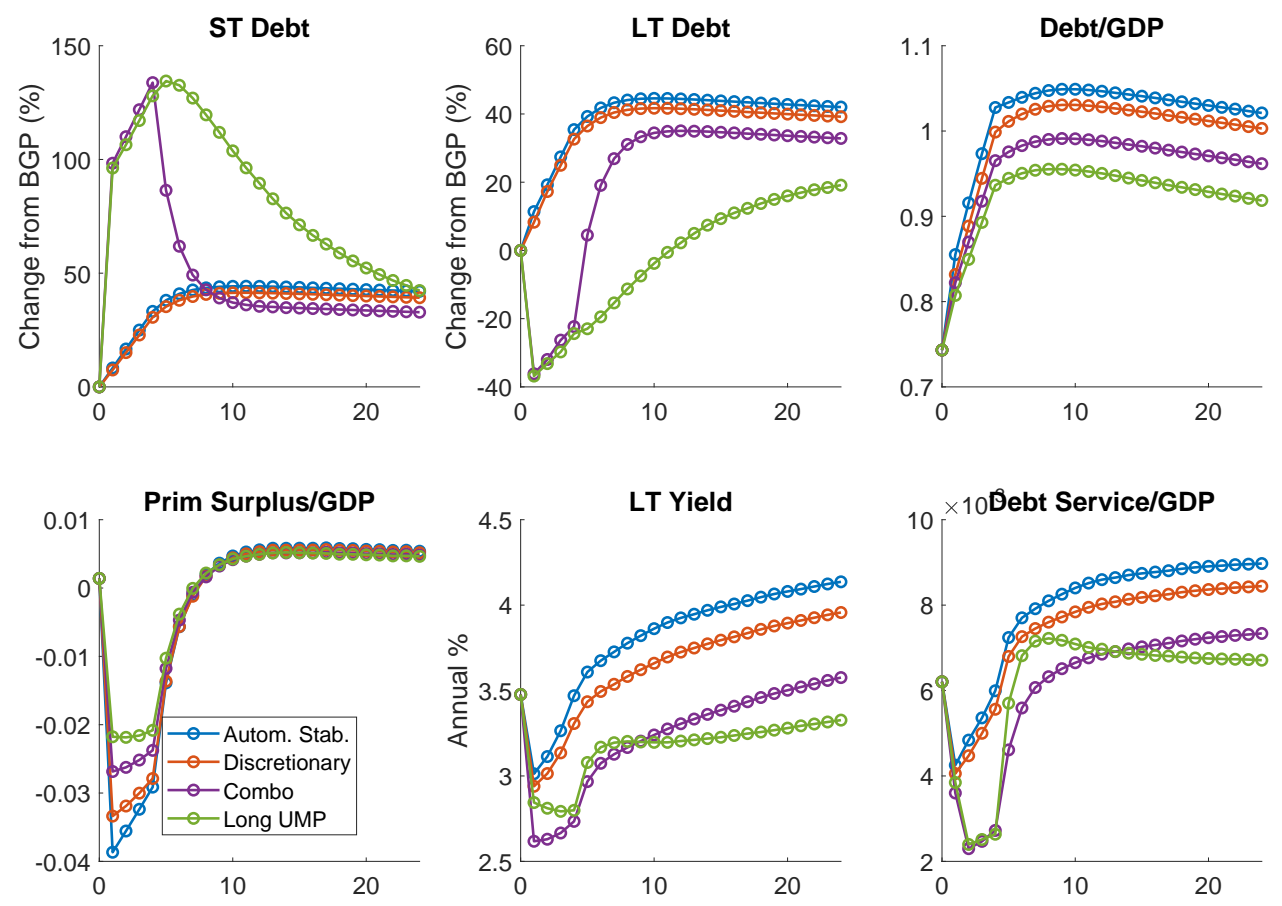

\subsubsection{Fiscal Variables}

Figure 5 displays the evolution of debt quantities and long-term bond yields. Absent additional policy intervention, debt/GDP increase sharply from $75 \%$ to above $100 \%$. The primary surplus turns sharply negative to $-3 \%$ of GDP. Yields on long-term government bonds initially decline as the central bank slashes the short rate to zero. But as short-term interest rates recover after 4 quarters of the shock and the quantity of debt/GDP increases, so do long-term bond yields. The highly persistent increase in yields and quantities of long-term debt feed back on each other, as high bond yields increase the cost of servicing the debt, which in turn requires the government to issue more debt.

Additional discretionary spending lowers the deficit/GDP and the debt/GDP ratio through the fiscal multiplier effects on GDP discussed above. The debt service is modestly lower than in the baseline.

The addition of unconventional monetary policy (purple line, Combo) makes a big difference for fiscal dynamics. To implement QE, the central bank swaps $40 \%$ of the fraction of outstanding 
long-term debt for short-term debt. This reduction in the quantity of long-term debt causes households to move up their demand curve for long-term debt, implying higher long-term bond prices and lower bond yields. The reduction in long-term bond yields, and the fact that a larger fraction of debt held by the public is short-term with QE, both contribute to lower government interest expenses, which in turn lead to a smaller rise of the debt/GDP ratio.

Turning to the long UMP experiment, long-term bond yields decline slightly less on impact in Figure 5, since GDP is higher, debt/GDP lower, and long-term yields move opposite to debt/GDP. However, yields stay lower for longer. These dynamics add up to lower debt servicing costs in the long-run. Combined with the strong positive effects on output in the short-run, these dynamics cause a smaller rise and steeper recovery of debt/GDP.

Each policy helps to alleviate the severity of the crisis and therefore causes a less sharp rise of the debt/GDP ratio. In the top right panel of Figure 5, the difference between the red and green lines measures the effectiveness of UMP in lowering the debt/GDP ratio relative to a central bank that follows its standard MP rule. The main result of the paper is that UMP creates fiscal space. The debt/GDP ratio is nearly nearly $10 \%$ points lower five years after the start of the crisis with long UMP than without it. Debt service is commensurately lower.

Fiscal Risk Avoidance As result of a smaller rise in debt/GDP, the economy is at lower risk of entering the austerity region. Thus, UMP helps the economy avoid detrimental tax hikes during this crisis episode. We refer to this benefit of UMP as the fiscal risk avoidance channel. We can see this channel at work in Figure 6.

This figure plots the dynamics of tax adjustments triggered by profligacy or austerity for the baseline crisis with only automatic stabilizers on the left, with discretionary government purchases in the middle, and with additional persistent UMP on the right. The bold lines plot mean paths. In addition, Figure 6 shows standard errors as dashed lines around each mean path. Furthermore, the color intensity around each line indicates the likelihood that the economy's stochastic path will visit the corresponding levels of tax adjustments. ${ }^{17}$ For the

\footnotetext{
${ }^{17}$ We generate the IRF graphs by simulating 5,000 random paths. For each period of the IRF, we estimate the kernel density of possible paths. Darker shades indicate higher density. Since austerity-induced tax increases are a nonlinear function of debt/GDP, expected mean tax increases due to austerity are positive even though the average debt/GDP path never enters the austerity region in Figure 7.
} 
Figure 6: Main Policy Experiments: Government Debt Paths
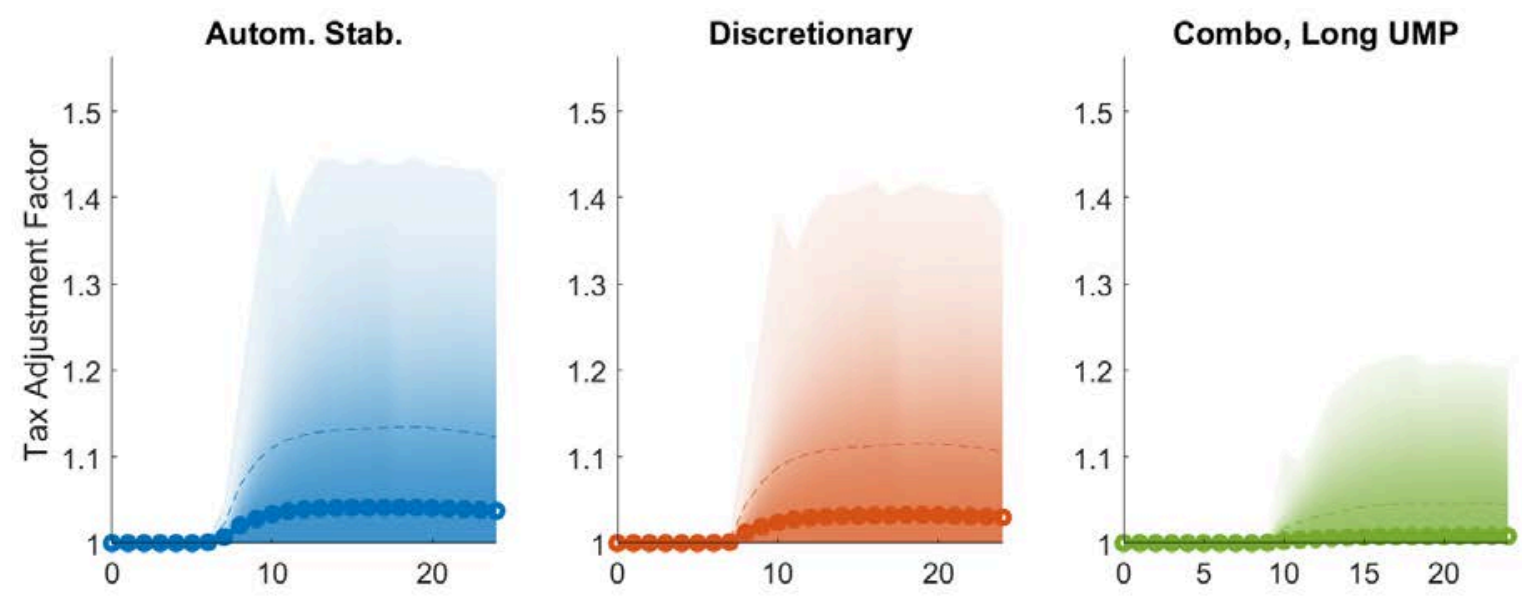

baseline scenario with only automatic stabilizers (left panel), austerity-induced tax adjustments occur along the mean path. The figures also illustrates that there is considerable fiscal risk: the worst paths out of the crisis require tax rates that are close to 1.4 times the baseline tax rates. Additional discretionary government spending (middle panel) reduces this risk slightly by mitigating the severity of the crisis; the fact that higher spending reduces fiscal risk during the recovery highlights that the model generates a large fiscal multiplier in crises. Adding longrunning UMP to the policy combo (right panel) almost eliminates the need for tax increases completely along the mean path. It also significantly reduces the risk of austerity, with the worst paths now only needing $20 \%$ higher tax rates.

Figure 7 shows the corresponding paths of debt/GDP. The mean paths in this figure are identical to those displayed for the respective policies in the top right panel of Figure 5. At the top of each panel, the austerity region is shaded in grey. We can see that government policies reduce the risk that the economy enters the austerity region. Specifically, government spending decreases the probability from $40 \%$ to $33 \%$. Long-running UMP reduces this probability further to only 10\%. Not only can monetary policy help the government ease the future debt burden from additional borrowing on average, but it also alleviates fiscal risks by lowering the probability of explosive debt expansion that requires painful fiscal adjustments.

In Section 5.2, we provide additional results that break out the different components of UMP in the crisis experiments above. There we also compare the effect of QE during economic crisis to the effect in normal times. 
Figure 7: Main Policy Experiments: Government Debt Paths
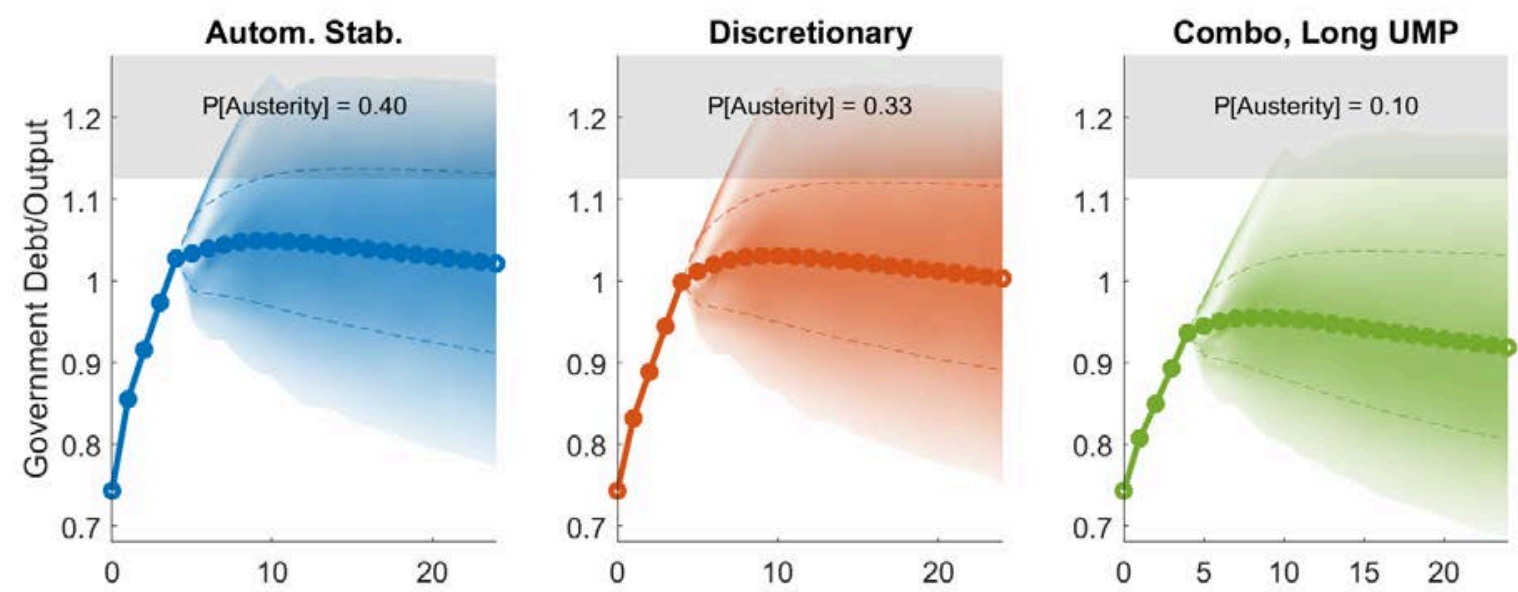

Figure 8: Main Policy Experiments: Risk Premia
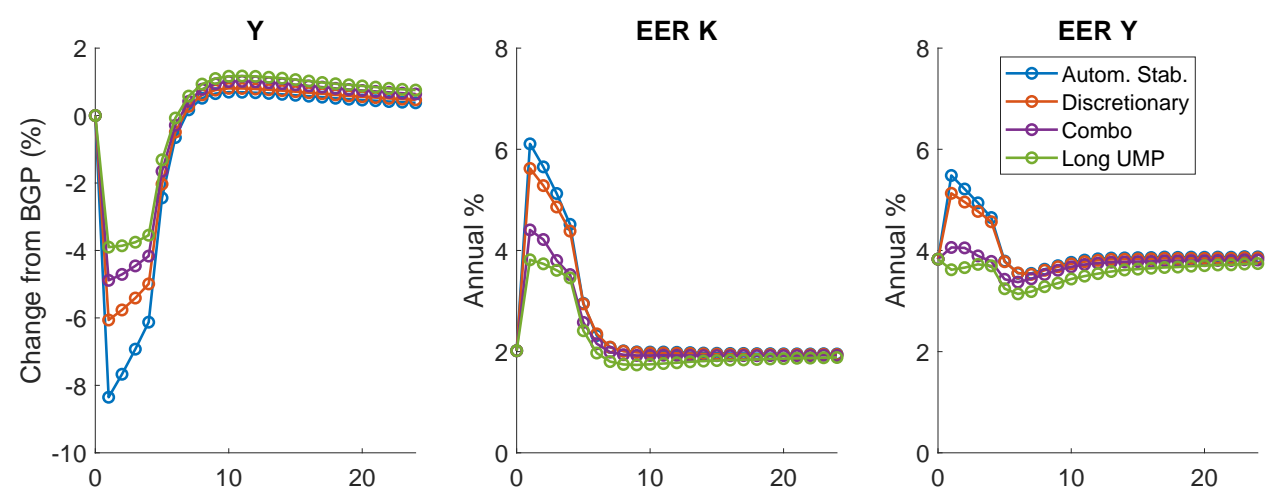

\subsubsection{The Financial System and Risk Premia}

Figure 8 displays the response of expected excess returns on firm capital claims (middle panel) and on output (right panel) during the crisis. Output changes are repeated in the left panel for convenience. Absent policy interventions, risk premia spike sharply - the capital risk premium by $4 \%$ points annually and the output premium by close to $2 \%$ points.

Discretionary fiscal spending (red line) has limited effects on these elevated risk premia. However, UMP significantly reduces risk premia on both claims, with the magnitude of the effect being almost the same for short- and long-running UMP. This demonstrates that UMP reduces required returns on risky assets, a stated objective of the policy. 
Figure 9: Effect of UMP in Crisis: Macro Variables
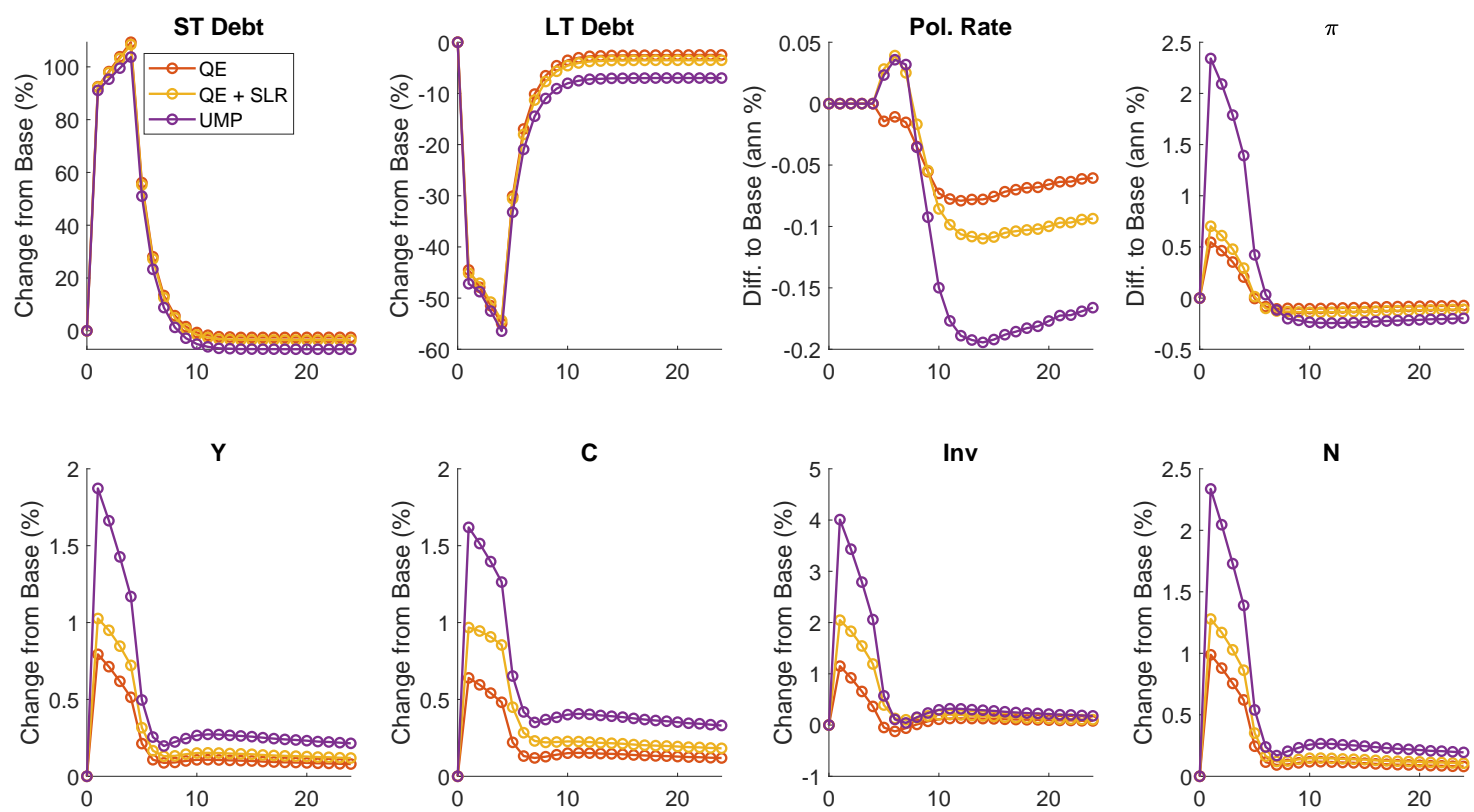

\subsection{Understanding the Effects of Unconventional Monetary Policy}

We recall that UMP in Figures 4-8 is a combination of three policy changes (Combo). The first leg is QE, which entails the central bank buying long-term debt from households by issuing reserves to intermediaries. The second component is a relaxation of the SLR constraint for reserves and short-term debt. The third component is an increase in the inflation target from $2 \%$ annually to $3 \%$.

\subsubsection{Decomposition: Effects During Crisis}

Figure 9 shows a decomposition of the effects of these policies relative to the baseline model with only automatic stabilizers; i.e., all lines in Figure 9 are differences with the blue lines in 4-8. The red line shows the effects of only QE, decreasing the supply of long-term debt held by the public and replacing it by short-term debt. This policy by itself has moderate positive effects on macro aggregates, reflecting both the liquidity creation and fiscal risk avoidance channels. When combined with a relaxation of the SLR for reserves (yellow line), the policy accounts for about half of the total effect of UMP on output. Adding the higher inflation target leads to the full effect of increasing output by roughly $2 \%$, consumption by roughly $1.5 \%$, and investment 
by $4 \%$ relative to the baseline.

Figure 10: Effect of UMP in Crisis: Fiscal Variables
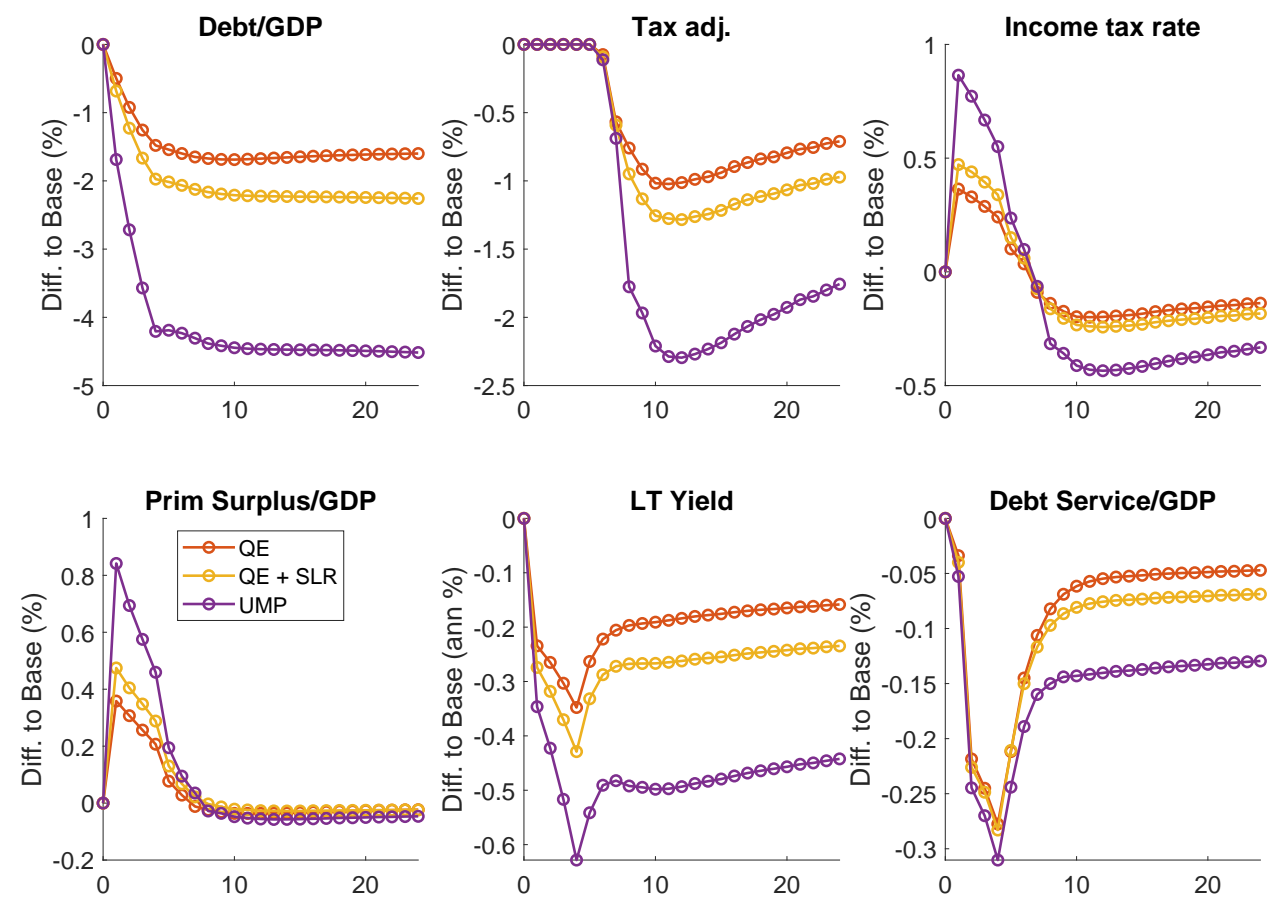

Simulated paths in crisis. Demand and productivity shocks last for four quarters before mean-reverting stochastically. The figure plots the difference of the economy's path under different policy scenarios relative to the automatic stabilizer baseline. "QE" (red) is quantitative easing only, "QE + SLR" (yellow) adds SLR exemption for reserves, and "UMP" adds higher inflation target.

We can see how these policies affect fiscal variables in Figure 10. In total, UMP reduces debt/GDP by about 4.5\%. QE accounts for about $1 / 3$ of this effect, the higher inflation target contributes more than $1 / 2$, with the SLR relaxation contributing the remainder. QE is effective at reducing the government's debt service, both by lowering long-term bond yields by about 30 basis points and by shifting the maturity structure of debt held by the public towards the short-term. The higher inflation target mainly affects debt dynamics through improving the real economy and thus causing a much smaller primary deficit. The lower debt/GDP ratio in turn results in lower long-term yields.

The middle and right panels in the top row of Figure 10 show the change in the tax adjustment due to austerity, and the change in the effective tax rate on wage income. In total, UMP causes a $2 \%$ smaller increase in tax rates on average by avoiding austerity. As a result, income tax rates during the recovery from the crisis are lower by about 50bp. Why does UMP cause higher 
Figure 11: Effect of UMP in Crisis: Financial Variables
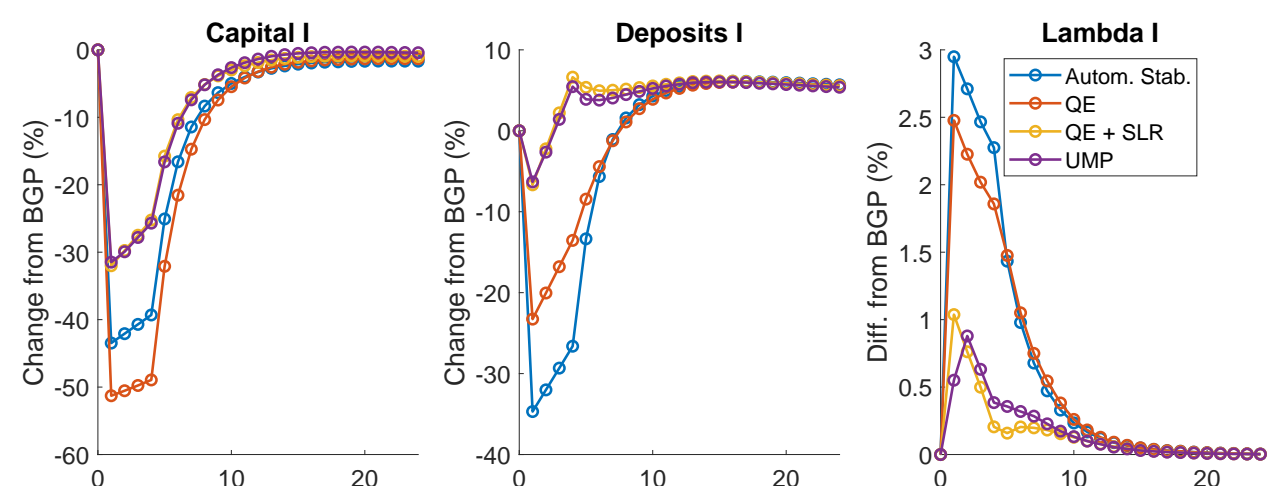

income tax rates in the short-run during the crisis relative to the economy without UMP? This is because UMP causes a less steep decline in output, and tax rates are pro-cyclical in output deviations from trend due to the pro-cyclical tax rule in equation (22).

In Figure 11 we study how QE affects key financial intermediary variables. Unlike Figures 9 and 10 this figure does not plot differences to the baseline automatic stabilizers scenario, but instead deviations from the no-shock growth path. Under a business-as-usual policy (blue line), the demand shock induced crisis causes a sharp tightening of the intermediary's leverage constraint, as can be seen from the value of the Lagrange multiplier on the constraint $\lambda^{I}$ in the right panel. Before the crisis, the constraint is not binding and the multiplier is zero. When the demand shock hits, intermediaries become equity constrained as capital prices drop sharply. They respond by shedding the more expensive collateral asset, capital, which they sell to households. As a result, intermediary capital holdings decrease by over $40 \%$ (left panel). Overall, intermediaries shrink their balance sheet, also reducing deposit issuance by roughly the same amount (middle panel).

Regular QE (red line) floods the balance sheet of intermediaries with reserves. This large increase in reserve supply has opposing effects. On the one hand, the liquidity cost of issuing each dollar of deposits is greatly reduced. However, because (and to the extent that) even reserves require scarce equity with the baseline SLR of 0.97, QE induces banks to sell even more of their capital holdings to households.

This capital sale to households is our model's representation of the crowding-out effect of lending, documented empirically by Diamond, Jiang, and Ma (2021). Even with this crowdingout effect, QE still causes a smaller net decline in deposit supply than the automatic stabilizer 
scenario, demonstrating the large liquidity creation benefit of QE during the crisis.

The equity squeeze of intermediaries stemming from the flood of reserves is substantially mitigated by eliminating the SLR requirement for reserves (yellow line). The Lagrange multiplier on intermediaries' leverage constraint is now much smaller, and intermediaries only sell $30 \%$ of their capital to households instead of over $50 \%$. As a result, overall deposit supply falls by less than $10 \%$ initially and even increases after a few quarters, allowing the economy to realize the full benefit of cheaper liquidity production.

Unsurprisingly, adding a higher inflation target to the policy mix (purple line) has little effect on these intermediary balance sheet quantities.

\subsubsection{Economic Mechanism: QE As A Positive Demand Shock}

To further our understanding of the economic mechanism through which QE works in our model, we perform the decomposition when QE is implemented in "normal times", i.e. without simultaneous occurrence of negative demand and productivity shocks. Details are in Appendix D.1. There, we first study the economy's transition from the baseline calibration to a world with permanent QE, where the central bank permanently alters the maturity composition of government debt towards short-term debt (the maturity of debt held by the public falls from 5.28 to 3.26 years). We then analyze the differences between this shift to permanent QE and a temporary QE policy shock that occurs independent of other (negative) economic shocks.

The discussion in Appendix D.1, visualized in Figures 12 and 13, clarifies that permanent QE causes a reallocation of capital from intermediaries to households, resulting in an economy with less investment and a permanently smaller capital stock. The reason is the crowding out effect discussed before: by providing intermediaries with plentiful reserves, the central bank reduces intermediaries' demand for physical capital as collateral to back deposit issuance. Reserves are a superior collateral asset since they alleviate both equity and liquidity (LCR) requirements of intermediaries. As intermediaries' valuation of capital decreases with greater reserve supply, they sell capital to households, and overall demand for capital declines. During the transition to a smaller capital stock, aggregate consumption rises. In the new steady state with permanent QE, consumption is slightly lower then in the initial economy, but intermediaries' balance sheets are larger and they have higher leverage, substantially boosting deposit supply. Household 
welfare in consumption-equivalent units is almost $0.4 \%$ greater. $^{18}$ The economy's behavior during the transition to permanent QE resembles a neoclassical growth model without nominal frictions: since the "QE shock" is permanent, the policy does not trigger short-term demand effects.

As we discuss in Appendix D.1, visualized in Figures 14 and 15, this behavior is different when the QE policy is temporary, as it is in our main policy experiment. The fundamental mechanism is still that QE temporarily provides plentiful high-quality collateral to intermediaries, causing them to shed physical capital to households. As in the permanent case, households respond to the decreased overall capital demand by temporarily consuming more. However, the transitory nature of the policy activates the New Keynesian elements of the model: QE affects the economy like a standard positive demand shock resulting from e.g. a temporary drop in households' discount factor. The shift from investment to consumption stimulates aggregate demand, causing producers to increase demand for production inputs. Equilibrium hours and real wages rise with higher labor demand, and aggregate output expands. Thus, unlike permanent QE which leads to a slow transition to lower output, the temporary QE policy is expansionary in the short-run and output-neutral in the long-run. Since temporary QE increases both consumption and deposit supply, the policy is welfare-increasing on impact. However, the magnitude of the overall positive effect is small: a replacement of $40 \%$ of long-term debt by reserves only leads to a 6 basis point rise in output, a $0.1 \%$ rise in consumption, and a $0.01 \%$ short-term welfare gain.

This is in sharp contrast to the effect of QE during the crisis (Figure 9), during which only QE causes output to rise by roughly $0.7 \%$ and the combination of QE and SLR relaxation causes a rise of 1\%. Therefore, comparing the economy's response to QE during crises, as in Figure 9, to its response in normal times, as in Figure 14, demonstrates that our model features a high multiplier on $Q E$. While these policies have very small short-term benefits when applied in normal times, they have ten times larger short-term output effects when applied during the crisis. Further, the policies have long-term benefits as they contribute to a smaller increase and faster recovery of the debt/GDP ratio.

\footnotetext{
${ }^{18}$ The fact that household welfare increases with permanent QE indicates that the initial economy suffers from a shortage of liquid assets that causes over-accumulation of physical capital and a shortage of deposits.
} 


\subsubsection{Economic Mechanism: Announcement Effects at the ZLB}

Figure 4 for our main policy experiment shows that adding persistence to UMP greatly enhances the benefits of this policy (Long UMP versus Combo). Since UMP in the main experiment is a combination of QE, a SLR constraint relaxation, and a higher inflation target, this section dissects the contribution of each component to this benefit of a longer-lasting policy. For this purpose, we turn off the higher inflation target as part of the policy mix. Figure 16 in Appendix D.2 reveals that without higher inflation target, the additional benefits stemming from greater persistence disappear. Put differently, all of the additional benefits of "Long UMP" over "Combo" in Figure 4 are due to the higher inflation target.

This finding is consistent with the results discussed above: making QE by itself more persistent reduces the short-term demand stimulus caused by the policy, since greater persistence moves the policy closer to the case of permanent QE, which we showed lowers output.

The central bank's commitment to a higher inflation target affects the economy by changing expectations of higher future interest rates once the economy recovers and lifts off from the ZLB (Werning, 2011; Basu and Bundick, 2017). Given the fact that QE on its own does not benefit from longer policy duration, a comparison of the "Long UMP" and "Combo" lines in Figure 4 isolates the effect of forward guidance about the central bank's monetary policy rule. In the "Long UMP" scenario, the central bank credibly promises to keep the inflation target higher at $3 \%$ rather than $2 \%$ for an additional 10 quarters after the crisis on average. Since the policy rate is stuck at the ZLB during the crisis, this commitment has no effect on actual interest rates in the crisis period. However, upon announcement the policy has a large positive effect on aggregate demand, causing a relative increase in output by $1 \%$ and investment by almost $5 \%$. Our policy experiment highlights the quantitative force of this expectations-driven mechanism, both in terms of how much it can limit the severity of the crisis and affect its long-term fiscal consequences. 


\section{Conclusion}

We study economic crisis dynamics in a New Keynesian model with realistic risk and risk premia. Conventional monetary (Taylor rule) and fiscal policy (automatic stabilizers) are insufficient to stabilize government debt in many states of the world. Keeping government debt risk-free implies a high risk of future austerity, a regime where fiscal policy must abandon stabilizing macro-economic fluctuations and focus on debt reduction instead. We find that unconventional monetary policy can significantly reduce this fiscal risk, and that it leads to a smaller increase in debt/GDP during the crisis and a faster reduction thereafter.

In our model both QE and committing to a higher inflation target are powerful policies in economic crises, when conventional monetary policy is stuck at the ZLB. Temporary QE affects the economy akin to a positive demand shock by shifting macroeconomic activity from investment to consumption. An announcement of permanent QE in response to a crisis acts as a negative supply shock in the long run with little effect on output in the short run. These results highlight that the effectiveness of QE arises from its temporary nature. In contrast, forward guidance about the inflation target in the crisis becomes more powerful as the promised persistence of the policy post recovery increases. This sheds new light on the Fed's new monetary policy strategy, which promises to tolerate higher inflation while the economy is still recovering from a recession. 


\section{References}

Philippe Andrade, Jordi Galí, Hervé Le Bihan, and Julien Matheron. Should the ECB Adjust its Strategy in the Face of a Lower r*? Working Papers 1236, Barcelona Graduate School of Economics, February 2021. URL https://ideas.repec.org/p/bge/wpaper/1236.html.

Robert J Barro. r minus g. NBER Working Paper, October 2020.

Marco Bassetto. A game-theoretic view of the fiscal theory of the price level. Econometrica, 2002.

Susanto Basu and Brent Bundick. Uncertainty shocks in a model of effective demand. Econometrica, 2017.

Ben S. Bernanke. The new tools of monetary policy. American Economic Review, 110(4):943-83, April 2020. doi: 10.1257/aer.110.4.943. URL https://www . aeaweb.org/articles?id=10.1257/ aer.110.4.943.

Francesco Bianchi and Leonardo Melosi. The dire effects of the lack of monetary and fiscal coordination. Journal of Monetary Economics, 2019.

Francesco Bianchi, Renato Faccini, and Leonardo Melosi. Monetary and fiscal policies in times of large debt: Unity is strength. 2020.

Roberto M. Billi and Carl E. Walsh. Seemingly irresponsible but welfare improving fiscal policy at the lower bound. 2021.

BIS. Basel III: The Liquidity Coverage Ratio and liquidity risk monitoring tools. Technical Report January, 2013.

Olivier Blanchard. Public debt and low interest rates. American Economic Review, 109(4):1197-1229, 2019.

Markus Brunnermeier, Sebastian Merkel, and Yuliy Sannikov. The fiscal theory of price level with a bubble. 2020.

John Y. Campbell, Carolin Pflueger, and Luis M. Viceira. Macroeconomic drivers of bond and equity risks. Journal of Political Economy, 128(8):3148-3185, 2020. doi: 10.1086/707766.

Lawrence Christiano, Martin Eichenbaum, and Sergio Rebelo. When is the government spending multiplier large? Journal of Political Economy, 2011.

John H. Cochrane. A frictionless model of u.s. inflation. NBER Macroeconomics Annual, 1998.

John H. Cochrane. Long term debt and optimal policy in the fiscal theory of the price level. Econometrica, 2001.

John H Cochrane. The fiscal roots of inflation. Technical report, National Bureau of Economic Research, 2019a.

John H Cochrane. The value of government debt. Technical report, National Bureau of Economic Research, 2019b.

Alexandre Corhay, Thilo Kind, Howard Kung, and Gonzalo Morales. Discount rates, debt maturity, and the fiscal theory. 2021. 
Max Croce, Howard Kung, Thien Nguyen, and Lukas Schmid. Fiscal policies and asset prices. Review of Financial Studies, 2012a.

Max Croce, Thien Nguyen, and Lukas Schmid. The market price of fiscal uncertainty. Journal of Monetary Economics, 2012b.

Max Croce, Thien Nguyen, Steven Raymond, and Lukas Schmid. Government debt and the returns to innovation. Journal of Financial Economics, 2019.

Bianca De Paoli, Alasdair Scott, and Olaf Weeken. Asset pricing implications of a new keynesian model. Journal of Economic Dynamics and Control, 34(10):2056-2073, 2010. ISSN 0165-1889. doi: https: //doi.org/10.1016/j.jedc.2010.05.012. URL https://www.sciencedirect.com/science/article/ $\mathrm{pii} / \mathrm{S} 0165188910001156$.

William Diamond, Zhengyang Jiang, and Yiming Ma. The reserve supply channel of unconventional monetary policy. Working Paper, 2021.

Gauti Eggertsson. What fiscal policy is effective at zero interest rates? NBER Macroeconomics Annual 2010, 2011.

Vadim Elenev. Mortgage credit, aggregate demand, and unconventional monetary policy. 2020.

Vadim Elenev, Tim Landvoigt, and Stijn Van Nieuwerburgh. A macroeconomic model with financially constrained producers and intermediaries. Econometrica, 89(3):1361-1418, 2021. doi: https://doi.org/10.3982/ECTA16438. URL https://onlinelibrary.wiley.com/doi/abs/10. 3982/ECTA16438.

Miguel Faria-e-Castro. Fiscal policy instruments. Covid Economics: Vetted and Real-Time Papers, 2020.

Federal Reserve System. Temporary exclusion of u.s. treasury securities and deposits at federal reserve banks from the supplementary leverage ratio. Fed. Reg., 85(72):20578, April 2020.

John G. Fernald. A Quarterly, Utilization-Adjusted Series on Total Factor Productivity. 2012.

Jordi Galí. Monetary Policy, Inflation, and the Business Cycle: An Introduction to the New Keynesian Framework and Its Applications Second edition. Number 10495 in Economics Books. Princeton University Press, April 2015. URL https://ideas.repec.org/b/pup/pbooks/10495.html.

Francois Gourio. Disaster risk and business cycles. American Economic Review, 2012.

Francois Gourio and Phuong Ngo. Risk Premia at the ZLB: A Macroeconomic Interpretation. Working Paper Series WP 2020-01, Federal Reserve Bank of Chicago, January 2020. URL https://ideas. repec.org/p/fip/fedhwp/87504.html.

Zhiguo He and Arvind Krishnamurthy. Intermediary asset pricing. American Economic Review, 103 (2):732-770, 2013.

Zhiguo He and Arvind Krishnamurthy. A macroeconomic framework for quantifying systemic risk. American Economic Journal: Macroeconomics, 11(4):1-37, October 2019. doi: 10.1257/mac. 20180011. URL https://www . aeaweb.org/articles?id=10.1257/mac . 20180011. 
Marlène Isoré and Urszula Szczerbowicz. Disaster risk and preference shifts in a new keynesian model. Journal of Economic Dynamics and Control, 79:97-125, 2017. ISSN 0165-1889. doi: https://doi. org/10.1016/j.jedc.2017.04.001. URL https://www.sciencedirect.com/science/article/pii/ S0165188917300751.

Zhengyang Jiang, Hanno Lustig, Stijn Van Nieuwerburgh, and Mindy Z. Xiaolan. The u.s. public debt valuation puzzle. Working Paper, April 2019.

Zhengyang Jiang, Hanno Lustig, Stijn Van Nieuwerburgh, and Mindy Z. Xiaolan. Manufacturing risk-free government debt. SSRN Working Paper No. 3646430, July 2020.

Zhengyang Jiang, Hanno Lustig, Stijn Van Nieuwerburgh, and Mindy Z. Xiaolan. What determines the government's funding costs when $\mathrm{r}=\mathrm{g}$ ? unpleasant fiscal asset pricing arithmetic. Working Paper, March 2021.

Oscar Jorda, Moritz Schularick, and Alan Taylor. Macrofinancial History and the New Business Cycle Facts, pages 213-263. University of Chicago Press, May 2016. doi: 10.1086/690241. URL http://www. nber.org/chapters/c13776.

Bryan Kelly, Lubos Pastor, and Pietro Veronesi. The price of political uncertainty: Theory and evidence from the option markets. Journal of Finance, 2015.

Mathias Klein and Roland Winkler. Austerity, inequality, and private debt overhang. European Journal of Political Economy, 2019.

E.M. Leeper and C. Leith. Chapter 30 - understanding inflation as a joint monetary-fiscal phenomenon. volume 2 of Handbook of Macroeconomics, pages 2305-2415. Elsevier, 2016. doi: https://doi.org/ 10.1016/bs.hesmac.2016.03.012. URL https://www.sciencedirect.com/science/article/pii/ S1574004816000136.

Eric M. Leeper. Equilibria under active and passive monetary and fiscal policies. Journal of Monetary Economics, 1991.

Moritz Lenel, Monika Piazzesi, and Martin Schneider. The short rate disconnect in a monetary economy. Journal of Monetary Economics, 106:59-77, 2019.

Yang Liu, Lukas Schmid, and Amir Yaron. The risks of safe assets. 2020.

N. Gregory Mankiw and Laurence M. Ball. Market power in neoclassical growth models. 2021.

Lubos Pastor and Pietro Veronesi. Uncertainty about government policy and stock prices. Journal of Finance, 2012.

Carolin Pflueger and Gianluca Rinaldi. Why does the fed move markets so much? a model of monetary policy and time-varying risk aversion. 2021.

Monika Piazzesi, Cieran Rogers, and Martin Schneider. Money and banking in a new keynesian model. 2021.

Ricardo Reis. Funding quantitative easing to target inflation. Discussion Papers, Centre for Macroeconomics, 2016.

Ricardo Reis. The constraint on public debt when $\mathrm{r}<\mathrm{g}$ but $\mathrm{g}<\mathrm{m}$. Working Paper London School of Economics, March 2021. 
Geert Rouwenhorst. Asset pricing implications of equilibrium business cycle models. In Cooley, editor, Frontiers of Business Cycle Research. Princeton University Press, 1995.

Thomas Sargent and Neil Wallace. Some unpleasant monetarist arithmetic. Federal Reserve Bank of Minneapolis Quarterly Review, 1981.

Stephanie Schmitt-Grohhe and Martin Uribe. Price level determinacy and monetary policy under a balanced-budget requirement. Journal of Monetary Economics, 2000.

Chistopher A. Sims. Fiscal policy, monetary policy, and central bank independence. Technical report, 2016.

Christopher A. Sims. A simple model for study of the determination of the price level and the interaction of monetary and fiscal policy. Economic Theory, 1991.

Eric Sims and Jing Cynthia Wu. The four equation new keynesian model. 2021.

Eric T. Swanson. Risk aversion, risk premia, and the labor margin with generalized recursive preferences. Review of Economic Dynamics, 28:290-321, 2018. ISSN 1094-2025. doi: https: //doi.org/10.1016/j.red.2017.10.003. URL https://www.sciencedirect.com/science/article/ $\mathrm{pii} / \mathrm{S} 1094202517300820$.

Has van Vlokhoven. Estimating the Cost of Capital and the Profit Share. 2020.

Annette Vissing-Jorgensen and Arvind Krishnamurthy. The effects of quantitative easing on interest rates: Channels and implications for policy. Brookings Papers on Economic Activity, 2011.

Annette Vissing-Jorgensen and Arvind Krishnamurthy. The aggregate demand for treasury debt. The Journal of Political Economy, 2012.

Annette Vissing-Jorgensen and Arvind Krishnamurthy. The ins and outs of large scale asset purchases. Technical report, 2013.

Annette Vissing-Jorgensen, Stefan Nagel, and Arvind Krishnamurthy. Ecb policies involving government bond purchases: Impact and channels. Review of Finance, 2018.

Olivier Wang. Banks, low interest rates, and monetary policy transmission. 2020.

Ivan Werning. Managing a liquidity trap: Monetary and fiscal policy. 2011.

Michael Woodford. Monetary policy and price level determinacy in a cash-in-advance economy. Economic Theory, 1994.

Michael Woodford. Price level determinacy without control of a monetary aggregate. CarnegieRochester Series of Public Policy, 1995.

Michael Woodford. Fiscal requirements of price stability. Journal of Money Credit and Banking, 2001.

Michael Woodford. Simple analytics of the government expenditure multiplier? American Economic Journal: Macroeconomics, 2011.

Michael Woodford. Methods of policy accomodation at the interest-rate lower bound. 2012. 


\section{A Model Appendix}

\section{A.1 Preliminary Definitions}

We reformulate the problems of the household, wholesaler, retailer, and intermediary to ensure stationarity. For nominal quantities, define real, stationary variables as

$$
\hat{X}_{t}=\frac{X_{t}}{Z_{t}^{p} P_{t}}
$$

where $Z_{t}^{p}$ is the permanent component of productivity. For real variables, we denote stationary values as

$$
\hat{X}_{t}=\frac{X_{t}}{Z_{t}^{p}}
$$

We define inflation as the gross growth rate on the price level

$$
\frac{P_{t}}{P_{t-1}}=\pi_{t}
$$

and the growth rate of the permanent component of productivity as

$$
\frac{Z_{t}^{p}}{Z_{t-1}^{p}}=\exp \left(g_{t}\right)
$$

Finally, we let $\mathcal{S}_{t}=\left\{Z_{t}^{r}, g_{t}, K_{t}, W_{t}^{H}, W_{t}^{I}, W_{t}^{G}\right\}$ be the vector of aggregate state variables.

\section{A.2 Household}

We write the household problem recursively, defining real household wealth using the payoffs to holding capital, deposits, and the long-term bond.

$$
\hat{W}_{t}^{H}=\exp \left(-g_{t}\right)\left(\left(r_{t}^{K}+(1-\delta) Q_{t}\right) \hat{X}_{t-1}^{H, K}+\frac{\hat{D}_{t-1}^{H}}{\pi_{t}}+\left(c+1-\delta^{B}+\delta^{B} p_{t}^{B}\right) \frac{\hat{X}_{t-1}^{H, l}}{\pi_{t}}\right) .
$$

The value function needs to be divided through by $\left(Z_{t}^{P}\right)^{1-\gamma}$ to ensure stationarity

$$
V^{H}\left(\hat{W}_{t}^{H}, \mathcal{S}_{t}\right)=\max _{\hat{C}_{t}, N_{t}, \hat{B}_{t}^{H}, \hat{D}_{t}^{H}}(1-\beta) u^{H}\left(\hat{C}_{t}, N_{t}, \hat{D}_{t}^{H}\right)-\beta \mathrm{E}_{t}\left[\exp \left((1-\sigma)\left(g_{t+1}\right)\right)\left(-V^{H}\left(\hat{W}_{t+1}^{H}, \mathcal{S}_{t+1}\right)\right)^{\frac{1-\sigma}{1-\gamma}}\right]^{\frac{1-\gamma}{1-\sigma}}
$$

subject to

$$
\begin{aligned}
\hat{C}_{t} & =\hat{W}_{t}^{H}+\left(1-\tau_{t}^{w}\right) \hat{w}_{t} N_{t}+Q_{t} \hat{I}_{t}+\left(1-\tau^{d i v}\right)\left(\operatorname{Div}_{t}^{I}+\operatorname{Div}_{t}^{P}\right)+\Theta_{t}+\text { Rebates }_{t} \\
& -\hat{I}_{t}-\Phi\left(\hat{I}_{t} / \hat{K}_{t-1}\right)-\Xi^{L}\left(\hat{X}_{t}^{H, L}, \hat{Y}_{t}\right)-p_{t}^{D} \hat{D}_{t}^{H}-p_{t}^{L} \hat{X}_{t}^{H, L}-Q_{t} \hat{X}^{H, K}-\Xi^{K}\left(\hat{X}_{t}^{H, K}, \hat{K}_{t}\right),
\end{aligned}
$$


where intra-period utility is

$$
u^{H}\left(\hat{C}_{t}, N_{t}, \hat{D}_{t}^{H}\right)=\frac{\left(\hat{C}_{t}^{1-\psi}\left(D_{t}^{H}\right)^{\psi}\right)^{1-\gamma}}{1-\gamma}-\omega_{0} \frac{N_{t}^{1+\omega_{1}}}{1+\omega_{1}}-\bar{u} .
$$

Note that the aggregate capital stock is $\hat{K}_{t-1}=K_{t-1} / Z_{t}^{p}$, since it is chosen in $t-1$ for production in $t$.

We define the intra-temporal marginal rate of substitution between deposits and consumption as

$$
\operatorname{MRS}_{t}^{D}=\frac{u_{D}}{u_{C}}=\frac{\psi \hat{C}_{t}}{(1-\psi) \hat{D}_{t}^{H}}
$$

Denote $V\left(\hat{W}_{t}, \mathcal{S}_{t}\right) \equiv V_{t}$ and the certainty equivalent.

$$
C E_{t}=-\mathrm{E}_{t}\left[\exp \left((1-\sigma)\left(g_{t+1}\right)\right)\left(-V^{H}\left(\hat{W}_{t+1}^{H}, \mathcal{S}_{t+1}\right)\right)^{\frac{1-\sigma}{1-\gamma}}\right]^{\frac{1-\gamma}{1-\sigma}} .
$$

The partial derivative of the certainty equivalent with respect to the value function is then given by

$$
\begin{aligned}
\frac{\partial C E_{t}\left(V_{t+1}^{H}\right)}{\partial V^{H} t+1} & =\exp \left((1-\sigma)\left(g_{t+1}\right)\right)\left(V_{t+1}^{H}\right)^{\frac{\gamma-\sigma}{1-\gamma}} \mathrm{E}_{t}\left[\exp \left((1-\sigma) g_{t+1}\right)\left(-V_{t+1}\right)^{\frac{1-\sigma}{1-\gamma}}\right]^{\frac{1-\gamma}{1-\sigma}-1} \\
& =\exp \left((1-\sigma)\left(g_{t+1}\right)\left(\frac{V_{t+1}^{H}}{C E_{t}}\right)^{\frac{\gamma-\sigma}{1-\gamma}}\right.
\end{aligned}
$$

We can denote the partial derivatives of the portfolio cost functions as

$$
\begin{aligned}
& \Xi_{X, t}^{K} \equiv \frac{\partial \Xi^{L}\left(\hat{X}_{t}^{H, L}, \hat{Y}_{t}\right)}{\partial \hat{X}_{t}^{H, L}}=\xi_{0}^{L}\left(\frac{\hat{X}_{t}^{H, L}}{\hat{Y}_{t}}\right)^{\xi_{1}^{L}-1} \\
& \Xi_{X, t}^{L} \equiv \frac{\partial \Xi^{K}\left(\hat{X}_{t}^{H, K}, \hat{K}_{t}\right)}{\partial \hat{X}_{t}^{H, K}}=\xi_{0}^{K}\left(\frac{\hat{X}_{t}^{H, K}}{\hat{Y}_{t}}\right)^{\xi_{1}^{K}-1}
\end{aligned}
$$

and the partial derivatives of the value function with respect to bond and capital holdings as

$$
\begin{aligned}
V_{B, t}^{H} & \equiv \frac{\partial V_{t}^{H}}{\partial \hat{X}_{t-1}^{H, L}}=\frac{\exp \left(-g_{t}\right)}{\pi_{t}}\left(c+1-\delta^{B}+\delta^{B} p_{t}^{L}\right), \\
V_{K, t}^{H} & \equiv \frac{\partial V_{t}^{H}}{\partial \hat{X}_{t-1}^{H, K}}=\exp \left(-g_{t}\right)\left(r_{t}^{K}+(1-\delta) Q_{t}\right) .
\end{aligned}
$$




\section{A.2.1 First-order conditions}

Stochastic Discount Factor Define the household's intertemporal marginal rate of substitution between time $t$ and $t+1$ as

$$
\begin{aligned}
\mathcal{M}_{t, t+1} & =\frac{\frac{\partial V_{t}^{H}}{\partial C_{t+1}}}{\frac{\partial V_{t}^{H}}{\partial C_{t}}}=\frac{\partial V_{t}^{H}}{\partial V_{t+1}^{H}} \exp \left(-g_{t+1}\right) \frac{\partial V_{t+1}^{H} / \partial C_{t+1}}{\partial V_{t}^{H} / \partial C_{t}} \\
& =\beta \exp \left(-\sigma g_{t+1}\right)\left(\frac{V_{t+1}}{C E_{t}}\right)^{\frac{\gamma-\sigma}{1-\gamma}} \frac{\frac{1}{\hat{C}_{t+1}}(1-\beta)(1-\psi)\left(\hat{C}_{t+1}^{1-\psi} \hat{D}_{t+1}^{\psi}\right)^{1-\gamma}}{\frac{1}{\hat{C}_{t}}(1-\beta)(1-\psi)\left(\hat{C}_{t}^{1-\psi} \hat{D}_{t}^{\psi}\right)^{1-\gamma}}
\end{aligned}
$$

Hence, we can define the household stochastic discount factor as

$$
\mathcal{M}_{t, t+1}=\beta \exp \left(-\sigma g_{t+1}\right)\left(\frac{\hat{C}_{t+1}}{\hat{C}_{t}}\right)^{-1}\left(\frac{\hat{C}_{t+1}^{1-\psi} \hat{D}_{t+1}^{\psi}}{\hat{C}_{t}^{1-\psi} \hat{D}_{t}^{\psi}}\right)^{1-\gamma}\left(\frac{V_{t+1}}{C E_{t}}\right)^{\frac{\gamma-\sigma}{1-\gamma}} .
$$

Consumption Attaching multiplier $\lambda_{t}$ to multiplier on the budget constraint, the FOC for consumption is given by

$$
\lambda_{t}=\frac{(1-\beta)(1-\psi)\left(C_{t}^{1-\psi} D_{t}^{\psi}\right)^{1-\gamma}}{C_{t}} .
$$

Long-term bonds The FOC for long-term bonds, $\hat{X}_{t}^{H, L}$ is

$$
-\lambda_{t} p_{t}^{L}-\lambda_{t} \Xi_{X, t}^{K}+\mathrm{E}_{t}\left[\beta \frac{\partial V_{t+1}^{H}}{\partial \hat{X}_{t}^{H, L}} \frac{\partial C E_{t}}{\partial V_{t+1}^{H}}\right]=0
$$

Hence, we can write the FOC for the household's holding of the long-term bond as follows

$$
p_{t}^{L}=\Xi_{X, t}^{K}+\mathrm{E}_{t}\left[\beta \frac{\lambda_{t+1}}{\lambda_{t}} \exp \left((-\sigma)\left(g_{t+1}\right)\right)\left(\frac{V_{t+1}^{H}}{C E_{t}}\right)^{\frac{\gamma-\sigma}{1-\gamma}}\left(\frac{c+1-\delta^{B}+\delta^{B} p_{t+1}^{L}}{\pi_{t+1}}\right)\right] .
$$

Simplifying, we get

$$
p_{t}^{L}=\Xi_{X, t}^{K}+\mathrm{E}_{t}\left[\mathcal{M}_{t, t+1}\left(\frac{c+1-\delta^{B}+\delta^{B} p_{t+1}^{L}}{\pi_{t+1}}\right)\right]
$$

Deposits The FOC for the household's purchases of deposits is given by

$$
-\lambda_{t} p_{t}^{D}+\psi(1-\beta) \frac{\left(\hat{C}_{t}^{1-\psi}\left(\hat{D}_{t}^{H}\right)^{\psi}\right)^{1-\gamma}}{\hat{D}_{t}^{H}}+\mathrm{E}_{t}\left[\beta \frac{\partial V_{t+1}^{H}}{\partial \hat{D}_{t}} \frac{\partial C E_{t}}{\partial V_{t+1}}\right]=0 .
$$

Then using the definition of the intratemporal marginal rate of substitution between deposits and consumption, and the stochastic discount factor, we have that the FOC for deposits is 
given by

$$
p_{t}^{D}=\mathrm{MRS}_{t}^{D}+\mathrm{E}_{t}\left[\mathcal{M}_{t, t+1} \frac{1}{\pi_{t, t+1}}\right] \text {. }
$$

Capital Households operate the economy's investment technology and optimally solve the intratemporal problem of producing $I_{t}$ unites of capital from $I_{t}+\Phi\left(I_{t}, K_{t}\right)$ units of the consumption good. The first order condition is given by

$$
Q_{t}=1+\phi\left(\iota_{t}-\delta\right)
$$

Labor The household FOC for labor supply is given by

$$
N_{t}=\left((1-\psi)\left(\hat{C}_{t}\right)^{-1}\left(\hat{C}_{t}^{1-\psi}\left(\hat{D}_{t}^{H}\right)^{\psi}\right)^{1-\gamma} \frac{\left(1-\tau_{t}^{w}\right) w_{t}}{\omega_{0}}\right)^{\frac{1}{\omega_{1}}} .
$$

In summary, the household's optimality conditions are given by Equations (32) to (35).

\section{A.3 Banks}

The stationarized recursive bank problem is

$$
V^{I}\left(\hat{W}_{t}^{I}, \mathcal{S}_{t}\right)=\max _{\hat{X}_{t}^{I, K}, \hat{X}_{t}^{I, S}, \hat{D}_{t}^{I} \hat{A}_{t},} \tau \hat{W}_{t}^{I}-\hat{A}_{t}+\mathrm{E}_{t}\left[\mathcal{M}_{t, t+1} \exp \left(g_{t+1}\right) V^{I}\left(\hat{W}_{t+1}^{I}, \mathcal{S}_{t+1}\right)\right]
$$

subject to

$$
(1-\tau) \hat{W}_{t}^{I}+\hat{A}_{t}+\left(p_{t}^{D}-\varrho_{t}\right) \hat{D}_{t}^{I}+\operatorname{Rebates}_{t}^{I} \geq p_{t}^{S} \hat{X}_{t}^{I, S}+Q_{t} \hat{X}_{t}^{I, K}+\frac{\chi}{2} \hat{A}_{t}^{2}
$$

and

$$
\begin{aligned}
\hat{D}_{t}^{I} & \leq \nu\left(\hat{X}_{t}^{I, s}+\nu^{K} Q_{t} \hat{X}_{t}^{I, K}\right) . \\
\hat{X}_{t}^{I, S} & \geq 0 \\
\hat{X}_{t}^{I, K} & \geq 0
\end{aligned}
$$

where the first constraint reflects the regulatory constraint and the final two constraints reflecting no-shorting constraints for short-term bonds and capital. Bank equity evolves according to

$$
\hat{W}_{t+1}^{I}=\exp \left(-g_{t+1}\right)\left[\left(r_{t+1}^{K}+\left(1-\delta_{t+1}\right) Q_{t+1}\right) \hat{X}_{t}^{I, K}+\frac{\hat{X}_{t}^{I, S}}{\pi_{t+1}}-\frac{\hat{D}_{t}^{I}}{\pi_{t+1}}\right]
$$

Bank equity We attach multiplier $\hat{\lambda}_{t}^{I}$ to the budget constraint. Then the FOC for raising new equity is given by

$$
0=\hat{\lambda}_{t}^{I}\left(1-\chi A_{t}\right)-1
$$


Short-term bond First, note that the partial derivative of the liquidity cost with respect to short-term debt is given by

$$
\frac{\partial \varrho_{t}}{\partial \hat{X}_{t}^{I, S}}=\left(1-\varrho_{1}\right) \varrho_{0}\left(\frac{\hat{X}_{t}^{I, S}}{\zeta_{\varrho} \hat{D}_{t}^{I}}\right)^{-\varrho_{1}}
$$

Attaching multipliers $\hat{\lambda}_{t}$ and $\hat{\sigma}_{t}^{I, S}$ to the leverage constraint and non-negativity constraint, respectively, we can we write the first order condition for short-term bonds as

$$
0=-\hat{\lambda}_{t}^{I}\left(p_{t}^{S}-\left(1-\varrho_{1}\right) \varrho_{0} \zeta_{\varrho}\left(\frac{\hat{X}_{t}^{I, S}}{\hat{D}_{t}^{I}}\right)^{-\varrho_{1}}\right)+\mathrm{E}_{t}\left[\mathcal{M}_{t, t+1}\left(V^{I}\right)^{\prime}\left(\hat{W}_{t+1}^{I}\right) \frac{1}{\pi_{t+1}}\right]+\hat{\lambda}_{t} \nu+\hat{\sigma}_{t}^{I, S}
$$

Deposits Noting that the partial derivative of the liquidity cost with respect to deposits is given by

$$
\frac{\partial \varrho_{t}}{\partial \hat{D}_{t}^{I}}=\varrho_{0} \varrho_{1} \zeta_{\varrho}\left(\frac{\hat{X}_{t}^{I, S}}{\zeta_{\varrho} \hat{D}_{t}^{I}}\right)^{1-\varrho_{1}}
$$

we can write the first order condition for deposits as

$$
0=\hat{\lambda}_{t}^{I}\left(p_{t}^{D}-\varrho_{0} \varrho_{1} \zeta_{\varrho}\left(\frac{\hat{X}_{t}^{I, S}}{\zeta_{\varrho} \hat{D}_{t}^{I}}\right)^{1-\varrho_{1}}\right)-\mathrm{E}_{t}\left[\mathcal{M}_{t, t+1}\left(V^{I}\right)^{\prime}\left(\hat{W}_{t+1}^{I}\right) \frac{1}{\pi_{t+1}}\right]-\hat{\lambda}_{t}
$$

Capital Attach multiplier $\hat{\sigma}_{t}^{I, K}$ to the non-negativity constraint on capital. Then the FOC for capital is

$$
0=-\hat{\lambda}_{t}^{I} Q_{t}+\mathrm{E}_{t}\left[\mathcal{M}_{t, t+1}\left(V^{I}\right)^{\prime}\left(\hat{W}_{t+1}^{I}\right)\left(r_{t+1}^{K}+\left(1-\delta_{t+1}\right) Q_{t+1}\right)\right]+\hat{\lambda}_{t} \nu \nu^{K} Q_{t}+\hat{\sigma}_{t}^{I, K} .
$$

Envelope condition To further simplify the bank's first order conditions, we note that the envelope condition is given by

$$
\left(V^{I}\right)^{\prime}\left(\hat{W}_{t}^{I}\right)=\tau+\hat{\lambda}_{t}^{I}(1-\tau)
$$

Combining envelope condition and first FOC for new equity, $\hat{\lambda}_{t}^{I}=1 /\left(1-\chi \hat{A}_{t}\right)$, we can define the bank stochastic discount factor as

$$
\mathcal{M}_{t, t+1}^{I}=\mathcal{M}_{t, t+1}\left(1-\chi \hat{A}_{t}\right)\left(\tau+\frac{1-\tau}{1-\chi \hat{A}_{t+1}}\right)
$$

and the rescaled multipliers as

$$
\begin{array}{r}
\lambda_{t}=\hat{\lambda}_{t}\left(1-\chi \hat{A}_{t}\right), \\
\sigma_{t}^{I, S}=\hat{\sigma}_{t}^{I, S}\left(1-\chi \hat{A}_{t}\right) \\
\sigma_{t}^{I, K}=\hat{\sigma}_{t}^{I, K}\left(1-\chi \hat{A}_{t}\right) .
\end{array}
$$


Then the bank FOC can be rewritten as

$$
\begin{aligned}
& p_{t}^{S}=\mathrm{E}_{t}\left[\mathcal{M}_{t, t+1}^{I} \frac{1}{\pi_{t+1}}\right]+\lambda_{t} \nu+\left(1-\varrho_{1}\right) \varrho_{0}\left(\frac{\hat{X}_{t}^{I, S}}{\zeta_{\varrho} \hat{D}_{t}^{I}}\right)^{-\varrho_{1}}+\sigma_{t}^{I, S}, \\
& p_{t}^{D}=\mathrm{E}_{t}\left[\mathcal{M}_{t, t+1}^{I} \frac{1}{\pi_{t+1}}\right]+\lambda_{t}+\varrho_{0} \varrho_{1} \zeta_{\varrho}\left(\frac{\hat{X}_{t}^{I, S}}{\zeta_{\varrho} \hat{D}_{t}^{I}}\right)^{1-\varrho_{1}}, \\
& Q_{t}=\mathrm{E}_{t}\left[\mathcal{M}_{t, t+1}^{I}\left(r_{t+1}^{K}+\left(1-\delta_{t+1}\right) Q_{t+1}\right)\right]+\lambda_{t} \nu \nu^{K} \bar{Q}_{t}+\sigma_{t}^{I, K} .
\end{aligned}
$$

Note that when the leverage constraint and no-shorting constraint on short-term debt are not binding, the Euler equations for short-term debt and deposits imply that the spread between the two prices is a static function of the liquidity coverage ratio:

$$
p_{t}^{S}-p_{t}^{D}=\varrho_{0}\left(\frac{\hat{X}_{t}^{I, s}}{\zeta_{\varrho} \hat{D}_{t}^{I}}\right)^{-\varrho}\left(\varrho_{1}-1-\frac{\hat{X}_{t}^{I, s}}{\zeta_{\varrho} \hat{D}_{t}^{I}} \zeta_{\varrho} \varrho_{1}\right)
$$

At $100 \% \mathrm{LCR}$, this reduces to $p_{t}^{s}-p_{t}^{d}=\rho_{0}\left(\varrho_{1}-1-\zeta_{\varrho} \varrho_{1}\right)$. Because $\zeta<<1$, the price spread is increasing in $\varrho_{1}$. When $\varrho_{1}$ is closer to 1 , short-term bonds are cheaper than deposits and have a higher rate. When $\varrho_{1}$ is high, short-term bonds are more expensive than deposits and have a lower rate. The prices are exactly equal at $100 \%$ LCR if $\varrho_{1}=\frac{1}{1-\zeta}$.

\section{A.4 Firms}

\section{A.4.1 Retailers}

Final output is

$$
\hat{Y}_{t}=\left(\int_{0}^{1} Y_{t}(i)^{1-\frac{1}{\epsilon}} d i\right)^{\frac{\epsilon}{\epsilon-1}}
$$

Retailers maximize profit

$$
\max _{\left\{\hat{Y}_{t}(i)\right\}} P_{t} \hat{Y}_{t}-\int_{0}^{1} P_{t}(i) \hat{Y}_{t}(i) d i .
$$

This implies the demand functions for all $i$

$$
\hat{Y}_{t}(i)=\left(\frac{P_{t}(i)}{P_{t}}\right)^{-\epsilon} \hat{Y}_{t}
$$

Further, perfect competition and free entry among retailers requires that they make zero profit in equilibrium. This in turn means $P_{t} \hat{Y}_{t}=\int_{0}^{1} P_{t}(i) \hat{Y}_{t}(i) d i$ and

$$
P_{t}=\left(\int_{0}^{1} P_{t}(i)^{1-\epsilon} d i\right)^{\frac{1}{1-\epsilon}}
$$




\section{A.4.2 Wholesalers}

We simplify notation by dropping $i$ subscripts and writing $p_{t}=P_{t}(i)$. Then

$$
y\left(p_{t}\right)=\left(\frac{p_{t}}{P_{t}}\right)^{-\epsilon} \hat{Y}_{t}
$$

The stationarized recursive problem of a wholesale firm is in real terms

$$
V^{W}\left(p_{t-1}, \mathcal{S}_{t}\right)=\max _{p_{t}, n_{t}, \hat{k}_{t}} \frac{p_{t}}{P_{t}} y\left(p_{t}\right)-\left(\hat{w}_{t} n_{t}+r_{t}^{K} \hat{k}_{t}\right)-\frac{\xi}{2}\left(\frac{p_{t}}{\bar{\pi} p_{t-1}}-1\right)^{2}+\mathrm{E}_{t}\left[\mathcal{M}_{t, t+1} \exp \left(g_{t+1}\right) V^{W}\left(p_{t}, \mathcal{S}_{t+1}\right)\right]
$$

subject to

$$
\left(Z_{t}^{r} n_{t}\right)^{\alpha} \hat{k}_{t}^{1-\alpha} \geq y\left(p_{t}\right)
$$

We first solve the cost minimization problem for given output

$$
\min _{n_{t}, \hat{k}_{t}} \hat{w}_{t} n_{t}+r_{t}^{K} \hat{k}_{t}
$$

subject to

$$
\left(Z_{t}^{r} n_{t}\right)^{\alpha} \hat{k}_{t}^{1-\alpha} \geq \bar{y}
$$

We denote the multiplier on the output constraint as $m_{t}$. Then the FOC are

$$
\begin{aligned}
\hat{w}_{t} & =m_{t}\left(Z_{t}^{r}\right)^{\alpha} \alpha n_{t}^{\alpha-1} \hat{k}_{t}^{1-\alpha}, \\
r_{t}^{K} & =m_{t}\left(Z_{t}^{r}\right)^{\alpha}(1-\alpha) n_{t}^{\alpha} \hat{k}_{t}^{-\alpha},
\end{aligned}
$$

which implies

$$
(1-\alpha) \hat{w}_{t} n_{t}=\alpha r_{t}^{K} \hat{k}_{t}
$$

and factor demands

$$
\begin{aligned}
& n_{t}=\frac{\bar{y}}{\left(Z_{t}^{r}\right)^{\alpha}}\left(\frac{\alpha}{1-\alpha}\right)^{-\alpha}\left(\frac{\hat{w}_{t}}{r_{t}^{K}}\right)^{-\alpha}, \\
& \hat{k}_{t}=\frac{\bar{y}}{\left(Z_{t}^{r}\right)^{\alpha}}\left(\frac{\alpha}{1-\alpha}\right)^{1-\alpha}\left(\frac{\hat{w}_{t}}{r_{t}^{K}}\right)^{1-\alpha} .
\end{aligned}
$$

Combining these with the binding constraint $\left(Z_{t}^{r} n_{t}\right)^{\alpha} \hat{k}_{t}^{1-\alpha}=\bar{y}$ gives the following expression for the multiplier, which equals marginal cost

$$
m_{t}=\frac{1}{\left(Z_{t}^{r}\right)^{\alpha}}\left(\frac{1}{1-\alpha}\right)^{1-\alpha}\left(\frac{1}{\alpha}\right)^{\alpha} \hat{w}_{t}^{\alpha}\left(r_{t}^{K}\right)^{1-\alpha}
$$

With this solution in hand, we write the profit maximization problem

$$
V^{W}\left(p_{t-1}, \mathcal{S}_{t}\right)=\max _{p_{t}} y\left(p_{t}\right)\left(\frac{p_{t}}{P_{t}}-m_{t}\right)-\frac{\xi}{2}\left(\frac{p_{t}}{\bar{\pi} p_{t-1}}-1\right)^{2}+\mathrm{E}_{t}\left[\mathcal{M}_{t, t+1} \exp \left(g_{t+1}\right) V^{W}\left(p_{t}, \mathcal{S}_{t+1}\right)\right] .
$$


The FOC for the price is

$$
0=y^{\prime}\left(p_{t}\right)\left(\frac{p_{t}}{P_{t}}-m_{t}\right)+\frac{y\left(p_{t}\right)}{P_{t}}-\xi\left(\frac{p_{t}}{\bar{\pi} p_{t-1}}-1\right) \frac{1}{\bar{\pi} p_{t-1}}+\mathrm{E}_{t}\left[\mathcal{M}_{t, t+1} \exp \left(g_{t+1}\right) \frac{\partial V^{W}\left(p_{t}, \mathcal{S}_{t+1}\right)}{\partial p_{t}}\right] .
$$

The marginal value of today's price is given by the envelope theorem

$$
\frac{\partial V^{W}\left(p_{t-1}, \mathcal{S}_{t}\right)}{\partial p_{t-1}}=\xi\left(\frac{p_{t}}{\overline{\bar{\pi}} p_{t-1}}-1\right) \frac{p_{t}}{\bar{\pi} p_{t-1}^{2}} .
$$

In equilibrium, all firms choose the same price and we have $p_{t}=P_{t}$. Therefore $y\left(p_{t}\right)=\hat{Y}_{t}$, and $y^{\prime}\left(p_{t}\right)=-\epsilon \hat{Y}_{t} / P_{t}$.

We can thus write the FOC as

$$
\xi\left(\frac{\pi_{t}}{\bar{\pi}}-1\right) \frac{\pi_{t}}{\bar{\pi}}=\hat{Y}_{t}\left(1-\epsilon+\epsilon m_{t}\right)+\mathrm{E}_{t}\left[\mathcal{M}_{t, t+1} \exp \left(g_{t+1}\right) \xi\left(\frac{\pi_{t+1}}{\bar{\pi}}-1\right) \frac{\pi_{t+1}}{\bar{\pi}}\right],
$$

which is the New Keynesian Phillips curve.

\section{A.5 Aggregate Capital Transition}

The aggregate capital stock is a state variable of the economy contained in $S_{t}$. It is needed to compute adjustment costs, and the aggregate output of intermediate goods. Since $\hat{K}_{t-1}=\frac{K_{t-1}}{Z_{t}^{p}}$, the stationarized law of motion for capital is

$$
\begin{aligned}
\hat{K}_{t} & =\frac{Z_{t}^{p}}{Z_{t+1}^{p}}\left(\left(1-\delta_{t}\right) \hat{K}_{t-1}+\hat{I}_{t}\right), \\
& =\exp \left(-g_{t+1}\right)\left(\left(1-\delta_{t}\right) \hat{K}_{t-1}+\hat{I}_{t}\right)
\end{aligned}
$$

\section{A.6 Government}

\section{A.6.1 Fiscal rules}

The fiscal rules are parameterized by the following coefficient matrix

$$
\mathbf{F}=\left[\begin{array}{ccc}
1 & 0 & -b_{\gamma}^{2} \\
0 & b_{\theta} & -b_{\theta}^{2} \\
0 & b_{\tau} & -b_{\tau}^{2}
\end{array}\right] .
$$

We consider two transformations of output for the fiscal rules. The first below, is a modification for the implementation of the fading stabilizing rule described in the main body of the text, and the second is simply the log of detrended output.

$$
\begin{aligned}
& \tilde{y}_{t}=m \tanh \left(\frac{b_{\gamma} \log \left(\hat{Y}_{t}\right)}{m}\right) \\
& \hat{y}_{t}=\log \left(\hat{Y}_{t}\right)
\end{aligned}
$$


Then we can consider a vector fiscal variables given by

$$
\mathbf{x}_{t}=\left[\begin{array}{c}
\tilde{y}_{t} \\
\hat{y}_{t} \\
\sigma_{z}^{2}
\end{array}\right] .
$$

The fiscal authority follows rules for transfers, and discretionary spending characterized by

$$
\begin{aligned}
& \theta_{t}=\theta\left(\hat{Y}_{t}\right)=\theta_{0} \exp \left(\left(\mathbf{F} \mathbf{x}_{t}\right)^{\prime} \mathbf{e}_{\mathbf{1}}\right) \\
& \gamma_{t}=\gamma\left(\hat{Y}_{t}\right)=\gamma_{0} \exp \left(\left(\mathbf{F} \mathbf{x}_{t}\right)^{\prime} \mathbf{e}_{\mathbf{2}}\right)
\end{aligned}
$$

where $\mathbf{e}_{i}$ is the basis vector that selects the $i t h$ element of a vector. The rule for discretionary spending, equation (42), gives the fading stabilizer rule shown in the main body of the text. Given rules characterized by equations (41) and (42), real total spending is:

$$
\hat{F}_{t}=\gamma_{t} \hat{Y}_{t}+\theta_{t} \hat{Y}_{t}
$$

Active fiscal policy If the spending and transfer rules imply that the government follow active fiscal policy (i.e. the government actively tries to stabilize the economy by responding to deviations to the stochastic growth trend), the tax rates on wage income and profits depend on cyclical output

$$
\tilde{\tau}_{t}^{n}=\tilde{\tau}_{0}^{n} \exp \left(\left(\mathbf{F} \mathbf{x}_{t}\right)^{\prime} \mathbf{e}_{\mathbf{3}}\right)
$$

for $n \in\{w, d i v\}$. Real tax revenue is given by

$$
\hat{\tilde{T}}_{t}=\tilde{\tau}^{w} w_{t} \hat{N}_{t}+\tilde{\tau}_{t}^{d i v}\left(\hat{D i v_{t}^{P}}+\hat{D i v_{t}^{I}}\right)
$$

Given taxes and spending, the real primary surplus is given by $\hat{S}_{t}=\hat{\tilde{T}}_{t}-\hat{F}_{t}$. Then the government needs to issue new debt, $\hat{\tilde{W}}_{t}$ at the end of the period such that

$$
\hat{\tilde{W}}_{t}^{G}=\hat{W}_{t}^{G}-\hat{\tilde{S}}_{t}
$$

Passive fiscal policy When the fiscal authority targets the level $\hat{\vec{W}}_{t}^{G}$ of end of period debt as a function of the active issuance in Equation (44), we refer to the fiscal regime as passive. In this case, tax rates are determined indirectly as a result of the debt issuance target. Passive policy is characterized by profligacy with threshold $\underline{W}^{G}$ and austerity with threshold $\bar{W}^{G}$.

Combined tax rule The combination of active and passive fiscal policy can best be described as an algorithm.

Algorithm 1. 1. Compute desired primary surplus $\hat{S}_{t}$ under active fiscal policy using fiscal rules $(41)-(43)$.

2. Determine desired active debt issuance $\hat{\tilde{W}}_{t}^{G}$ from (44). Check whether desired issuance 
under active policy is within profligacy and austerity bounds:

$$
\tilde{\hat{W}}_{t}^{G}= \begin{cases}(1-v) \underline{\hat{W}}^{G}+v \tilde{\hat{W}}_{t}^{G} & \text { if } \tilde{\hat{W}}_{t}^{G} \leq \hat{\hat{W}}^{G} \\ \tilde{\hat{W}}_{t}^{G} & \text { if } \hat{\hat{W}}^{G}>\hat{\hat{W}}_{t}^{G}>\hat{W}^{G} \\ (1-v) \hat{\hat{W}}^{G}+v \tilde{\hat{W}}_{t}^{G} & \text { if } \hat{\tilde{W}}_{t}^{G} \geq \hat{\bar{W}}^{G} .\end{cases}
$$

3. If target issuance equals desired active issuance $\hat{\vec{W}}_{t}^{G}=\tilde{\hat{W}}_{t}^{G}$, tax rates are determined based on active rule (43). Otherwise, switch to profligacy or austerity regime, with tax rate determined as implicit function of issuance target $\hat{\vec{W}}_{t}^{G}$ given by (45) (i.e., solve for the tax rate needed to achieve surplus $\hat{\vec{S}}_{t}^{G}$ that yields the issuance target for debt).

In the algorithm above, parameter $v$ in (45) regulates the strength of the profligacy or austerity policy. In particular, $v=1$ implies no responsiveness of fiscal policy to debt/GDP, a case for which the model with active monetary policy does not have a stationary solution since government debt would be non-stationary. $v=0$ implies the most aggressive austerity or profligacy. If tax rates are bounded below at zero, and taxation is distortionary, such a policy may be infeasible since there is no feasible tax rate to achieve the target surplus. In our calibration, we choose $v=0.8$, a value that guarantees stationary and implies feasible tax rate adjustments away from the active rule.

The market value of next period government debt, given fiscal and monetary policy choice is then

$$
\tilde{W}_{t+1}^{G}=\frac{\exp \left(-g_{t+1}\right)}{\pi_{t+1}}\left(\left(\tilde{B}_{t}^{G, s}-\tilde{B}_{t}^{C B, s}\right)+\left(\tilde{B}_{t}^{G, l}-\tilde{B}_{t}^{C B, l}\right)\left(c+1+\delta^{B}+\delta^{B} p_{t+1}^{L}\right)\right)
$$

\section{B Data}

Our primary data sources are the NIPA data tables provided by the Bureau of Economic Analysis (BEA) and Financial Accounts of the United States provided by the Federal Reserve Board of Governors (BoG). The table below provides the variables we download via FRED, the associated variable code, and the underlying source of the data. 


\section{Table 4: Data from the BEA and BoG}

Variable

Government current tax receipts

Gross Domestic Income: Taxes on Production and Imports

Government current tax receipts: Taxes on corporate income

Federal government current tax receipts: Taxes from the ROW

Government current receipts: Contributions for government social insurance

Federal government current receipts: Contributions for government social insurance: From the ROW

Government current receipts: Income receipts on assets: Interest receipts

Government current transfer receipts

National income: Business current transfer payments (net): to government (net)

Personal current transfer payments: to government

Current surplus of government enterprises

Government consumption expenditures

Government current transfer payments

Federal government current transfer payments: Government social benefits: to the ROW

Federal government current transfer payments: Other current transfer payments to the ROW (net)

Government current expenditures: Interest payments

Government current expenditures: Interest payments: to the rest of the world

Gross Domestic Income: Subsidies

Private Nonresidential Fixed Investment

Population Level

Gross private domestic investment: Fixed investment: Nonresidential (implicit price deflator)

Personal Consumption Expenditures: Chain-type Price Index

Current-Cost Net Stock of Fixed Assets: Private: Nonresidential: Structures

Current-Cost Net Stock of Fixed Assets: Private: Nonresidential: Equipment

Current-Cost Net Stock of Fixed Assets: Private: Intellectual property products

Current-Cost Net Stock of Consumer Durable Goods

Current-Cost Net Stock of Fixed Assets: Residential

Personal Consumption Expenditures: Nondurable Goods

Personal Consumption Expenditures: Durable Goods

Personal Consumption Expenditures: Services

Private Residential Fixed Investment

Change in Private Inventories

Personal consumption expenditures: Nondurable goods (implicit price deflator)

Personal consumption expenditures: Durable goods (implicit price deflator)

Personal consumption expenditures: Services (implicit price deflator)

Gross private domestic investment: Fixed investment: Residential (implicit price deflator)

Government consumption expenditures and gross investment (implicit price deflator)

Current-Cost Depreciation of Fixed Assets: Private: Nonresidential: Structures

Current-Cost Depreciation of Fixed Assets: Private: Nonresidential: Equipment

Current-Cost Depreciation of Fixed Assets: Private: Intellectual property products

Current-Cost Depreciation of Fixed Assets: Residential

U.S. National Income

Households and Nonprofit Organizations

Monetary Authority; Total Treasury Securities

U.S.-Chartered Depository Institutions; Treasury Securities

Property-Casualty Insurance Companies; Treasury Securities

Money Market Funds; Treasury Securities; Asset, Level

Households and Nonprofit Organizations; Treasury Securities; Asset, Market Value Levels

Private Pension Funds; Treasury Securities

Rest of the World; Treasury Securities

Federal Government; Treasury Bills; Liability, Level

Federal Government; Treasury Securities; Liability, Level (FGTSL)
FRED Code

W054RC1Q027SBEA

GDITAXES

W025RC1Q027SBEA

W008RC1Q027SBEA

W782RC1Q027SBEA

W781RC1Q027SBEA

Y703RC1Q027SBEA

W060RC1Q027SBEA

W061RC1Q027SBEA

W062RC1Q027SBEA

A108RC1Q027SBEA

A955RC1Q027SBEA

A084RC1Q027SBEA

W016RC1Q027SBEA

W017RC1Q027SBEA

A180RC1Q027SBEA

Y712RC1Q027SBEA

GDISUBS

PNFI

CNP16OV

A008RD3Q086SBEA

PCEPI

K1NTOTL1ST000

K1NTOTL1EQ000

K1NTOTL1IP000

K1CTOTL1CD000

K1R53101ES000

PCND

PCDG

PCESV

PRFI

CBI

DNDGRD3Q086SBEA

DDURRD3Q086SBEA

DSERRD3Q086SBEA

A011RD3Q086SBEA

A822RD3Q086SBEA

M1NTOTL1ST000

M1NTOTL1EQ000

M1NTOTL1IP000

M1R53101ES000

BOGZ1FA086010005Q

HNOCERQ027S

BOGZ1LM713061103Q

BOGZ1LM763061100Q

BOGZ1FL513061105Q

BOGZ1FL633061105Q

BOGZ1LM153061105Q

BOGZ1LM573061105Q

BOGZ1LM263061105Q

BOGZ1FL313161110Q

FGTSL
Data Source Release table

BEA Table 3.1

BEA Table 3.1

BEA Table 3.1

BEA Table 3.1

BEA Table 3.1

BEA Table 3.1

BEA Table 3.1

BEA Table 3.1

BEA Table 3.1

BEA Table 3.1

BEA Table 3.1

BEA Table 3.1

BEA Table 3.1

BEA Table 3.1

BEA Table 3.1

BEA Table 3.1

BEA Table 3.1

BEA Table 3.1

BEA Table 1.1.5

BLS Table A-1

BEA Table 1.1.9

BEA Table 2.8.4

BEA Table 1.1

BEA Table 1.1

BEA Table 1.1

BEA Table 1.1

BEA Table 1.1

BEA Table 1.1.5

BEA Table 1.1.5

BEA Table 1.1.5

BEA Table 1.1.5

BEA Table 1.1.5

BEA Table 1.1.9

BEA Table 1.1.9

BEA Table 1.1.9

BEA Table 1.1.9

BEA Table 1.1.9

BEA Table 1.3

BEA Table 1.3

BEA Table 1.3

BEA Table 1.3

BoG Z.1

BoG Z.1

BoG Z.1

BoG Z.1

BoG Z.1

BoG Z Z

BoG Z.1

BoG Z.1

BoG Z.1

BoG Z.1

BoG Z.1 


\section{Computational Methods}

\section{C.1 Numerical Solution Method}

We solve the model globally using time iteration. We extend the solution method proposed by Elenev, Landvoigt, and Van Nieuwerburgh (2021). Since that model is a real model without monetary policy, the nominal side of the model is new. Methodologically, this paper innovates by solving for a fixed point in key parameter values, in addition to equilibrium prices and quantities. This extension is necessary, since New Keynesian models like ours specify policy rules that characterize the actions taken by the government to stabilize output deviations from trend. With respect to the solution method, this means that the model contains endogenous parameters: trend output along the balanced growth path (i.e, the scale of the economy in the stationarized model) is endogenous, yet the policy rules that are part of the equilibrium system of equations depend on this trend output parameter. In NK models with small shocks that are solved using local methods this problem has a simple solution: trend output is given by the deterministic balanced growth path of the model, which is easy to compute. However, in our model with large risk premia, trend output is only known once we compute the model's solution and simulate its ergodic distribution.

For simplicity, we will use the term "steady state" to refer to deterministic balanced growth path going forward. To see the additional computational challenge, consider the Taylor-style monetary policy rule in our model: the central bank adjusts the interest rate based on deviations of output from trend output. Households in our model have a strong precautionary savings motive. As a result, the average output in a simulation of the stochastic model is approximately $6.8 \%$ higher than the steady state value. If we defined conventional monetary policy and fiscal policy rules using the deviation of output from steady state, as is usually done when computing local approximations, these rules would be significantly "off target". The average simulated time path would cause a contractionary policy response because the economy would appear to be significantly above trend. Thus, this dependence of policy rules on average output creates another fixed point: average output in the ergodic distribution of the stochastic model $\mathrm{E}\left[\hat{Y}_{t}\right]$ depends on policy rules, and the policy rules must be centered around $\mathrm{E}\left[\hat{Y}_{t}\right]$. To solve this additional fixed point, we extend the solution algorithm to normalize the average scale of 
aggregate output to one: $\mathrm{E}\left[\hat{Y}_{t}\right]=1$. Fiscal and monetary policy rules are all centered around this value.

We can choose the disutility of labor $\omega_{0}$ to achieve this normalization, while jointly matching all other targets using the other calibrated parameters. Importantly, once we have found the correct value of $\omega_{0}$, we keep this value fixed across policy experiments.

We proceed as follows:

1. Solve a nonlinear system of equations defining the equilibrium conditions at steady state $\left(\sigma_{g}=\sigma_{z}=0\right)$ assuming the intermediary leverage constraint binds. The system is augmented by an unknown parameter $\omega_{0}^{(0)}$ and an additional equation $\bar{Y}=1$.

2. Implicitly differentiate the system with respect to $\omega_{0}^{(0)}$ at the solution and solve for $\frac{\partial Y^{*}}{\partial \omega_{0}^{(0)}}$.

3. Given the guessed value $\omega_{0}^{(i)}$, solve the model using transition function iteration as in Elenev et al. (2021). We discretize the exogenous process into $N_{e}=3$ states using the Rouwenhorst (1995) method and define rectangular grids for 3 endogenous state variables: $\log$ market value of government debt $\log \hat{W}^{G}$, aggregate capital $K$, and intermediary wealth share $\frac{W^{I}}{(M P K+(1-\delta) Q) K+W^{G}}$. The grid for $\log \hat{W}^{G}$ is dense in and near profligacy and austerity regions since many equilibrium quantities, particularly labor and inflation, are highly nonlinear around the transitions into those states. We iterate several hundred times to convergence.

4. Simulate the model. We start at the steady state values and simulate $N$ runs of $T_{\text {ini }}+T$ periods each discarding the first $T_{\mathrm{ini}}$ to eliminate the effect of initial conditions. Government debt / GDP is highly persistent, so one long simulation may not adequately sample the true ergodic distribution. To obtain robust simulation results, we set $N=24$, $T_{\text {ini }}=3,000$ and $T=5,000$.

5. Compute the error $e=E\left[\hat{Y}_{t}\right]-1$. If $|e|<\tau$, proceed to the next step. Otherwise, update $\omega_{0}^{(i+1)}=\omega_{0}^{(i)}-\frac{e}{\partial Y^{*} / \partial \omega_{0}}$ using the derivative computed in Step 2, and repeat steps 3 to 5 .

6. Re-solve the model holding $\omega_{0}$ fixed at the optimized value and augmenting the discretized exogenous states with zero-probability states representing unanticipated shocks and policy responses (e.g. QE). 
7. Compute impulse response functions (IRFs) starting from the average exogenous state, a fixed level of government debt, and values of the other two endogenous state variables consistent with the fixed level of government debt in the simulation. We compute generalized nonlinear IRFs by simulating 5,000 paths of 25 quarters from this starting point, and calculating the mean path for each model variable.

\section{C.2 Numerical Risk Aversion Calculation}

Proposition 1 in Swanson (2018) derives the Arrow-Pratt measure of risk aversion in models with recursive preferences. Adapting these derivations to our model where $V<0$, we find that the Arrow-Pratt measure of risk aversion at point $x_{t}$ in the state space can be written as

$$
R R A\left(x_{t}\right)=-\frac{\mathrm{E}_{t}\left[-\left(-V\left(x_{t+1}\right)\right)^{-\alpha} V_{W W}\left(x_{t+1}\right)+\alpha\left(-V\left(x_{t+1}\right)\right)^{-\alpha-1} V_{W}^{2}\right]}{\mathrm{E}_{t}\left[-\left(V\left(x_{t+1}\right)\right)^{-\alpha} V_{W}\left(x_{t+1}\right)\right]} W\left(x_{t}\right)
$$

where $V$ is the value function, $V_{W}$ is the derivative of the value function with respect to wealth (i.e. marginal value of wealth), and $V_{W W}$ is the second derivative (curvature) of the value function. In our model,

$$
\begin{aligned}
V_{W}\left(x_{t}\right) & =(1-\beta) C\left(x_{t}\right)^{-\gamma} \\
V_{W W}\left(x_{t}\right) & =-(1-\beta) \gamma C\left(x_{t}\right)^{-\gamma-1} \frac{\partial C}{\partial W}\left(x_{t}\right)
\end{aligned}
$$

We approximate the marginal propensity to consume out of wealth $\frac{\partial C}{\partial W}\left(x_{t}\right)$ using its steady state value

$$
\frac{\partial C}{\partial W}(\bar{x})=\frac{1-\beta e^{-(1+\gamma) \bar{g}}}{1+\left(1-\tau_{0}^{w}\right)^{2} \bar{w}^{2} \frac{\gamma \bar{C}_{t}^{-\gamma-1}}{\omega_{0} \omega_{1} N^{\omega_{1}-1}}}
$$

and compute $R R A_{t}$ at every point in a long simulation using numerical solutions for $C(x), W(x)$ and $V(x)$. We find that relative risk aversion always lies between 4.2 and 6.8 , with the average value being 5.4 .

\section{Additional Results}

\section{D.1 QE in Normal Times}

Permanent QE. To understand the mechanism by which QE affects the aggregate economy in our model, we first study the transition from the calibrated baseline model to a world with 
permanent QE, i.e. an economy in which the central bank permanently expands its balance sheet and shifts the maturity structure of government debt from long- to short-term. We start this transition in a neutral productivity state and without demand shock, in the economy's steady state without a concurrent economic crisis. The policy parameters are the same as for the QE policy in the main experiment: the central bank buys $40 \%$ of the stock of outstanding long-term debt and replaces it with reserves. In addition, regulators exempt reserves from the SLR constraint. The only difference is that these policies now last permanently, unlike in the main experiment where the policies mean revert with probability 0.5 each quarter. In this experiment, the average maturity of debt held by the public changes from 5.28 years before the policy change to 3.26 years under permanent QE.

Figure 12: Permanent QE: Macro Variables
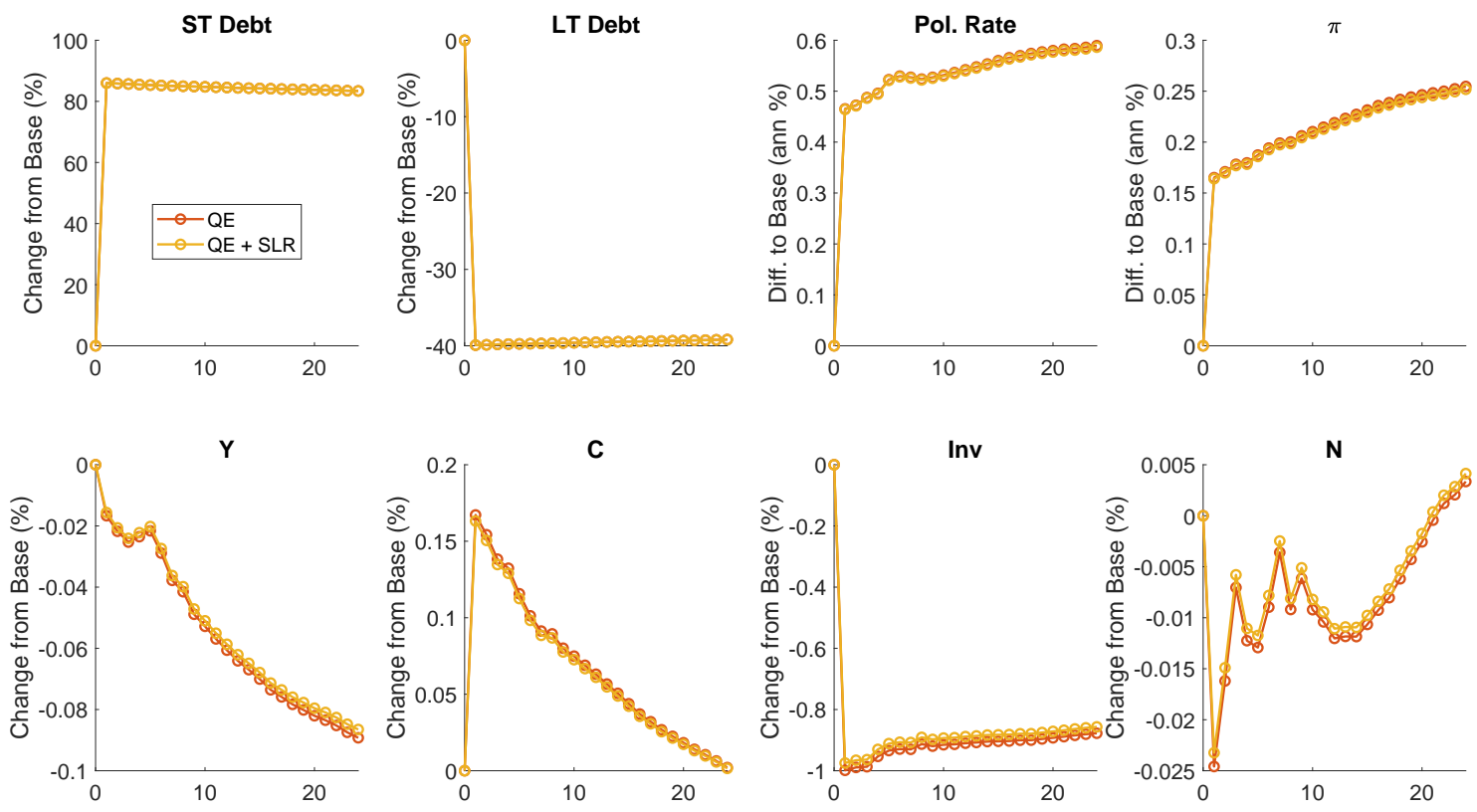

Transition paths from the calibrated baseline to an economy with permanent quantitative easing.

Figure 12 shows the transition paths of important macro variables to the new ergodic state with permanent QE. As is immediately obvious, the SLR exemption of reserves has little to no effect for these transitions (the red line which includes QE and SLR exemption policies almost perfectly covers the blue line, which includes only QE); unlike for the main experiment with QE implemented during a crisis, the SLR constraint is not binding in normal times. Therefore, its relaxation has very little effect. Hence, we can discuss the effects QE and SLR exemption 
jointly, keeping in mind that these effects are driven exclusively by QE.

The first two panels in the top row show the direct effect of the policy on the supply of shortand long-term debt. In the bottom row of Figure 12 we can see that permanent QE causes a transition to an economy with about $0.1 \%$ lower output (relative to trend) with roughly $1 \%$ lower investment. This transition to a permanently smaller capital stock leads to a consumption boom along the transition path. The effect on equilibrium labor is minimal. Since QE causes a permanent reduction in aggregate supply, it is an inflationary policy (top right panel). As a result, the central bank sets a higher policy rate.

Figure 13: Permanent QE: Financial Variables
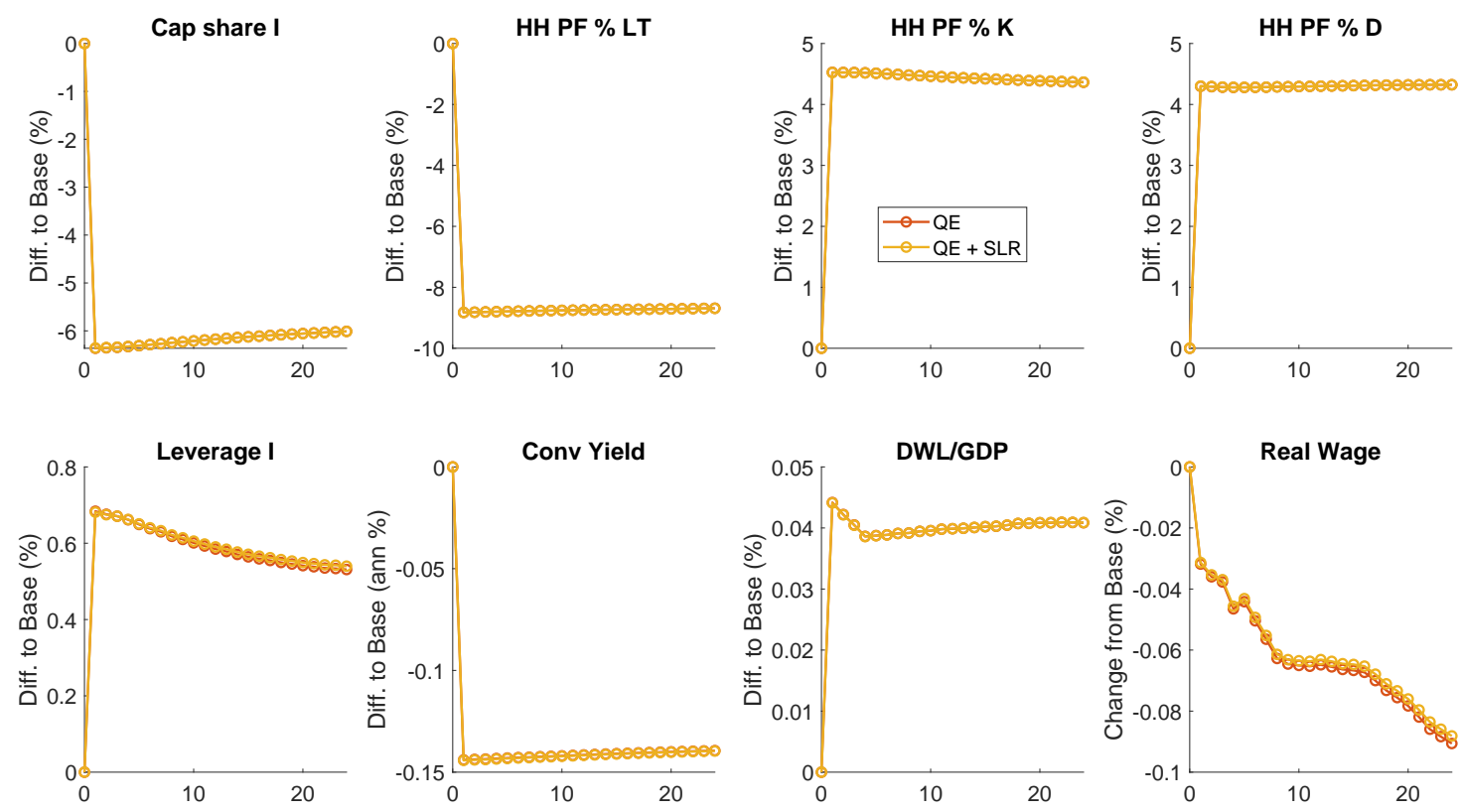

Transition paths from the calibrated baseline to an economy with permanent quantitative easing.

Figure 13 reveals the reasons for this shift to a smaller capital stock. As the central bank floods intermediary balance sheets with reserves (top left panel of Figure 12), intermediaries expand in size and supply a greater quantity of deposits. Due to liquidity costs of deposit production (equation (7)) and a smaller equity requirement, reserves are a superior collateral asset than physical capital for intermediaries. The increase in reserve supply thus leads to a crowding out effect of intermediary capital holdings, with the share of the aggregate capital stock held by intermediaries declining by $6 \%$ points (top left panel of Figure 13). 
The expansion in deposit supply and reduction in intermediary capital holdings are reflected in household balance sheets: households decrease holdings of long-term debt by selling these to the central bank (QE), and replenish their portfolio with capital purchased from intermediaries and additional deposits in about equal parts (three rightmost panels in the top row). Since intermediaries hold a more liquid and less risky portfolio, they increase leverage by $0.7 \%$ points. Deposits are less scarce and thus convenience yields on deposits decline by about 15bp.

As households must absorb extra capital, their holding costs increase, causing slightly higher DWL/GDP. However, aggregate welfare increases by over $0.4 \%$ on impact of the policy change, with the positive effects from greater liquidity provision outweighing the negative effects of less efficient capital allocation. Hence the baseline economy, before the switch to permanent QE, suffers from a shortage of liquid assets, which inflates intermediary demand for physical capital as a collateral asset. Relative to the post-QE economy with more ample liquidity, the pre-QE economy over-accumulates capital. Greater permanent liquidity provision by the central bank causes a substantial increase in household utility from greater deposit supply, with a temporary consumption boost and nearly no long-run decline in consumption.

The experiment in Figures 12 and 13 likely underestimates the welfare benefits of permanent QE, since during the implementation of QE, the central bank is assumed to not adjust its long-run output target downward, leading to permanently higher inflation and interest rates. If the central bank accommodated the smaller scale of the economy in its conventional monetary policy rule, the welfare gain would likely be larger.

Temporary QE in normal times. The effects of QE in our main policy experiment differ from those of permanent QE above in two aspects: (1) rather than permanent, the policies in the main experiment are only temporary, either with the same persistence as the economic crisis, or with greater persistence in the "long UMP" scenario, and (2) in our main experiment the policies occur simultaneous with the onset of negative economic shocks that push the economy into the ZLB constraint. We now study the importance of difference (1) by simulating the economy's response to a temporary QE policy shock implemented in normal times. The only difference to the permanent QE case above is the persistence of the policy. Like for the main experiment, the policy now ends with 0.5 probability each quarter, and we study a specific path 
during which the policy lasts for 4 periods after which it mean reverts stochastically.

Figure 14: Temporary QE: Macro Variables
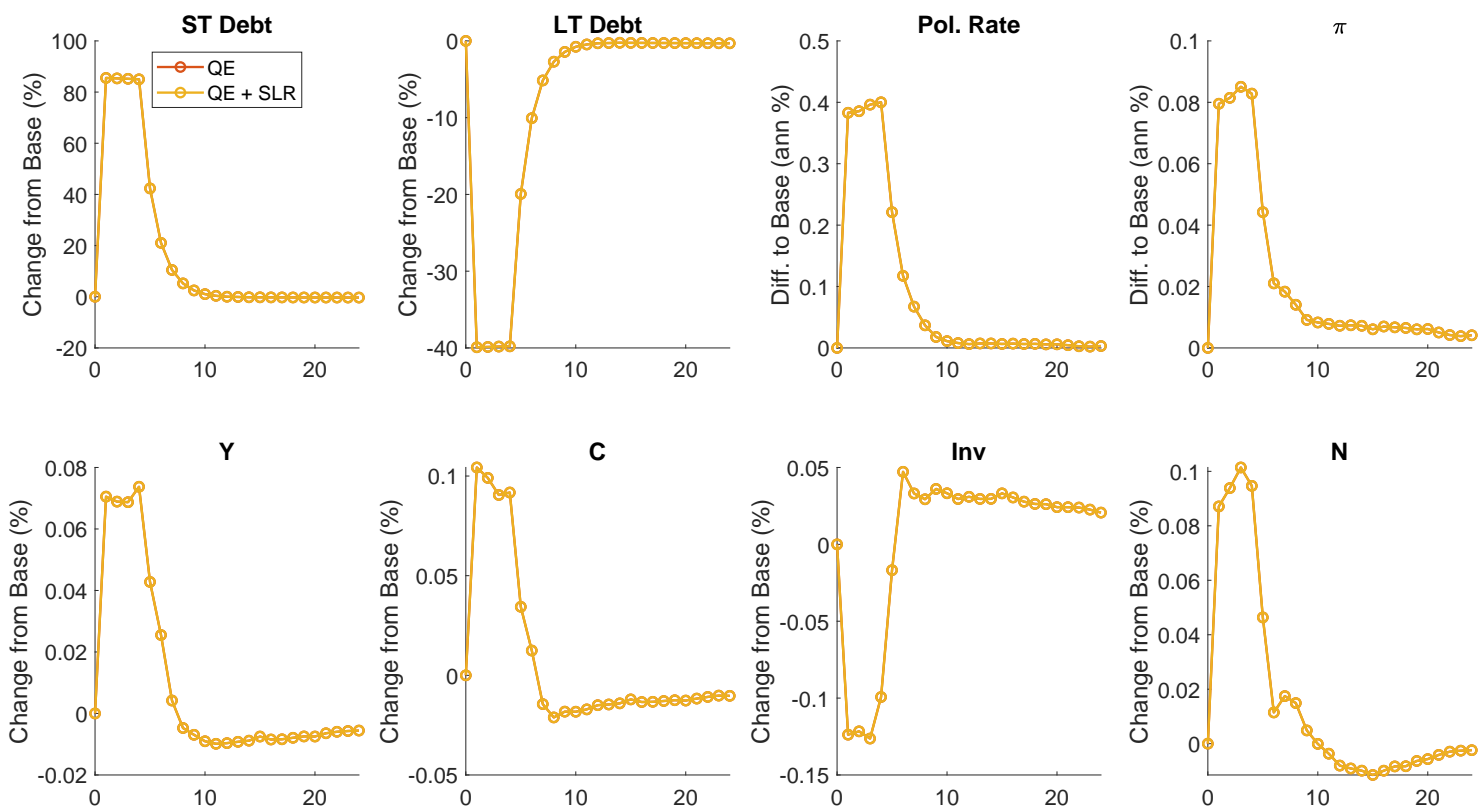

Response of economy to temporary QE in normal times. Policy parameters are identical to main policy experiment.

Figure 14 shows the effects of a temporary QE policy in normal times. The magnitude of the policy in the two leftmost panels in the top row is the same as for the permanent case, yet the duration is shorter. The qualitative effect on consumption and investment in the bottom row is the same as for the permanent transition to QE: consumption increases and investment declines. However, the effects of the temporary policy on GDP and labor are decidedly different. Equilibrium hours worked increase by about $0.1 \%$ and output by $7 \mathrm{bp}$ for the duration of the policy. The simultaneous rise in inflation, output, consumption and hours reveal that short-run QE triggers a positive aggregate demand shock.

Figure 15 mirrors the effects of the permanent QE transition in Figure 13, just with temporary duration. As the central bank sharply increases reserve supply, intermediaries increase the supply of deposits and sell capital to households. Households shed long-term debt and replace its value with capital and deposits. Intermediaries increase leverage and convenience yields on deposits decline. As households absorb more capital, their holdings costs increase, leading to higher DWL/GDP. 
Figure 15: Temporary QE: Financial Variables
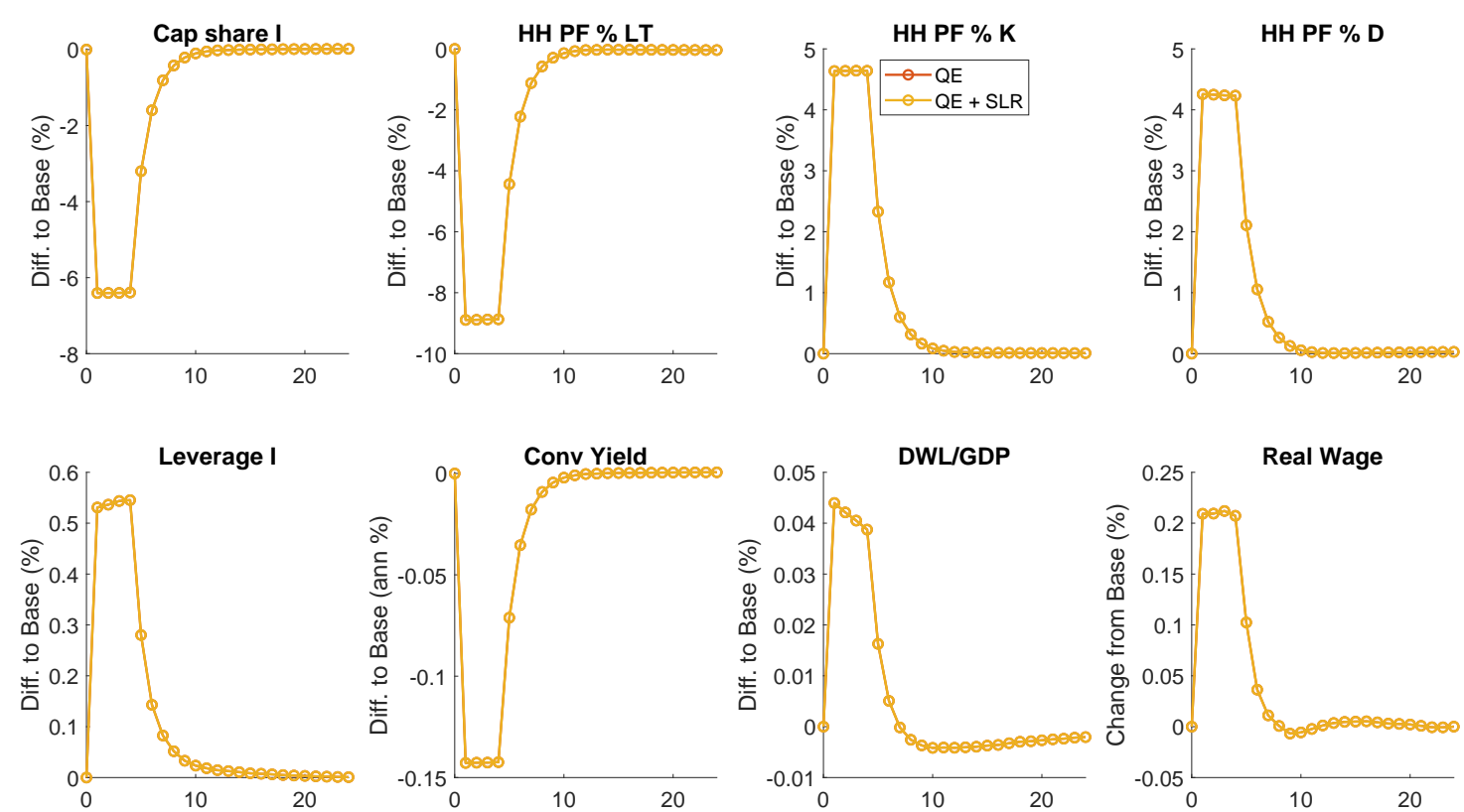

Response of economy to temporary QE in normal times. Policy parameters are identical to main policy experiment.

The key difference to the effects of permanent QE are apparent in the bottom right graph of Figure 15, which shows that real wages rise by $0.2 \%$ during temporary QE. This implies that the rise in hours worked is due to higher labor demand from firms, consistent with the aggregate demand shock nature of the economy's response to temporary QE. Intuitively, agents know that the shift to more consumption and less investment is only temporary. Higher consumption demand in the short-term triggers the New Keynesian production sector to raise prices, profits, and demand for both input factors. In summary, temporary QE triggers a small consumptiondriven boom.

The difference between the output and consumption effects of permanent and temporary QE are in line with the standard behavior of the New Keynesian model with capital accumulation. Permanent QE affects the economy like a negative supply shock through decreased investment and a lower capital stock. Since the shock is permanent, the New Keynesian model elements play a minor role, and the model essentially behaves like a real neoclassical growth model. However, short-run QE affects the economy like a positive demand shock (e.g., a temporary decrease in the discount factor), thus turning on New Keynesian nominal frictions and demand 
effects.

Temporary QE in the crisis. Our main policy experiment studies the effect of QE in a crisis triggered by a negative aggregate demand shock. We established above that temporary QE affects the economy like a positive demand shock. Therefore, QE is a well-suited policy in our model to counteract the negative demand shock that initiates the crisis. The difference between

temporary QE implemented in normal times such as in Figures 14 and 15, and temporary QE as part of the crisis policy response such as in Figure 9, therefore comes down the consumption multiplier effect associated with QE during demand-driven recessions at the ZLB. Comparing the magnitudes in Figures 9 and 14 implies a large multiplier: the same QE+SLR policy causes a GDP increase of 100bp when enacted during the crisis (Figure 9), but only of 7bp when implemented in normal times (Figure 14). The multiplier effect of QE is large enough to turn the $0.1 \%$ point decline in investment in normal times into a $2 \%$ point increase in investment in the crisis. In other words, the positive effect on aggregate demand is large enough that the increased demand for capital by firms overturns the initial decline in investment caused by the crowding out effect of QE.

\section{D.2 Benefits of Long Lasting UMP}

Figure 16 shows the same policy experiments as in the main text, without an increased inflation target as part of the policy mix. Hence the lines "Combo (QE)" and "Long QE" show the combination of additional discretionary spending with QE and SLR exemption only. The figure clearly indicates that adding persistence to QE as in "Long QE" has no benefits in the short run over the short-duration QE policy that is part of "Combo".

We conclude that the additional output stimulus of "Long UMP" over "Combo" in Figure 4 is fully due to the higher inflation target component of UMP. 
Figure 16: Main Policy Experiments: No Higher Inflation Target
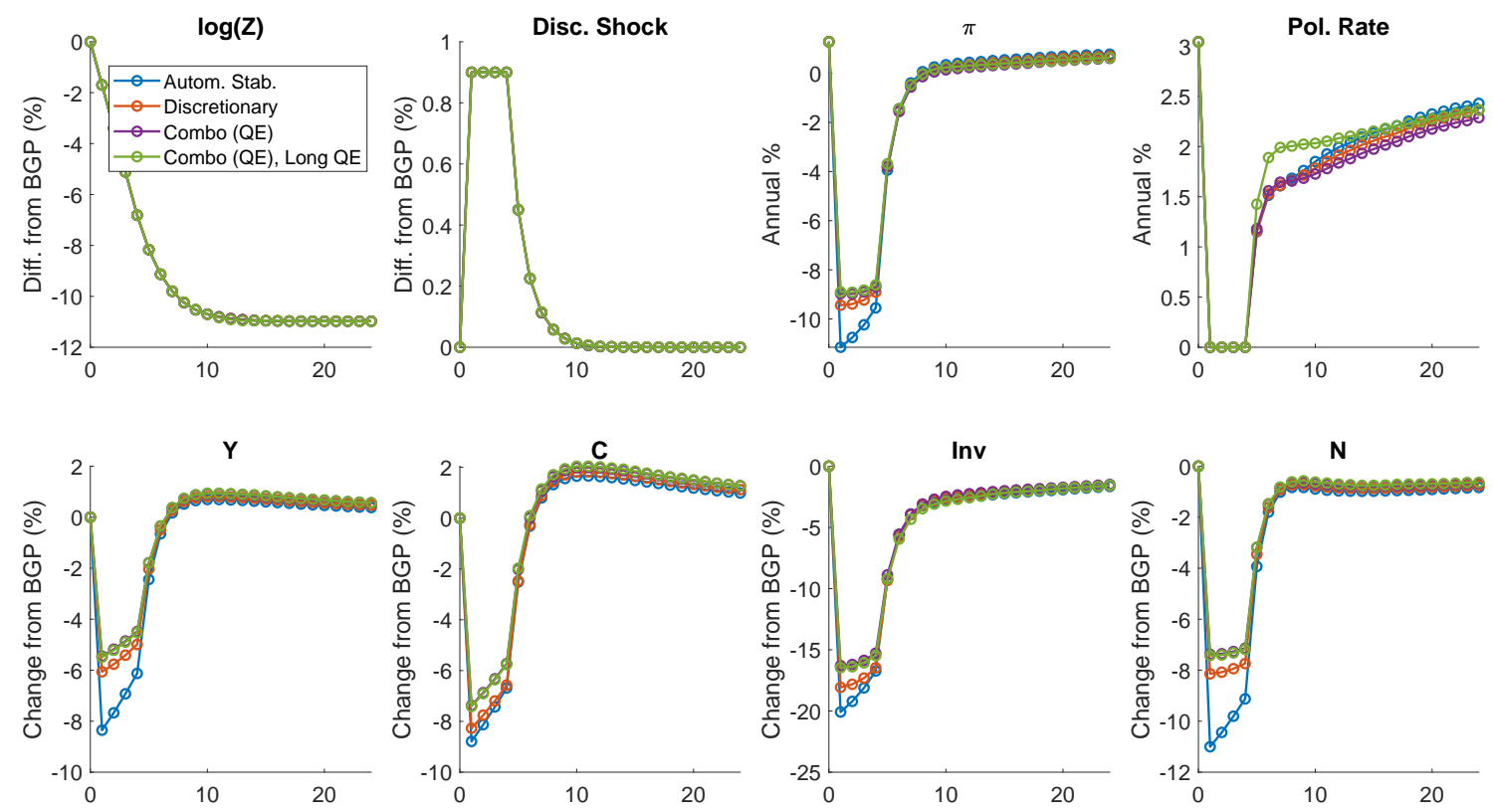